\title{
TAXONOMIA DAS ESPÉCIES DE Anastrepha Schiner, 1868 (Diptera, Tephritidae) ASSINALADAS NO BRASIL.
}

\author{
ROBERTO ANTONIO ZUCCHI
}

Orientador: JOSÉ HENRIQUE GUIMARĀES

Tese apresentada à Escola Superior de Agricultura "Luiz de Queiroz", da Universidade de São Paulo, para obtenção do título de Doutor em Entomologia.

PIRACICABA

Estado de São Paulo - Brasil

Setembro, 1978 
Aos meus pais, irmãos,

esposa e filho

DEDICO . 


\section{AGRADECIMENTOS}

Ao Dr. José Henrique Guimarães, Museu de Zoologia da Universidade de São Paulo, pela orientação e ensinamen tos recebidos.

Ao Dr. Domingos Gallo, Chefe do Departamento de Entomologia da Escola Superior de Agricultura "Luiz de Queiroz", e demais professores desse Departamento pela confiança em mim depositada.

Ao Dr. José Jurberg e Sr. Orlando Vicente Ferreira, Fundação Oswaldo Cruz, pelo empréstimo da coleção Costa Lima de moscas-das-frutas.

Aos colegas que me enviaram material e em especial ao Eng: Agr: Antonio Souza do Nascimento (EMBRAPA), Douto res João Stengle Morgante e Aldo Malavasi (Instituto de Biociências - USP) e Prof. Enrique Salazar Cavero (Faculdade de Agronomia "Eliseu Maciel" - UFPel).

$\bar{A}$ Dra. Ruth Lichtenberg, Naturhistorisches Museum Wien, pelo empréstimo de material tipico.

Ao Dr. H. Schumann, Zoologisches Museum an der Humboldt - Universität zu Berlin, pelas informações sobre mate rial tipo. 


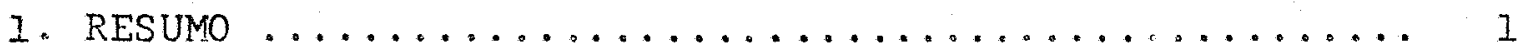

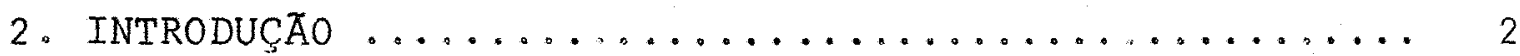

3. REVISÃO DE LITERATURA $\ldots \ldots \ldots \ldots \ldots \ldots \ldots \ldots \ldots \ldots \ldots$

4. METODOLOGIA ........................... 7

4.1. Coleções estudadas ................... 7

4.2. Exemplares coletados ................... 7

4.3. Conservação e montagem dos exemplares ......... 8

4.4. Preparação da genitália feminina ............ 8

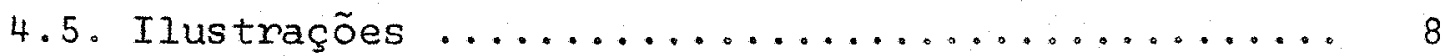

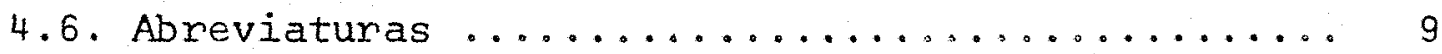

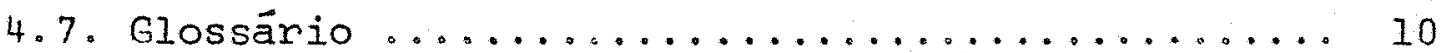

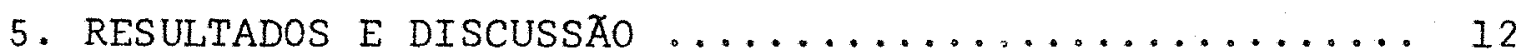

5.1. Gênero Anastrepha Schiner, $1868 \ldots \ldots \ldots \ldots \ldots .13$

5.2. Chave para as espëcies de Anastrepha

Schiner, 1868 assinaladas no Brasil ....... 15

5.3. Espécies de Anastrepha assinaladas no Brasil ... 23

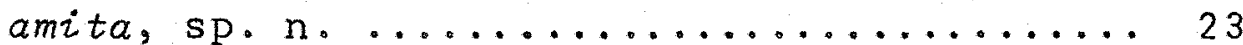

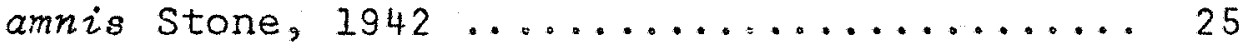

antunesi Lima, $1938 \ldots \ldots \ldots \ldots \ldots \ldots \ldots . \ldots \ldots$

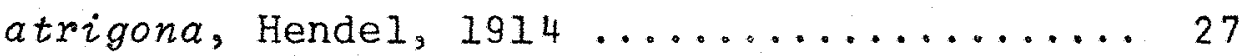

bahiensis Lima, $1937 \ldots \ldots \ldots \ldots \ldots \ldots \ldots 28$

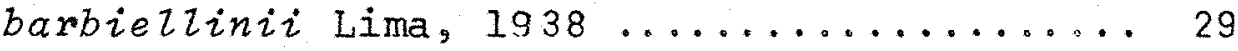

barnesi Aldrich, $1925 \ldots \ldots \ldots \ldots \ldots \ldots \ldots$

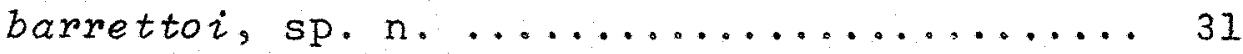

belenensis, sp.n...................... 31

benjamini Lima, $1938 \ldots \ldots \ldots \ldots \ldots \ldots \ldots \ldots . \ldots \ldots \ldots$

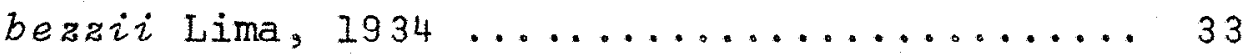

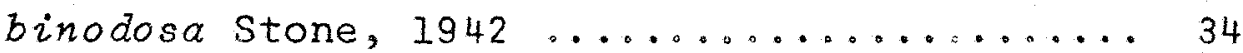

bistrigata Bezzi, $1919 \ldots \ldots \ldots \ldots \ldots \ldots \ldots . . \ldots$ 
bondari $\operatorname{Lima}, 1934 \ldots \ldots \ldots \ldots \ldots \ldots \ldots$

borgmeieri Lima, $1934 \ldots \ldots \ldots \ldots \ldots \ldots . \ldots \ldots$

caudata Stone, $1942 \ldots \ldots \ldots \ldots \ldots \ldots \ldots \ldots \ldots$

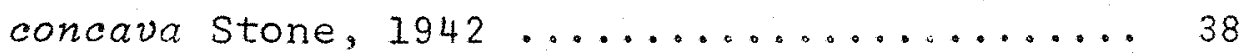

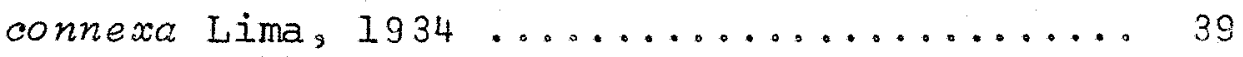

costalimai Autuori, $1936 \ldots \ldots \ldots \ldots \ldots . \ldots . \ldots . \ldots . \ldots$

curitis stone, $1942 \ldots \ldots \ldots \ldots \ldots \ldots \ldots \ldots . \ldots \ldots$

cruzi Lima, $1934 \ldots \ldots \ldots \ldots \ldots \ldots \ldots \ldots . \ldots 1$

daciformis Bezzi, $1909 \ldots \ldots \ldots \ldots \ldots \ldots .41$

dissimilis stone, $1942 \ldots \ldots \ldots \ldots \ldots \ldots . \ldots \ldots . \ldots \ldots \ldots$

distincta Greene, $1934 \ldots \ldots \ldots \ldots \ldots \ldots . \ldots . \ldots . \ldots$

duckei Lima, $1934 \ldots \ldots \ldots \ldots \ldots \ldots \ldots . \ldots \ldots$

elegans Blanchard, $1937 \ldots \ldots \ldots \ldots \ldots \ldots 46$

ethalea (Walker, 1849) ................ 46

fenestrata Lutz \& Lima, $1918 \ldots \ldots \ldots \ldots \ldots .47$

fischeri Lima, $1934 \ldots \ldots \ldots \ldots \ldots \ldots \ldots . \ldots 4$

flavipennis Greene, $1934 \ldots \ldots \ldots \ldots \ldots . \ldots . \ldots$

fraterculus (Wiedemann, 1830) .......... 49

fumipennis Lima, $1934 \ldots \ldots \ldots \ldots \ldots \ldots \ldots \ldots$

furcata Lima, $1934 \ldots \ldots \ldots \ldots \ldots \ldots \ldots \ldots . \ldots \ldots$

grandis (Macquart, 1846) .............. 56

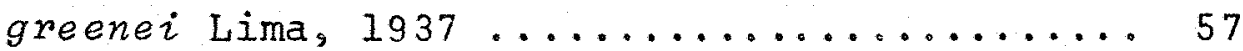

hambletoni Lima, $1934 \ldots \ldots \ldots \ldots \ldots \ldots . \ldots \ldots$

hastata stone, $1942 \ldots \ldots \ldots \ldots \ldots \ldots \ldots \ldots \ldots$

hendeliana Lima, $1934 \ldots \ldots \ldots \ldots \ldots \ldots . \ldots . \ldots$

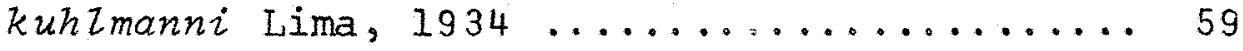

Zeptozona Hendel, $1914 \ldots \ldots \ldots \ldots \ldots \ldots \ldots 60 . \ldots \ldots \ldots$

Zongicauda Lima, $1934 \ldots \ldots \ldots \ldots \ldots \ldots \ldots .61$

Zuederwaldti Lima, $1934 \ldots \ldots \ldots \ldots \ldots 6 . \ldots \ldots \ldots$

Zutzi Lima, $1934 \ldots \ldots \ldots \ldots \ldots \ldots \ldots \ldots . \ldots \ldots$

macrura Hendel, $1914 \ldots \ldots \ldots \ldots \ldots \ldots \ldots 6 . \ldots \ldots$

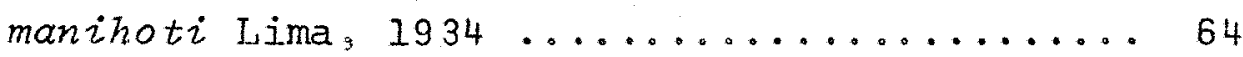

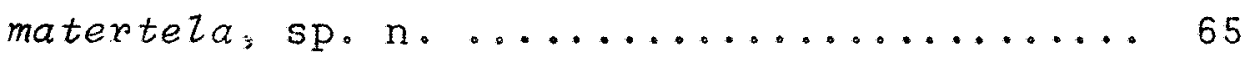

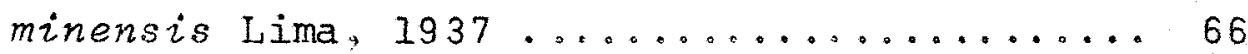


Página

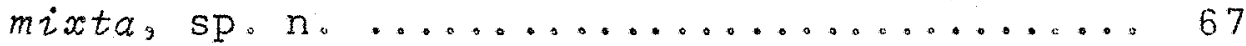

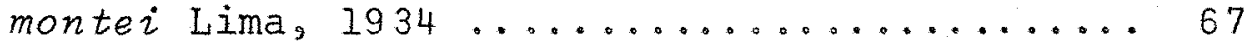

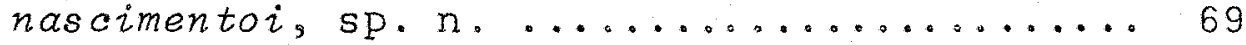

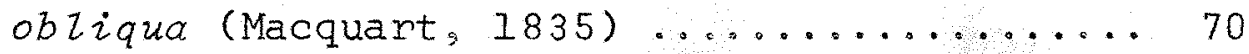

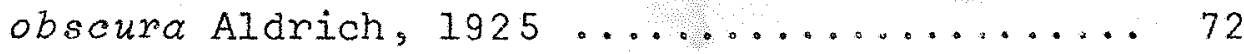

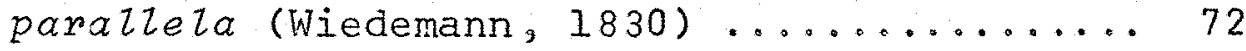

perdita stone, $1942 \ldots \ldots \ldots \ldots \ldots \ldots \ldots \ldots . \ldots \ldots$

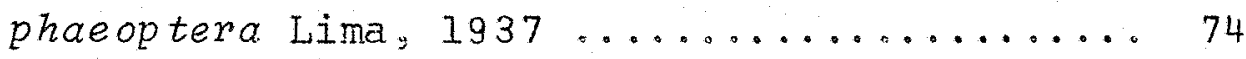

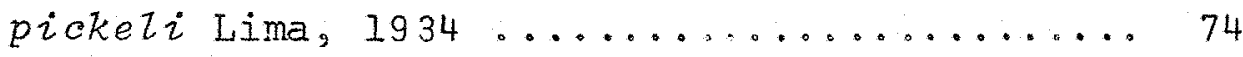

pseudoparallela (Loew, 1873) ............ 75

punctata Hendel, $1914 \ldots \ldots \ldots \ldots \ldots \ldots \ldots 76$

quararibeae Lima, $1937 \ldots \ldots \ldots \ldots \ldots \ldots . \ldots \ldots$

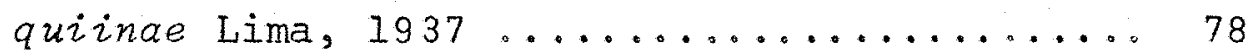

rheediae Stone, $1942 \ldots \ldots \ldots \ldots \ldots \ldots \ldots \ldots . \ldots \ldots$

sagittifera, sp. n. .................. 80

serpentina (Wiedemann, 1830) ........... 80

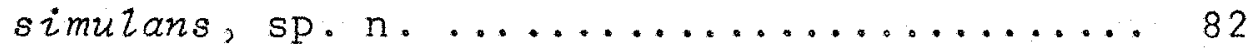

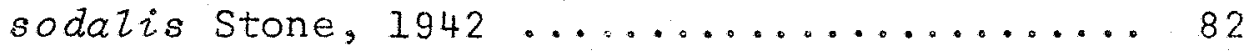

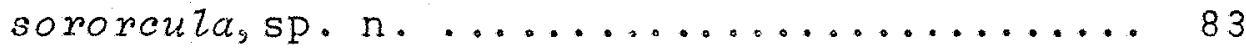

striata Schiner, $1868 \ldots \ldots \ldots \ldots \ldots \ldots . \ldots \ldots$

submunda Lima, $1937 \ldots \ldots \ldots \ldots \ldots \ldots . \ldots \ldots$

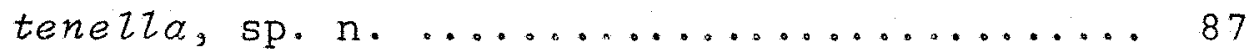

townsendi Greene, $1934 \ldots \ldots \ldots \ldots \ldots . \ldots . \ldots . \ldots . \ldots$

xanthochaeta Hendel, $1914 \ldots \ldots \ldots \ldots \ldots . \ldots 8$

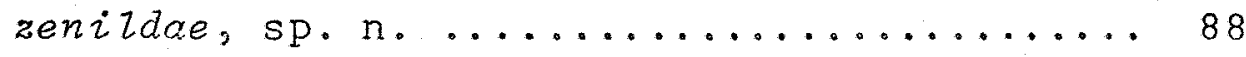

ze rnyi Lima, $1934 \ldots \ldots \ldots \ldots \ldots \ldots \ldots \ldots . \ldots \ldots$

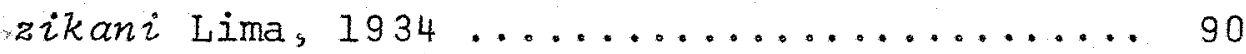

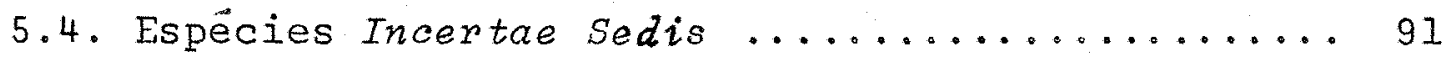

consobrina (Loew, 1873 ) .................. 91

hamata (Loew, 1873) ...................99 93

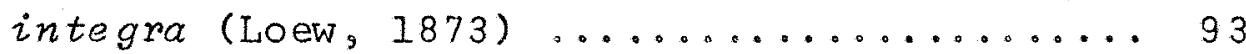

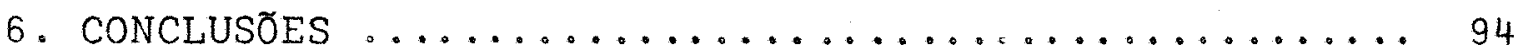

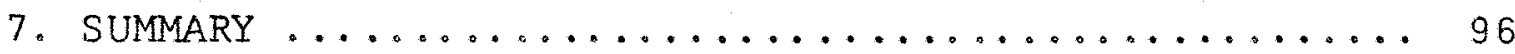

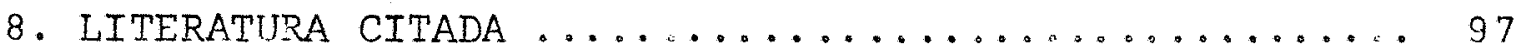


1. RESUMO

Estudou-se a taxonomia das espëcies brasileiras do gênero Anastrepha Schiner, 1868 (Diptera, Tephritidae) com base na coleção Costa Lima da Fundação Oswaldo Cruz e em exem plares provenientes de quinze estados brasileiros.

Dos 74 nomes considerados válidos, neste trabaTho, examinou-se o material típico de 38 espëcies. Para 12 es pécies não se estudou nenhum exemplar, sendo que 3 dessas espê cies foram consideradas incertae sedis. A. rhodiae stone, 1942 é assinalada pela primeira vez no Brasil.

Foram descritas 11 espëcies novas, cujos tipos foram depositados no Museu de Zoologia da Universidade de São Paulo (MZUSP), 5 nomes especificos foram considerados sinonimias e 12 lectótipos designados.

O äpice do ovipositor dos tipos de $A$. parallela (Wied., 1830), A. striata Schiner, 1868 e A. zernyi Lima, 1934 foram ilustrados pela primeira vez.

Elaborou-se uma chave para a identificação das espēcies. 
2. INTRODUÇÃO

Os dipteros do gênero Anastrepha Schiner, 1868 são conhecidos pela denominação de moscas das-frutas, pois as larvas desenvolvem-se especialmente no interior das frutas. Es se gênero pertence à familia Tephritidae e caracteriza-se pelas faixas alares e nervura $M_{1+2}$ procurvada apicalmente.

O gênero Anastrepha está distribuỉdo no Novo Mundo, sendo que a maioria das espécies encontram-se na Região Neotropical. Foram registrados ne literatura cerca de 155 no mes especificos, dos quais aproximadamente $50 \%$ foram assinalados para o Brasil.

Anastrepha carece de pesquisas bäsicas apesar da importância econômica de algumas espécies. Afora os estudos desenvolvidos com espécies neärticas, $A$. Ludens (Loew) e A. suspensa (Loew) principalmente, pouco se conhece sobre a sistemätica e biologia das espëcies neotropicais. Mesmo entre os gêneros de importância econômica da familia Tephritidae 
(Ceratitis, Dacus e Rhagoletis) Anastrepha è o menos estudado. Assim, a espēcie exōtica Ceratitis capitata (Wied.) è mais pes quisada no Brasil do que as espëcies nativas de Anastrepha. Por outro lado, autores nacionais que realizam levantamentos populacionais para as moscas do gênero Anastrepha, discutem os dados obtidos apenas em nivel genérico ou consideram apenas a ocorrência de A. fraterculus (Wied.), supondo ser esta a espé... cie predominante no Brasil.

Talvez, o desestímulo ao estudo desse complexo esteja relacionado principalmente à dificuldade da identificação especifica, que necessariamente envolve o exame acurado da genitälia feminina.

A presente pesquisa teve por objetivo o estudo sistemātico das espécies brasileiras de Anastrepha. Trata-se, pois, de etapa básica e indispensável para a realização de futuros estudos sobre este grupo, pois a taxonomia de um gênero tão grande e de distribuição continental só poderà ser corretamente interpretada com estudos complementares de biologia, etologia, ecologia e genética. 


\section{REVISAO DE LITERATURA}

o gênero Anastrepha foi criado por SCHINER (1868), tendo como espécie-tipo Dacus serpentinus Wied., 1830 por designação original.

BEZZI (1909) considerou os gêneros Acrotoxa Loew e Leptoxys Macquart sinônimos de Anastrepha Schiner, e apresentou catälogo e chave para a identificação das 19 espécies conhecidas. A segunda chave foi elaborada por HENDEL (1914) que reuniu as 33 espécies conhecidas nos grupos Pseudodacus e Anastrepha.

No Brasil, LUTZ e LIMA (1918) estudaram a varia bilidade de $A$. fraterculus (Wied.) e apresentaram um catälogo para as espēcies. Porém, o primeiro trabalho sobre as espé... cies brasileiras de Anastrepha foi realizado por BEZZI (1919a), que elaborou uma chave com 10 espëcies.

GREENE (1927) e EMMART (1933) efetuaram estudos para identificação de algumas espëcies de Anastrepha de impor- 
tância econômica atravês de ovos, larvas e pupas.

DAMPF (1933) fez um estudo comparativo do ovipositor de 5 espëcies de Anastrepha com o objetivo de facilitar a identificação dessas moscas nos serviços de quarentena. Estudos sobre morfologia e descrição de novas espëcies foram efetuados por FISCHER (1932 e 1934) e SEIN (1933), respectivamente.

GREENE (1934) apresentou uma revisão do gênero Anatrepha baseada em caracteres morfolögicos externos. Esse trabalho foi seguida pelo de LIMA (1934a), que estudou 62 espe cies ( 22 novas) e caracterizou, pela primeira vez, as espécies atravēs das genitālias. LIMA (1934b) discutiu o trabalho de GREENE (cit. loc.). Novas espēcies foram descritas por AUTUORI (1936), BLANCHARD (1937), LIMA (1937a, 1937b, 1938a, 1938 b) e HERING (1940).

STONE (1939a,b) criou o gênero Lucumaphila para as espécies de Anastrepha con ovipositor no máximo com $0,05 \mathrm{~mm}$ de largura, e elevou o subgênero Pseudodacus à categoria genërica.

HERING (194I) estudou as espécies peruanas de Anas trepha.

A mais recente revisão sobre Anastrepha foi rea lizada por STONE (1942a), que discutiu 126 espëcies, das quais 52 novas. Posteriormente, surgiram trabalhos esporädicos de descrições de novas espécies, discussões taxonômicas e sinonimies (STONE, 1942b; CAPOOR, 1954, 1955a; 1955b; SHAW, 1962; KORYTKOWSKI, 1974 e STEYSKAL, 1975), alëm dos estudos taxonômicos das espécies da VENEZUELA (FERNANDEZ, 1953), Angentina (BLANCHARD, 1961), Peru (KORYTKOWSKI e OJEDA, 1968) e Jamaica (WHERVIN, 1974).

FOOTE (1967) apresentou un catälogo com 150 espécies de Anastrepha. WASBAUER (1972) elaborou um catälogo dos hospedeiros de tefritideos em geral. 
STEYSKAL (1977a,b) considerou os gêneros Lucumaphiza Stone, Pseudodacus Hendel e Phobema Aldrich sinôni mos de Anastrepha Schiner, e elaborou uma chave ilustrada.

ZUCCHI (1977) discutiu 8 espécies brasileiras de Anastrepha do complexo fraterculus. 
4. METODOLOGIA

\subsection{Coleções estudadas}

Foram examinados exemplares da coleção Costa Li ma (Fundação Oswaldo Cruz) e do Museu de Zoologia da Universi.. dade de São Paulo. Estudou-se o material típico de 38 espë.. cies.

\subsection{Exemplares coletados}

Estudou-se exemplares, coletados em "frascos ca ça-moscas" ou obtidos de frutas, provenientes dos seguintes es tados: Amazonas, Parā, Sergipe, Alagoas, Pernambuco, Bahia, Goiás, Mato Grosso, Espírito Santo, Rio de Janeiro, Minas Gerais, São Paulo, Paranä, Santa Catarina e Rio Grande do Sul. A localidade de procedéncia para cada espécie acha-se no item "Material examinado". 
4.3. Conservação e montagem dos exemplares

As moscas coletadas em "frascos caça-moscas" ou obtidas de frutas foram conservadas em álcool 70\%. A montagem desses exemplares, quando necessária, baseou-se na técnica de VOCKEROTH (1966).

\subsection{Preparação da genitália feminina}

A fêmea, quando conservada em álcool, era colocada em posição ventral numa lâmina sob o microscôpio estereos cópio, e com o auxỉlio de dois estiletes extrovertia-se o ovipositor. O exame do ovipositor era feito num aumento de $40 \mathrm{X}$ ou de lo0x, neste caso, colocava-se uma gota de glicerina sobre o ovipositor e examinava-o ao microscópio.

Nos exemplares secos retirava-se o abdome e colocava-o num Becker com $\mathrm{KOH}$ (quente ou frio). A seguir o ovi positor era extraido e juntamente com o abdome era desidratado em fenol puro e seco em papel de filtro. 0 abdome e genitá. lia eram conservados em tubinhos de polietileno com glicerina (GURNEY et alii, 1964).

\subsection{Ilustrações}

As figuras do ápice do ovipositor foram efetuadas com câmara clara adaptada num microscópio Zeiss. Foram adaptados os esquemas de STONE (1942a) para as espëcies não es tudadas. As figuras das asas das espécies novas foram realizadas com câmara clara adaptada a um microscöpio estereoscópio Wild. 
4.6. Abreviaturas

As abreviaturas, encontradas no texto, indicam as coleções ou instituições onde os tipos e material examinado estão depositados, e são as seguintes:

BMNH - British Museum (Natural History), London (tipos de Walker, Macquart e Stone).

CPACS - Centro de Pesquisas Agropecuärias Centro-Sul, EMBRAPA, Rio de Janeiro (tipos de Costa Lima).

ESALQ - Escola Superior de Agricultura "Luiz de Queiroz", da Universidade de São Paulo - Departamento de Entomologia.

FOC - Fundação Oswaldo Cruz, Rio de Janeiro (coleção Costa Lima e tipos de stone).

IB - Instituto Biológico, Secretaria da Agricultura de São Paulo (tipo de Autuori).

INTA - Instituto Nacional de Tecnologia Agropecuäria, Casteldas (coleção E. Blanchard).

IZW - Institut Zoologique Warszawa, Stuttgart (tipos de Hering).

MCSN - Museo Civita di Storia Naturale, Milano (coleção Bezzi).

MNHN - Muséum National D'Histoire Naturelle, Paris (tipos de Macquart).

MNTHM - Magyar Nemzeti Természe Hudomānyi Múzeum, Budapest ( $t \underline{i}$ pos de Hendel e Bezzi).

MCZ - Museum of Comparative Zoology, Harward University, Cambridge (tipos de Loew). 
MZUSP - Museu de Zoologia da Universidade de São Paulo (tipo de Costa Lima).

NM - Naturhistorisches Museum, Wien (tipos de Wiedemann, Schiner, Hendel e Costa Lima).

NMNH - National Museum of Natural History, Washington, D.C. (tipos de Aldrich, Greene, Costa Lima, Stone, Sein e Townsend).

SMT - Staatliches Museum für Tierkunde, Dresden (tipos de Hende1).

ZMH - Zoologisches Museum an der Humboldt - Universität zu Berlin (tipos de Loew).

4.7. Glossärio

As seguintes terminologias foram utilizadas nas descrições das espēcies:

comprimento do törax: distância mäxima, em vista dorsal, compreendida entre a margem anterior do mesonoto e a extremidade posterior do escutelo. Utiliza--se essa medida como indicativa da dimensão do exemplar, pois o abdome é destacado do corpo durante as preparações da genitälia (fig. 2).

mesonoto: é a maior região do tórax e pode apresentar dorsalmente uma faixa mediana e duas faixas laterais de coloração mais clara do que o restante do corpo (fig. 2).

metanoto: é a porção do törax situado sob o pós escutelo

(STONE, 1942a e STEYSKAL, 1977b) e corresponde ao médio-tergito de CRAMPTON (1942) (fig. 9).

asa: apresenta uma faixa costal que geralmente estenderse sobre a margem anterion da asa atë o fim da nervura $R_{I}$; uma 
faixa S que apresenta uma porção basal que prolonga-se e corta obliquamente a asa atè a margem anterion e termina no ápice da asa; a faixa V quando completa, possui um raw mo proximal, que vai da margem posterior da asa ate a nervura $R_{4+5}$, e um ramo distal; o ponto de união desses ramos é o verrtice. o comprimento da asa foi tomado no pröprio exemplar, e vai da base da asa (margem anterior) até o fim da $R_{4+5}$ (fig. 1).

Bainha do ovipositor: peça tubular que envolve o ovipositor; corresponde ao VII urômero. É medido, em vista dorsal, da base dos discos pretos à extremidade apical (fig. 3).

Rasper: è uma porção membranısa invaginada no fim da bainha do ovipositor e que apresenta dentes dorsais; corresponde ao VIII urômero (fig. 3).

Ovipositor: peça subcilindrica (IX urômero); oviscapto de al guns autores. E medido, em vista ventral, da sua base até a extremidade distal (fig. 3 ).

Åpice: parte do ovipositor que vai do fim do oviduto à extre-midade distal ( $f i g, 3$ ).

Serra: porção do äpice do ovipositor com dentes (fig. 3). 
5. RESULTADOS E DISCUSSÃO

Após o exame dos exemplares de Anastrepha da co leção Costa Lima ( $F O C$ ), do Museu de Zoologia da Universidade de São Paulo e provenientes de 15 estados brasileiros, num total de 1.651 exemplares, foi possivel relacionar 74 espécies brasi leiras de Anastrepha e elaborar uma chave para identificá-las.

Foi examinado material tipico de 38 espëcies. As demais espécies, com exceção de 12, foram identificadas com base nas respectivas descrições ou com auxilio das determina̧̧ões de Costa Lima e Stone (FOC). Somente 3 espëcies, entre as 12 não examinadas, não podem ser identificadas através das descrições existentes, sendo que os tipos dessas 3 espëcies es tão aparentemente perdidos, e assim foram consideradas incertae sedis.

Foram descritas 11 espëcies novas, 5 nomes espe cificos considerados sinonimias e 12 lectötipos designados. 
5.1. Gênero Anastrepha Schiner, 1868

Anastrepha Schiner, 1868:263. Espëcie-tipo: Dacus serpentinus Wiedemann, des. orig.; Coquillet, 1899:259; Aldrich, 1905:601 (cat.); Bezzi, 1909:280 (chave, cat.); Hendel, 1914:5 (chave); Greene, 1934:130 (revisão); Limas 1934a: 490 (revisão): Stones $1942 a$ (revisão): Fernandez, 1953 (espëcies venezuelanas); Blanchard, 1961:281 (espëcies ar gentinas); Foote, 1967 (cat.); Korytkowski e Ojeda, 1968: 32 (espécies peruanas); Steyskal, 1977 (chave ilustrada).

Acrotoxa Loew, 1873:227. Espécie-tipo: Dacus frateroulus, des. subs.

Instrypeta Herrera, Rangel \& Barreda, 1900:5. Nomen nudum

Pseudodacus Hendel, 1914:13 (como subgênero). Espëcie-tipo: Anastrepha daciformis Bezzi, des. orig.; Bezzi, 1909:5; Lima, 1934a:493; Stone, 1939b:282 (como gênero); Blanchard, 1961:293 (como subgênero); Steyskal, 1977b:75 (sinonimia de Anastrepha).

Phobema Aldrich, 1925:7. Espëcie-tipo: Phobema atrox Aldrich, des. orig.; Steyskal, 1977b:75 (sinonimia de Anastrepha).

Lucumaphila Stone, 1939a:340. Espëcie-tipo: Lucumaphila sagittata stone, des. orig.: Blanchard, 1961:293 (como subgê nero); Steyskal, 1977b:77 (sinonimia de Anastrepha).

Diagnose: Cabeça ligeiramente mais larga do que alta, e distintamente mais alta do que comprida; fronte aproximadamente 1/3 da largura da cabeça.

Törax com 1 par de acrosticais próximo ao escutelo; I par de umerais: 2 pares de notopleurais: 1 par de prë-suturais; 1 par de supra-alares; 1 par de intra-alares e 2 pares de escutelares (fig. 2). Presença de uma mäcula ne- 
gra aträs do ponto de inserção das asas. Asas, em geral, com faixa costal, em forma de $S$ e em forma de $V$ intertido, de colo ração amarela a marrom: ápice de $R_{1}$ terminando, aproximadamen te, no meio de $C, M_{1+2}$ distintamente curvada pröximo ao äpice; $R_{1}$ e $R_{4+5}$ com cerdas na metade anterior da distância para $r-m$ (fig. 1). Fêmures anteriores com uma fileira de longas cerdas ventrais; tibias anteriores e medianas com cerdas apicais.

Bainha do ovipositor com a base alargada, e com dois discos pretos laterais. Ovipositor esclerosado, achatado, e com abertura do oviduto pröximo ao äpice (fig. 3 ).

Genitália masculina pequena, consistindo de um epândrio, surstilos longos, e dois pares de fortes e curtos es pinhos ("prensisetae") localizados medianamente na parte inter na de cada surstilo.

Discussão: HENDEL (1914) reuniu as espécies de Anastrepha nos subgèneros: Pseudodacus e Anastrepha s. str., sendo que carac terizou Pseudodacus pelo terceiro antenômero alongado, apenas 1 par de cerdas fronto-orbitais superiores e padrão alar reduzido. Esse procedimento foi adotado por BEZZI (1919a, 1919b) e LIMA (1934a). Todavia, FISCHER (1933) observou que o número de fronto-orbitais superiores não era um caräter seguro para a separação dos subgêneros, pois apresentava variação intra-especifica. STONE (1939b) reconheceu esse fato, mas afin mou que os caracteres da genitälia do macho e da fêmea permitiam o reconhecimento desses grupos, e considerou Pseudodacus como gènero distinto. Anteriormente, STONE (1939a) havia separado as espécies de Anastrepha com ovipositor fino (no mäximo com $0,05 \mathrm{~mm}$ de largura) no gênero Lucumaphiza. Conside rou, ainda, Pseudodacus mais relacionado com Lucumaphila do que com Anastrepha.

ALDRICH (1925) criou o gênero Phobema para uma única espécie, que apresentava asas com faixas semelhantes às de Anastrepha. Justificou a criação do gênero Phobema devido 


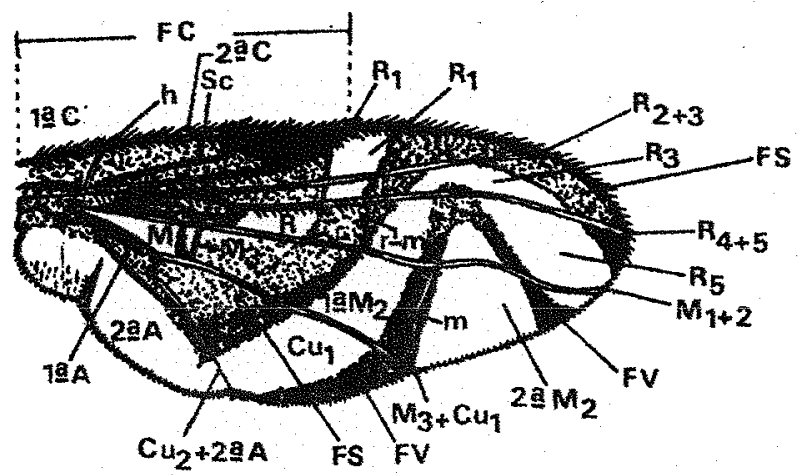

Fig. 1. Esquema padrão de asa.

FC: fajxa costal. FS: faixa em $S$. FV: fajxa em V.
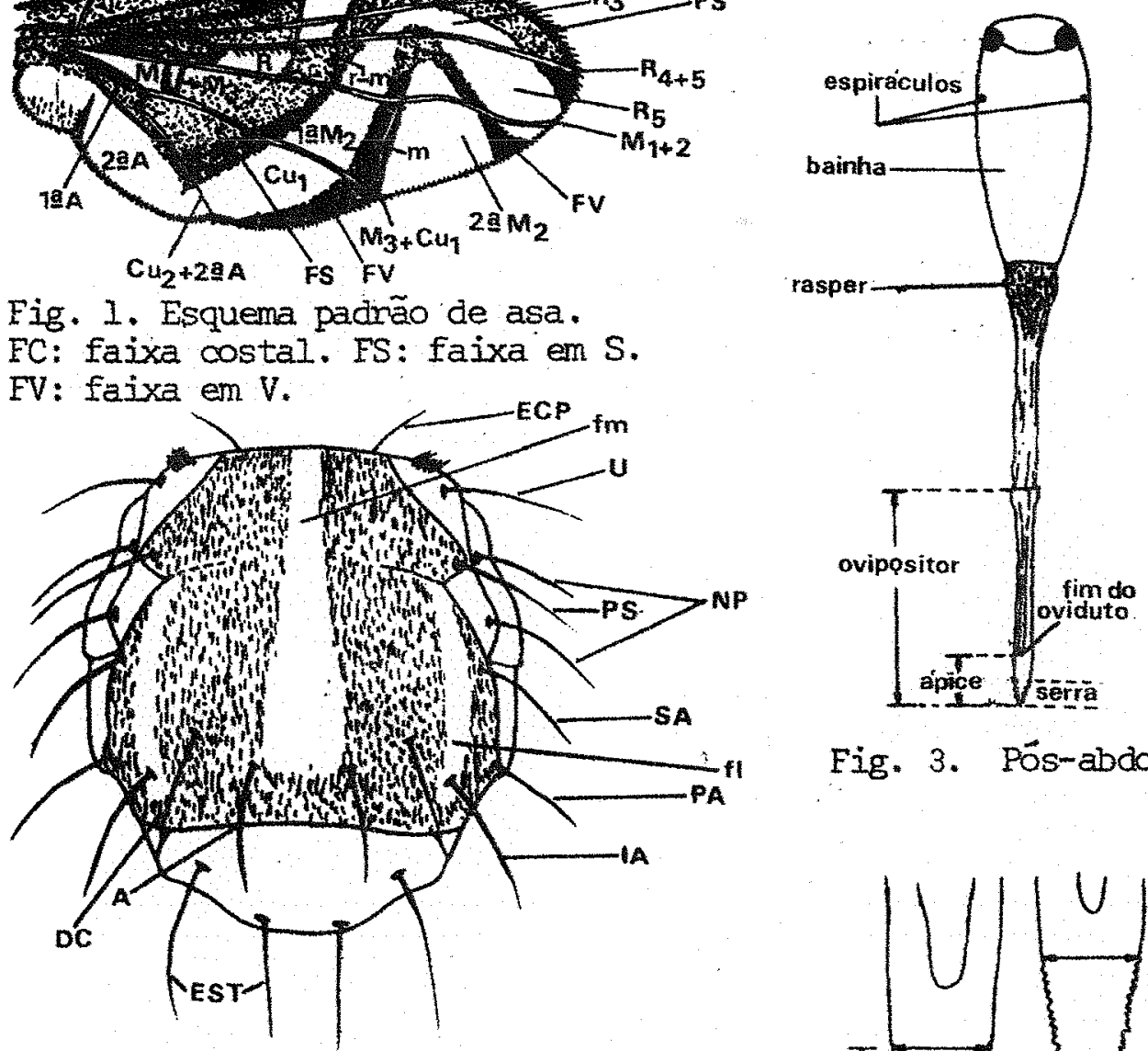

Fig. 3. Pös-abdome.

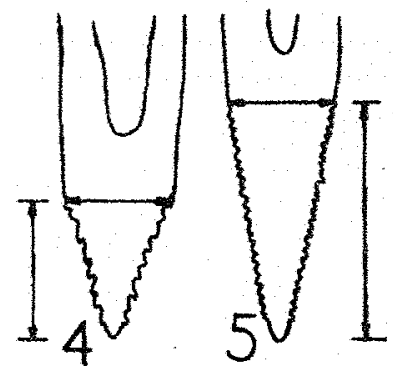

Fig. 2. Törax (vista dorsal). A: acros tical. DC: dorso-central. ECP: escapu= lar. EST: escutelar. U: umeral. IA: in tra-alar. NP: notopleural. PA: pós-alar. PS: pré-sutural. SA: supra-alar. fl: faixa lateral. fm: faixa mediana.

Figs. 4 e 5 . Aspectos da sema.
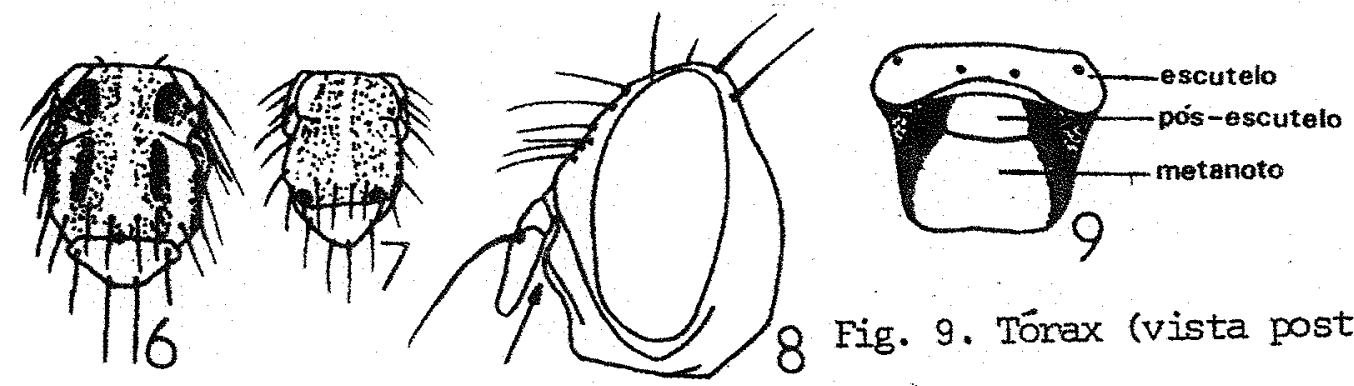

Fig. 9. Törax (vista posterior).

Fig. 6. Tónax de grantis... Fig. 7. Törax de punctata.

Fig. 8. Cabeça de benjamini. 
principalmente a presença de um processo proeminente entre a base das antenas.

BLANCHARD (1961) considerou Pseudodacus ao nivel de gênero e Lucumaphiza como subgênero de Anastrepha.

STEYSKAL (1977a) verificou que algumas espëcies de Anastrepha possuiam processo proeminente na face inferior, e assim considerou Phobema sinōnimo de Anastrepha. Observou ainda que não havia razäo para manter Lucumaphiza e Pseudodacus como gêneros distintos, e considerou-os sinônimos de Anastrepha, afirmando: "If Pseudodacus and Lucumaphiza are to be considered of generic or even of subgeneric rank, then a few other groups in Anastrepha should also be recognized. It seems to me to be both more consistent and of greater practicality in maintaining an easily recognizable group to consider all of these related groups with upcurved distal end of wing vein $M$ as members of one genus, Anastrepha".

Distribuição: Região tropical e subtropical das Amëricas (da Flörida ao Norte da Argentina).

5.2. Chave para as espécies de Anastrepha Schiner, 1868 assinaladas no Brasil (fêmeas)

1 Faixa costal estendendo-se por toda margem anterior da asa (Figs. 10, 12, 13 e 14) ................ 2

I' Faixa costal interrompida pröximo ao äpice da nervura $R_{1}$ (Figs. 11,15 a 21 ) ................... 6

2(1) Faixa $S$ ausente (Figs. 12 e 13$) \ldots \ldots \ldots \ldots$

$2^{\prime} \quad$ Faixa $S$ presente, às vezes pouco distinta (Figs. 10 e

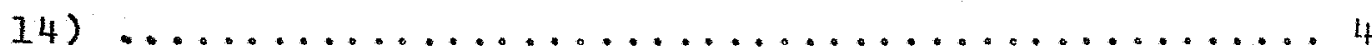

3(2) Célula $R_{2+3}$ hialina, exceto no äpice (Fig. I2); ovipo sitor Fig. $39 \ldots \ldots \ldots$ daciformis Bezzi

connexa Lima não foi incluida nesta chave. 
3' Cêlulas $R_{I}$ e $R_{2+3}$ igualmente coloridas (Fig. 13); ovi positor Fig. $59 \ldots . . . \ldots . . . . .$. macrura HendeI

$4\left(2^{\prime}\right)$ Nervura $R_{2+3}$ sinuosa (Fig. 14); metanoto totalmente amarelado ................................ Lezi Lima

4 Nervura $R_{2+3}$ não sinuosa, metanoto com faixas negras 5

$\left.54^{\prime}\right)$ Mesonoto sem faixas negras; ovipositor Fig. 25 ....

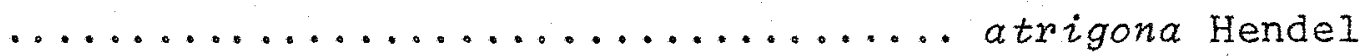

5' Mesonoto com faixas negras (Fig. 6); ovipositor Fig.

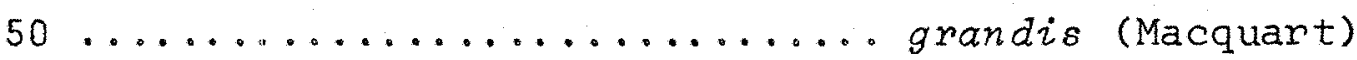

6(1') Margem posterior do mesonoto com 2 manchas circulares (Fig. 7) .......................... 7

6 Margem posterior do mesonoto sem manchas circulares 8

$7(6)$ Manchas circulares escuras; ovipositor Fig. 72 ....

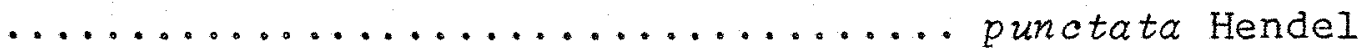

$7^{\prime}$ Manchas circulares amarelo pälidas ....... cruzi Lima

$\left.86^{\prime}\right)$ Ovipositor com menos de $0,07 \mathrm{~mm}$ de largura ........9 $8^{\prime}$ Ovipositor com ma is de $0,07 \mathrm{~mm}$ de largura ........ 16

$9(8)$ Ovipositor com menos de $2,5 \mathrm{~mm}$ de comprimento ..... 10

$9^{\prime} \quad$ Ovipositor com mais de $2,5 \mathrm{~mm}$ de comprimento ...... 11 10(9) Apice do ovipositor 1 iso (Fig. 64) ...... montei Lima 10' Apice do ovipositor denteado (Fig. 45) . fischeri Lima II(9') Faixas alares indistintas (Fig. 15); ovipositor Fig.

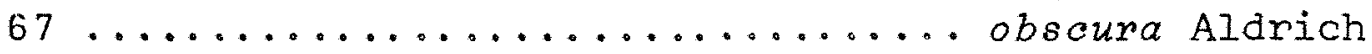

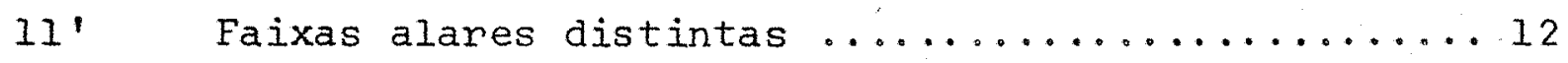

12 (11') Faixas $C$ e $S$ separadas (Figs. 19 e 21) ......... 13 12 , Faixas $c \in S$ unidas (Fig. 11) ...................

13(12) Faixa $V$ completa (Fig. 11); ovipositor Fig. $52 \ldots . .$.

$13^{\prime}$ Faixa $V$ incompleta; ovipositor Fig. $56 \ldots \ldots$ $\ldots \ldots \ldots \ldots \ldots \ldots \ldots \ldots \ldots$ zuederwaldti Lima

$14\left(12^{\prime}\right)$ Ovipositor com 4, 0mm de comprimento (Fig. 87) ....... $14^{\prime}$ Ovipositor no minimo com 5 , 0mm de comprimento .... 15

Espëcies descritas com base em exemplar macho apenas. 
15(14') Ramo distal da faixa $V$ ausente; äpice do ovipositor denteado (Fig. 76) ................ sagittifera, sp.n.

15. Ramo distal da faixa $V$ presente; ápice do ovipositor Iiso (Fig. 58) .................. Longicauda Lima

$16\left(8^{\prime}\right)$ Placa facial convexa em perfil (Fig. 8) ........ 17

16' Placa facial côncava em perfil .............. 18

I7(16) Bainha do ovipositor acentuadamente alargada na base; apice do ovipositor com dentes sobre mais da metade api

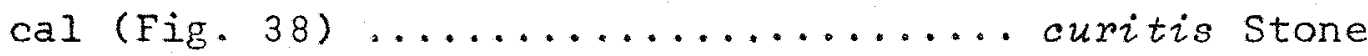

17' Bainha do ovipositor pouco alargada na base; ápice do ovipositor com distinta constrição antes da serra $e$ com dentes sobre menos da metade apical (Fig. 31) ....

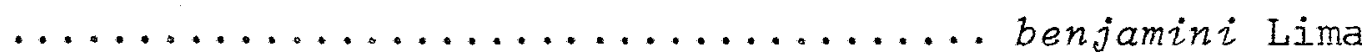

18(16') Espëcie escura com faixas amarelas no mesonoto e abdome; faixa $V$ com ramo distal ausente (Fig. 20) .....

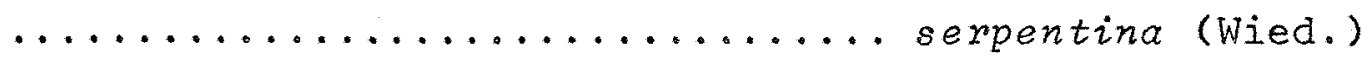

$18^{\prime}$ Espécies amareladas .................. 19

$19\left(18^{\prime}\right)$ Mesonoto com faixas negras longitudinais (Fig. 6) . 20 $19^{4}$ Mesonoto sem faixas negras longitudinais ........ 21

20(19) Ovipositor com menos de $3,0 \mathrm{~mm}$ de comprimento (Fig. 81)

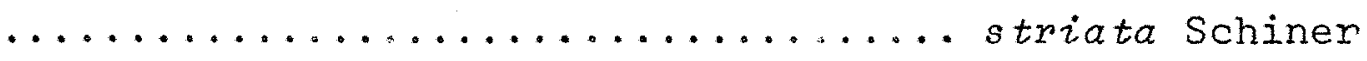

$20^{\prime}$ Ovipositor com mais de $3,0 \mathrm{~mm}$ de comprimento (Fig. 33)

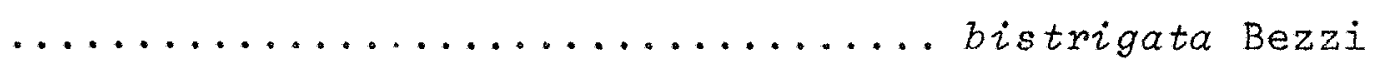

$21\left(19^{\prime}\right)$ Faixas alares marrom escuras ............... 22

21' Faixas alares marrom claras e/ou amareladas ....25

22 (21) Faixa $s$ com prolongamento basal (Fig. 16) ......... $\ldots \ldots \ldots \ldots \ldots \ldots \ldots . \ldots \ldots$ fenestrata Lima

$22^{\prime}$ Faixa $S$ sem prolongamento basal ............. 23

$23\left(22^{\prime}\right)$ Faixa $v$ completa (Fig. 11) ................. 24

$23^{\prime}$ Faixa $\mathrm{V}$ incompleta ..........................

24(22') Porção basal da faixa S com reentrância triangular (Fig. 17); ovipositor Fig. 49 ........ furcata Lima $24^{\prime}$ Porção basal da faixa $S$ diferente... hendeliana Lima

* Espécies descritas com base em exemplar macho apenas. 
25(21') Célula M manchada (Fig. 18); äpice do ovipositor terminando arredondado (Fig. 48) ...... fumipennis Lina

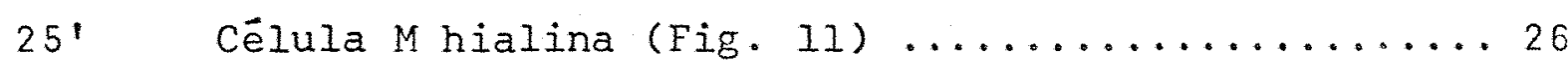

$26\left(25^{\prime}\right)$ Metanoto sem faixas escuras laterais .......... 27

26 , Metanoto escurecido lateralmente (Fig.9) .......64

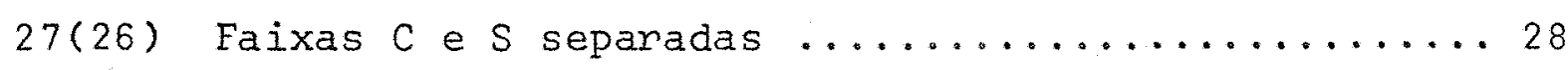

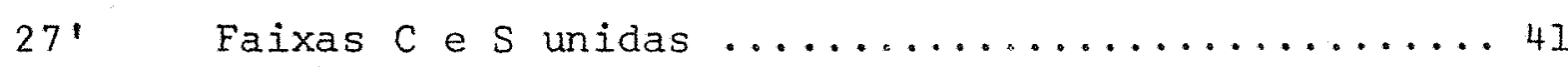

$28(27)$ Nervura $R_{2+3}$ sinuosa (Fig. 19) ............... 29

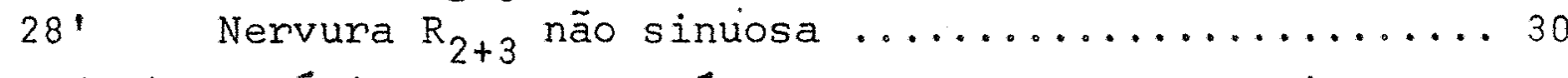

29(28) Espëcie pequena, tónax com $2,5 \mathrm{~mm}$ de comprimento e asas com $5,5 \mathrm{~mm}$ de comprimento ....... borgmeieri Lima

29. Espëcie grande, törax com 3,5-4,5mm de comprimento $\epsilon$ asas com 8,5-10,5mm de comprimento; ovipositor Fig.

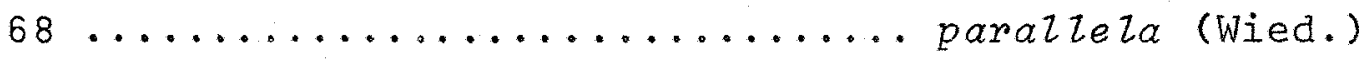

$30\left(28^{\prime}\right)$ Apice do ovipositor denteado ................... 31

$30^{\prime} \quad$ Apice do ovipositor Iiso $\ldots \ldots \ldots \ldots \ldots \ldots \ldots \ldots$

$3 I$ (30) Ovipositor com 6,0-10,0mm de comprimento .......32

$31^{\prime}$ Ovipositor com $2,0-3,5 \mathrm{~mm}$ de comprimento $\ldots \ldots \ldots 3$

$32(31)$ Dentes diminutos sobre $1 / 5$ apical (Fig. 28) .......

32' Dentes pequenos estendendo-se até a proximidade do fim do oviduto (Fig. $8 \theta$ ) ............... zikani Lima

$33\left(3 I^{\prime}\right)$ Serra aproximadamente tão longa quanto larga (Fig. 4)

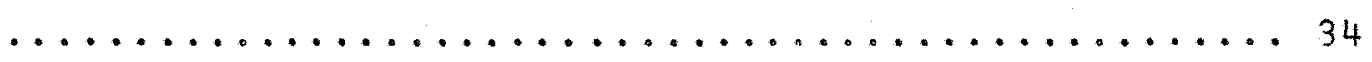

$33^{\prime}$ Serra mais longa do que larga (Fig. 5) ........ 35

34 (33) Âpice com constrição antes da serra; dentes conspicuos (Fig. 43) ................ elegans Blanchard 34' Âpice sem constrição; dentes diminutos (Fig. 85) ....

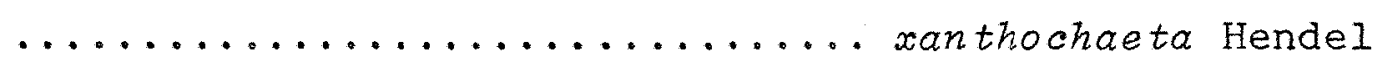

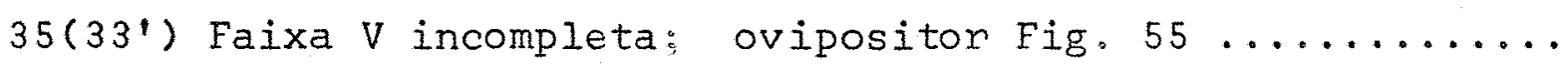

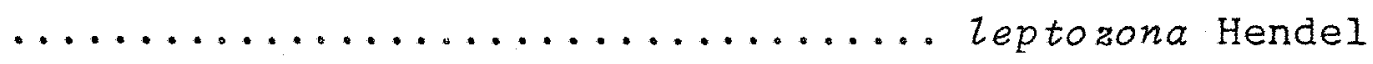

35' Faixa V completa; ovipositor Fig. $41 \ldots \ldots . . . .$. dissimilis stone

* Espëcie descrita com base em exemplar macho apenas. 
36(30') Ovipositor com 1,5-2,0mm de comprimento .......3 37

36 Ovipositor com $3,5-5,5 \mathrm{~mm}$ de comprimento ....... 38

$37(36)$ Faixas $V$ e $S$ separadas; ovipositor Fig. $82 \ldots \ldots \ldots$

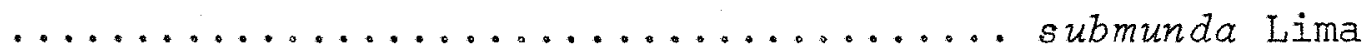

$37^{\prime}$ Faixas V e S unidas; ovipositor Fig. $73 \ldots \ldots \ldots \ldots$ quararibeae Lima

$38\left(36^{\prime}\right)$ Célula $R_{2+3}$ levemente estreitada .......................... $38^{\prime}$ Célula $R_{2+3}$ não estreitada ................. 40

39(38) Faixa $V$ incompleta e unida à $S$; ovipositor Fig. 53 hastata Stone

39' Faixa V completa e isolada; ovipositor Fig. 54 .....

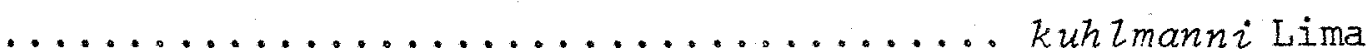

$40\left(38^{\prime}\right)$ Nervura $M_{I+2}$ com acentuada curvatura apical (Fig. 21); ovipositor Fig. $37 \ldots \ldots$.......... costalimai Autuori

40' Nervura $\mathrm{M}_{1+2}$ com curvatura normal; ovipositor Fig. 51 $\ldots \ldots \ldots \ldots \ldots \ldots \ldots \ldots \ldots \ldots$. $\ldots \ldots$ greenei Lima

41(27') Âpice do ovipositor com intumescimento lateral próximo ao fim do oviduto e outro antes da serra (Fig. 32) ...

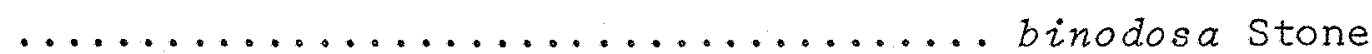

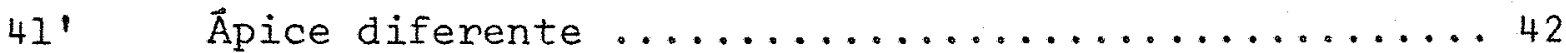

42(4I') Äpice com dentes no minimo até a metade apical ... 43 42' Âpice liso ou com dentes sobre menos da metade apical .................................. 55

43(42) Dentes estendendo-se até o nivel do fim do oviduto ou ultrapassando-o ...................... 44

$43^{\prime}$ Dentes não estendendo-se atẻ o nỉvel do fim do oviduto

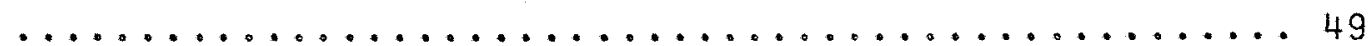

44 (43) Serra mais longa do que larga (Fig。 5) ........45 $4^{\prime}$ Serra aproximadamente tão longa quanto larga (Fig. 4)

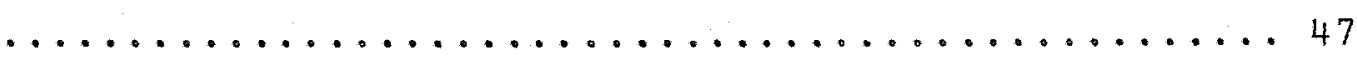

45(44) Ovipositor com 3,5-4,0mm de comprimento (Fig. 44) ...

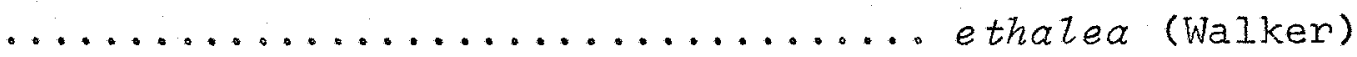

45' Ovipositor no máximo com $2,5 \mathrm{~mm}$ de comprimento ....4 46 46(45') ovipositor com 2,5m de comprimento; base da serra alargada (Fig. 57) ................. lutzi Lima 
46' Ovipositor com 1,2-1,5m de comprimento (Fig. 70) ...

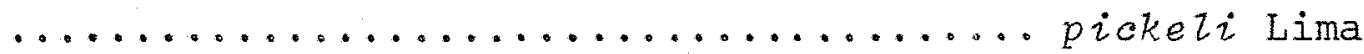

$47\left(44^{\prime}\right)$ Ovipositor com $3,75 \mathrm{~mm}$ de comprimento (Fig. 29) ......

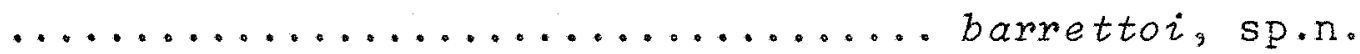

$47^{\prime}$ Ovipositor no mäximo com $2,5 \mathrm{~mm}$ de comprimento ... 48

48(47') Âpice tão largo na base quanto a haste do ovipositor

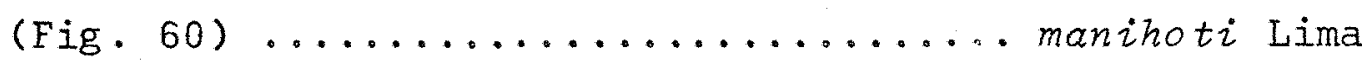

48' Apice mais largo na base do que a haste do ovipositor (Fig. 65) .............................

49(43') Apice do ovipositor com cerca de 5 dentes conspicuos

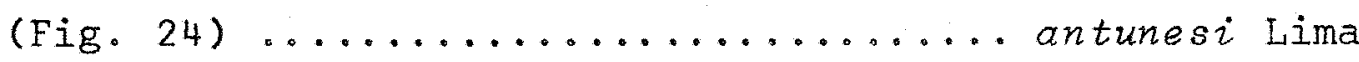

$49^{\prime}$ Apice do ovipositor com numerosos dentes ........550

$50\left(49^{\prime}\right)$ ovipositor com mais de $6 \mathrm{~mm}$ de comprimento (Fig. 23) .. $\ldots \ldots \ldots \ldots \ldots \ldots \ldots \ldots \ldots \ldots \ldots \ldots \ldots \ldots \ldots \ldots$ amis stone

$50^{\prime}$ Ovipositor com menos de $5 \mathrm{~mm}$ de comprimento .......51

51 (50') Âpice com constrição antes da serra ........... 52

$51^{\prime} \quad \vec{p}$ ice sem constrição antes da serra ........... 54

$52(51)$ Faixa $V$ unida à $s$; ovipositor (Fig. 35 ) ..........

$52, \quad$ Faixa $V$ separada da $s \ldots \ldots \ldots \ldots \ldots$

$53\left(52^{\prime}\right)$ Ovipositor com 4,25m de comprimento; dentes sobre mais da metade apical (Fig. 63) ........ mixta, sp.n.

53. Ovipositor com cerca de 4,0mm de comprimento; dentes até a metade do ápice (Fig. 42) ........ duckei Lima

$54\left(5 I^{\prime}\right)$ ovipositor com 4,87mm de comprimento (Fig. 84) ...... $\ldots \ldots \ldots \ldots \ldots \ldots$ townsendi stone

54' Ovipositor no mäximo com 3,0 mm de comprimento (Fig.71)

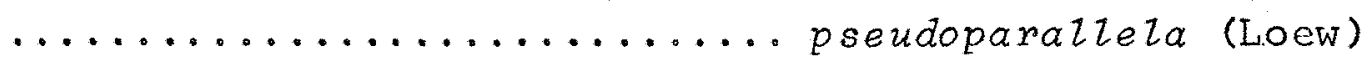

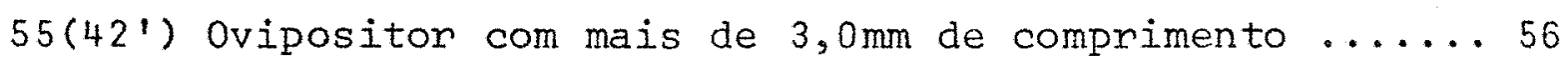

55' Ovipositor no mäximo com 2,5mm de comprimento .... 58

56(55) Ovipositor com 3,4mm de comprimento; ápice com dentes extremamente diminutos (Fig. 79) ....... sodalis stone $56^{\prime} \quad$ Apice do ovipositor 1 iso ................... 57

$57\left(56^{\prime}\right)$ ovipositor com $6,3 \mathrm{~mm}$ de comprimento (Fig, 36) ...... 
57' Ovipositor com 4,2-4,7mm de comprimento (Fig. 34) ...

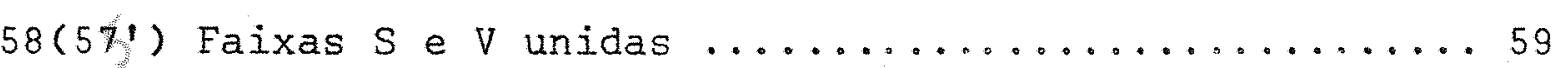

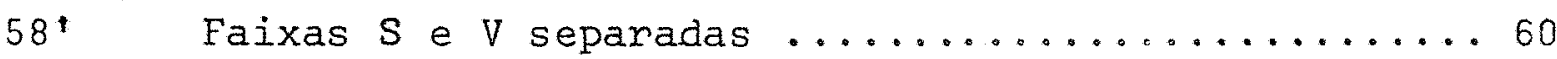

$59(58)$ Ovipositor com 1,8-1,9mm de comprimento (Fig. 46) ...

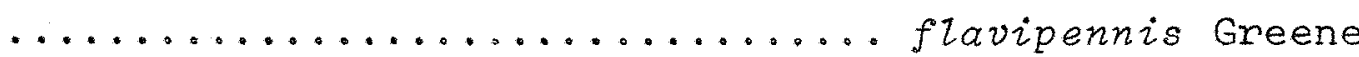

59' Ovipasitor com 1,2-1,3mm de comprimento (Fig. 78) ...

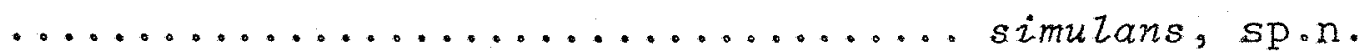

$60\left(58^{\prime}\right)$ Ovipositor com $1,5 \mathrm{~mm}$ de comprimento (Fig, 83) ......

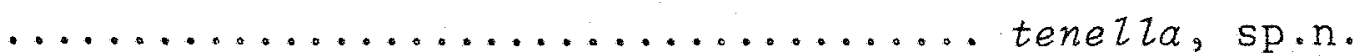

60' Ovipositor no minimo com 2,0mm de comprimento ....6.61

$61\left(60^{\prime}\right)$ Mesonoto sem faixa mediana ..................62

$61^{\prime}$ Mesonoto com faixa mediana ................63

62(61) Apice do ovipositor com leve intumescimento lateral

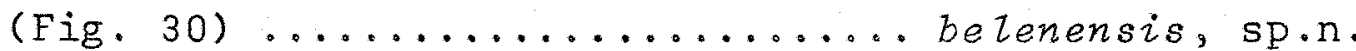

62' Apice afilando gradativamente da base à ponta (Fig.27) $\ldots \ldots \ldots \ldots \ldots$...............................

$63\left(6 I^{\prime}\right)$ Ovipositor com leve constrição antes da serra (Fig. 22)

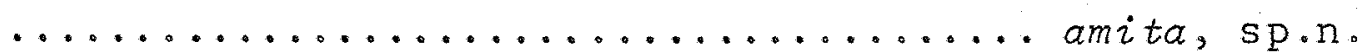

63' Ovipositor sem constrição antes da serra (Fig. 62) ... $\ldots \ldots \ldots \ldots \ldots \ldots \ldots \ldots$ minensis Lima

$64\left(26^{\prime}\right)$ Apice do ovipositor liso (Fig. 74) .... quiinae Lima 64 A Apice do ovipositor denteado ................65

$\left.65^{\prime} 64^{\prime}\right)$ Dentes no minimo ate a metade do ápice do ovipositor 66 $65^{\prime}$ Dentes sobre menos da metade apical .......... 72

$66(65)$ Dentes ate o nível do fim do oviduto (Fig. 75) ......

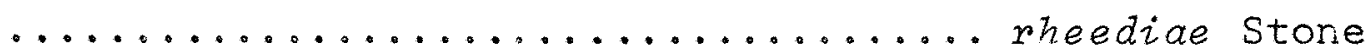

$66^{\circ}$ Dentes não estendendo-se atẻ o nivel do fim do oviduto

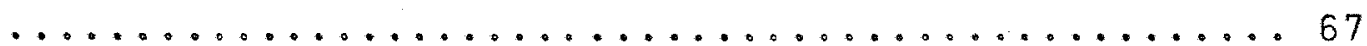

$67\left(66^{\circ}\right)$ Ápice do ovipositor com acentuada constrição antes da serra .............................. 68

$67^{\prime}$ Âpice do ovipositor com constrição moderada antes da serra ou sem constrição ................... 70

68(67) Apice do ovipositor com mais de 15 dentes (Fig. 61) ..

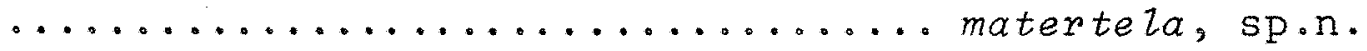

$68^{\prime}$ Aिpice do ovipositor com menos de 10 dentes .......69 
$69\left(68^{\prime}\right)$ Âpice com $0,25-0,27 \mathrm{~mm}$ de comprimento (Fig. 47) ..... $\ldots \ldots \ldots \ldots \ldots \ldots \ldots$ fraterculus (Wied.)

69, Apice com $0,17-0,19 \mathrm{~mm}$ de comprimento (Fig, 80) ..... $\ldots \ldots \ldots \ldots \ldots \ldots \ldots \ldots$ sororcuza, sp.n.

$70\left(67^{1}\right)$ Ápice do ovipositor com menos de 10 dentes (Fig. 69). $\ldots \ldots \ldots \ldots \ldots \ldots \ldots \ldots$ perdita stone $70^{\prime}$ Âpice do ovipositor com mais de 10 dentes ....... 71 $71\left(70^{\prime}\right)$ Apice com cerca de $0,20 \mathrm{~mm}$ de comprimento (Fig. 66) ... $\ldots \ldots \ldots \ldots \ldots \ldots \ldots \ldots \ldots \ldots \ldots \ldots \ldots \ldots$ obliqua (Macquart)

71' Ápice com $0,27-0,30 \mathrm{~mm}$ de comprimento (Fig. 86) ..... $\ldots \ldots \ldots \ldots \ldots \ldots \ldots \ldots \ldots$ zenizdae, sp.n.

$72\left(65^{\prime}\right)$ Ovipositor com menos de $2,0 \mathrm{~mm}$ de comprimento (Fig. 26)

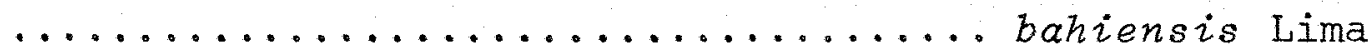

$72^{\prime}$ Ovipositor com mais de $2,0 \mathrm{~mm}$ de comprimento (Fig. 40)

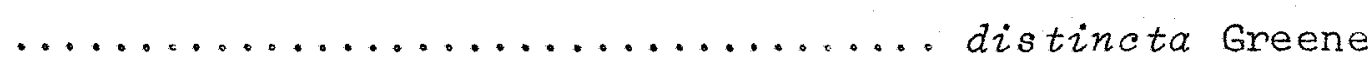

\subsection{Espécies de Anastrepha assinaladas no Brasil}

Anastrepha amita, sp. n.

(Figs. 22 e 89)

Espëcie pequena. Törax com 2,5-3,0mm de comprimento; mesonoto com faixas distintas, a faixa mediana inclui as acrosticais; ümero amarelo pálido. Metanoto e pôsescutelo inteiramente amarelado. Macroquetas marrom escuras; pilosidade amarelada. Asas com 7,0mm de comprimento; faixas $C$ e $S$ estreitamente ligadas ou não; faixa $V$ pouco nitida no vêrtice e separada da $S$. Bainha do ovipositor com 2,25m de comprimento: rasper com dentes alargados na base e espaçados entre si. Ovipositon com 2,0mm de comprimento; äpice com leve constrição antes da serra, esta com dentes arredondados e pouco salientes sobre a metade apical.

Holötipo + . Brasil, Bahia, Cruz das Almas, sem 

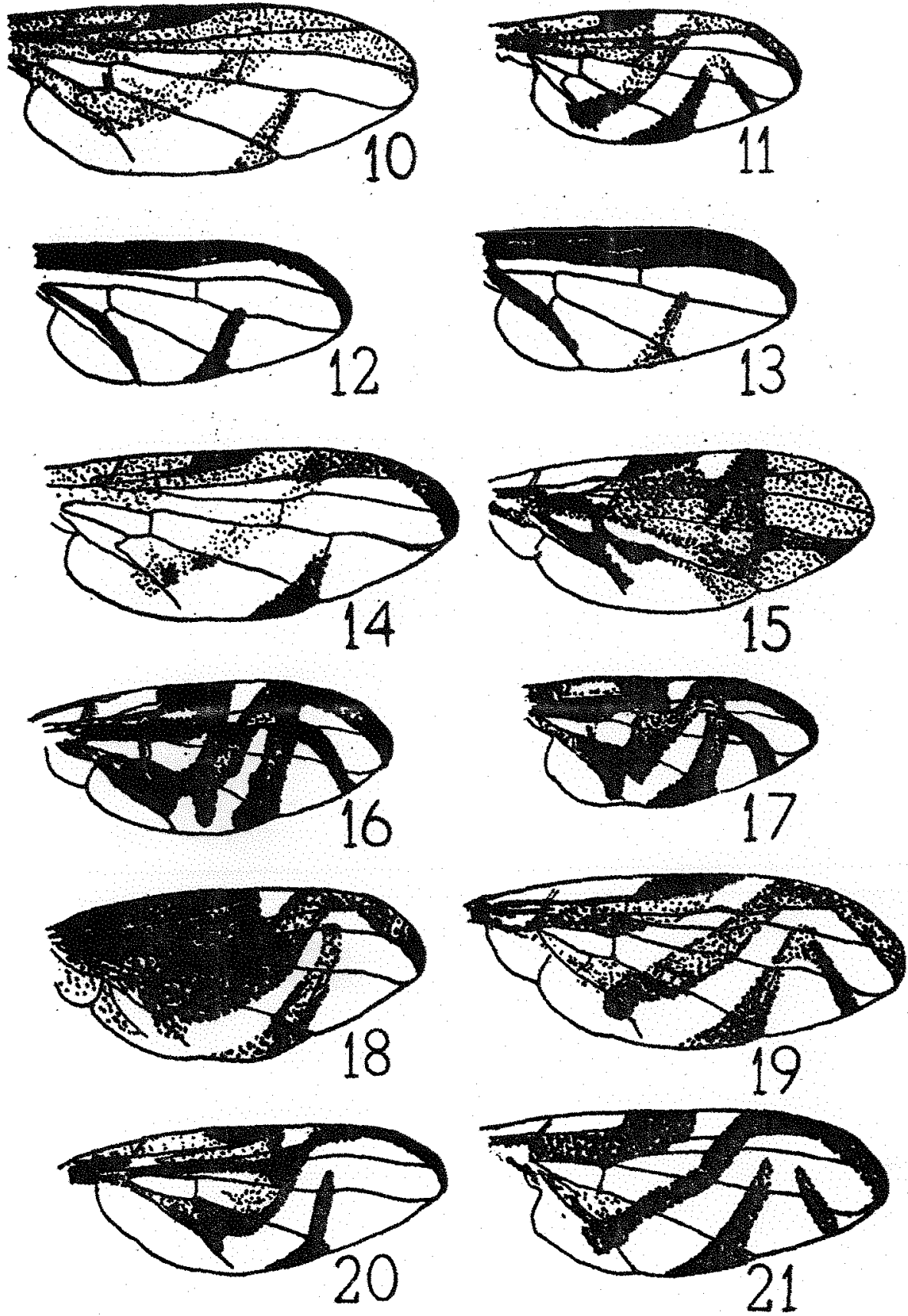

Asas. Fig. 10: grandis. Fig. 11: asa padrão. Fig. 12: daci formis. Fig. 13: macrura. Fig. 14: beazii. Fig. 15: obscura. Fig. 16: fenestrata. Fig. 17: furcata. Fig. 18:fumipennis. Fig. 19: paralzela. Fig. 20: serpentina. Fig. 21 : costalimai. 
data, A.S.Nascimento (MZUSP); 1 parätipo ( $q$ ), idem (ESALQ).

A. amita, sp. n. pertence ao complexo fratercuZus. Difere de $A$. fraterculus (wied.) e A. bahiensis Lima pelo metanoto totalmente amarelado e aspecto do äpice do oviposi tor; de $A$. minensis Lima pela constrição antes da serra.

\section{Anastrepha amnis stone, 1942}

(Fig. 23)

Anastrepha amnis Stone, 1942a:88 (holötipo 9 , Itatiaia, Rio de Janeiro, Brasil, FOC).

Anastrepha consobrina: Lima, 1934a:532, fig. 29; pr. 69, fig. 30; pr. 74, fig. 54 .

Espécie grande. Törax com $3,5 \mathrm{~mm}$ de comprimento. Mesonoto com faixa mediana indistinta e faixas laterais nitidas. Metanoto e pós-escutelo inteiramente amarelado. Macroquetas pretas; pilosidade esbranquiçada. Asas com 9,5mm de comprimento; faixas $C$ e $S$ unidas; faixa $V$ completa e isolada. Bainha do ovipositor com $6,8 \mathrm{~mm}$ de comprimento; rasper com dentes curtos, grossos e afastados entre si. Ovipositor com 6,8mm de comprimento; ápice com dentes pequenos que se es tendem atè as proximidades do fim do oviduto.

LIMA (1930) identificou värios exemplares, provenientes de Estrela, Rio de Janeiro, como A. consobrina (Loew). LIMA (1934a) contestou sua pröpria identificação de $A$. consobrina e descreveu a espécie A. zikani. Considerou, ainda, como $A$. consobrina um exemplar proveniente de Itatiaia, Rio de Janeiro, que apresentava as mesmas dimensões indicadas por Loew. STONE (1942a) considerou A. zikani Lima sinônimo de $A$. consobrina (Loew) e o exemplar de Itatiaia como espëcie nova $A$. amnis, sem ter examinado esses exemplares.

CAPOOR (1955b) estudou os exemplares envolvidos naquelas determinações, e observou que o exemplar de Itatiaia diferia dos de Estrela pelo aspecto do rasper. Considerou cor reto o ponto de vista de LIMA (1934a), ou seja A. consobrina 
(Loew) deveria apresentar rasper com dentes curtos e pouco numerosos, e A. zikani teria rasper com numerosos dentes delga dos. De acordo com esse autor, desde que o tipo de $A$. consobrina (Loew) está perdido, esta espēcie deveria ser reconhecida pela descrição de IIMA (cit. loc.).

BLANCHARD (1961) considerou A. consobrina (Loew) com dentes diminutos no rasper. Portanto, semelhante ao rasper do exemplar descrito por LIMA (1934a) também como A. consobrina (Loew).

Apös o exame dos exemplares de Estrela e o exem plar ünico de Itatiaia, póde-se constatar que se trata de duas espécies distintas. Desde que o tipo de A. consobrina (Loew) está perdido, é mais viävel considerar $A$ o amnis stone e A. zikani Lima espēcies distintas. Pois, enquanto não for examinado o tipo de $A$. consobrina (Loew) será impossivel a identificação correta dessa espécie, bem como optar pela opinião de Lima ou stone.

Distribuicão: Brasil (Rio de Janeiro, Itatiaia).

Material examinado: BRASIL. Rio de Janeiro, holötipo + , Itatiaia, 31.I.1939, J.F.Zikán, exemplar n: 1827, Iâminas etiquetadas Anastrepha consobrina sob no 1929 (asa) e 1930 (abdome) ( $F O C)$.

\section{Anastrepha antunesi Lima, 1938}

(Fig. 24)

Anastrepha antunesi Lima, 1938a:63, fig. 22; pr. 5, fig. 3; pr. 6, fig. 2 (holötipo +, Piraja, Bahia, Brasil, FOC); Stone, 1942a:73, fig. 14C; pr. 15B; Fernandes, 1953:33: Korytkowski e Ojeda, 1968:67, figs. 34, 48, 83, 106 e 139 .

Espécie mëdia. Törax com 3,0mn de comprimento; mesonoto com faixas medianas e laterais distintas. Metanoto inteiramente amarelado. Macroquetas marrom claras; pilosidade esbranquiçada. Asas com 7,0 mm de comprimento; faixas alares 
amarelo claras; faixas $C$ e $S$ unidas: faixa $V$ completa, pouco distinta e separada da $\mathrm{S}$. Ovipositor com 2,5m de comprimento; ápice com poucos dentes conspicuos.

Distribuição: Panamá, Trinidad, Peru e Brasil.

Plantas hospedeiras: Genipa americana (tipo), spondias mombin S. purpurea e Spondias sp.

Material examinado: BRASIL. Bahia: holötipo ㅇ, Piraja, 5.VI.1936, P.C.A.Antunes, exemplar n: 3030 , lâminas 3276 (ovipositor) e 3363 (asa) (FOC); I 9 , Santo Amaro da Purificação, 01.V.1976, J.Morgante (ESALQ). Pernambuco: 29, S. Felix, V.1976, J.Morgante (ESALQ). PANAMÄ. Zona do Canal: 19 , I $\delta$, Barro Colorado, 30.VII.1935, J.Zetek (FOC).

Anastrepha atrigona Hendel, 1914

(Fig。25)

Anastrepha atrigona Hendel, $1914: 15$ e 20, pr. 1, fig. 8 (holo-tipo fo, Suriname, NM); Greene, 1934:146, pr. 19, fig. 9; Lima, 1934a:499; Stone, 1942a:21, fig. 1C, pr. 1B; Fernande $z, 1953: 18$, fig. 2 .

Espëcie grande. Coloração geral marrom alaranjada. Törax com 3,58-4,00mm de comprimento; mesonoto com faixas distintas. Metanoto marrom escuro com uma faixa mediana marrom alaranjada. Macroquetas pretas; pilosidade amarela da. Asas com 8,6-9,2mm de comprimento: faixas marrom; ärea hialina ausente na margem costal antes da nervura $R_{I}$; faixa $V$ sem ramo distal; ramo proximal estreitamente ligado a $S$. Bai nha do ovipositor com 4,2-4,6mm de comprimento; ovipositor com $4,6 \mathrm{~mm}$ de comprimento, ponta arredondada e ápice sem dentes (apud STONE, 1942a).

A. atrigona Hendel ë próxima de A. bivittata (Macquart) e A. fumipennis Lima, das quais difere pelo oviposi tor maior e padrão alar, respectivamente (LIMA, $1934 a$ e STONE, 1942a). 
Distribuição: Suriname e Brasil.

Anastrepha bahiensis Lima, 1937

(Fig. 26)

Anastrepha silvai bahiensis Lima, 1937b, figs. 10-11; pr. 3, fig. 6: pr. 4, fig. 5 (holötipo \&. Bahia, Brasil, FOC). Anastrepha bahiensis; Stone, 1942a:107, fig. 22; pr. 23 A; Konytkowski e 0jeda, 1968:68, figs. 9, 68, 100, 130, 159 e 185.

Espëcie pequena. Törax com 2,5-3,0mm de comprimento; mesonoto com faixas mediana e laterais distintas. Metanoto e pós-escutelo escurecidos lateralmente. Macroquetas pretas, pilosidade amarelada. Asas com 5,25-6,00mm de comprimento; faixas $\mathrm{C}$ e $\mathrm{S}$ unidas; faixas $\mathrm{V}$ incompleta e sepa rada da $S$. Ovipositor com $1,5-2,0 \mathrm{~mm}$ de comprimento; äpice com moderada constrição antes da serra, esta com dentes diminu tos sobre menos da metade apical.

A variedade bahiensis Lima foi elevada à catego ria de espécie por STONE (1942a), devido principalmente ao ovi positor mais curto de bahiensis. Porém, alêm do tamanho do ovipositor, A. bahiensis difere de $A$. distincta ( $=A$. silvai) por apresentar uma leve constrição antes da serra.

Distribuição: Panamā, Peru e Brasil.

Plantas hospedeiras: Guarobeira (tipo), Helicostylis poeppigiana e amora preta (? Leonia cymosa).

Material examinado: BRASIL. Bahia: holötipo f, (sem cabeça), IX.1939, G.Bondar, exemplar no 2288, lâminas 2628 (asa) e 2629 (abdome) (FOC); Cruz das Almas, 1 9, 14.VI.1977, A.R.N.Farias (ESALQ); idem, 4\%,VII-VIII.1977, A.S.Nascimento (ESALQ); Mu ritiba, 2 9, 17.VIII.1977, A.S.Nascimento (ESALQ). PernambuCo: S.Felix, 2 \%, V.1976, J.Morgante e E.F.Silva (ESALQ). PA NAMA. Zona do Canal: Barro Colorado, 1 fo, I $9,30$. VII.1935, J.Zetek (FOC). 
Anastrepha barbiellinii Lima, 1938

(Fig. 27)

Anastrepha barbiellinii Lima, 1938a:61; fig. 21; pr. 5, fig.2 (holötipo q, São Paulo, Brasil, FoC); Stone, 1942a: 108, fig. 22D; pr. 23B); Blanchard, 1961:330, fig. 33;

Korytkowski e Ojeda, 1968:68, figs.33, 73, 103, 128 e 162. Anastrepha bosqui Blanchand, 1961:331. Nomen nudum. Anastrepha barbiezlini, erro.

Espêcie média. Tórax com $3,5 \mathrm{~mm}$ de comprimento; mesonoto sem faixa mediana e faixas laterais distintas. Metanoto totalmente amarelado. Macroquetas marrom escuras, pilosi dade amarelada. Asas com 7,25-8,50mm: faixas $C$ e $S$ unidas; faixa $V$ completa e separada da $S$. Ovipositor com $2,0-2,5 \mathrm{~mm}$; dentes diminutos sobre $1 / 5$ apical, às vezes, os dentes não são distintos.

A. barbielziniz caracteriza-se pelos reduzidos dentes sobre 1/5 apical. Examinou-se exemplares de Andes, São Paulo, que apesar de possuir o aspecto do äpice do ovipositor semelhante ao de barbielzinii, não apresentavam dentes. Todavia, considerou-se esse fato apenas uma variação intramespecifica.

Distribuicão: Peru, Argentina e Brasil.

Material examinado: BRASIL. São Paulo: holötipo + , sem data, sem coletor, exemplar n: 1990, lâminas 3359 (asa) e 3360 (abdo me) (FOC); Andes, 7 \%, II.1955, M.Carrera (MZUSP); Araçatuba, 3 7, XI.1962, Lane e Rabello (MZUSP). 
Anastrepha barnesi Aldrich, 1925

(Fig. 28)

Anastrepha barnesi Aldrich, 1925:3 (holötipo + , Cayuga, Guatemala, NMNH); Greene, 1934:166, pr. 23, fig. 2; Lima; 1934a: 516.

Anastrepha virescens Lima, 1937b:63, figs. 15, 16; pr. 3, figs. I e 5; pr. 4, fig. I. (2 \%, Rio de Janeiro, Tijuca e Campo Grande, FOC).

Anastrepha elongata Fernandez, 1953:27 (holötipo +9, Rancho Gran de, Aragua, Venezuela, encontra-se no Department of Tropical Research, New York); Steyskal, 1977:33.

Espécie grande. Tórax com 3,75-4,50mm mesonoto com faixas distintas ou não. Metanoto amarelado sem faixas escuras laterais. Macroquetas marrom escuras, pilosidade amarelada. Asas com 9,25-10,25mm de comprimento; todas as faixas separadas; a faixa $V$ completa ou não. ovipositor com 10, 0mm de comprimento; äpice com dentes diminutos.

LIMA (1937) teve düvidas para identificar as duas fêmeas, coletadas no Rio de Janeiro como $A$. barnesi Aldrich, porque este autor descreveu a bainha do ovipositor co mo sendo tão longa quanto o abdome, e os exemplares examinados por Lima possuiam bainha mais longa do que o abdome. GREENE (1934) estudou o tipo de barnesi e observou que a bainha era mais longa do que o abdome. STONE (1942a), que colocou os exemplares de Lima como sinônimo de $A$. barnesi, não discutiu o problema da relação da bainha com o corpo. Examinou-se os dois exemplares de Lima e um espécimen determinado por stone como A. barnesi, e concluiu-se que realmente são co-específi... cos.

Distribuição: Guatemala, Panamã, Guiana e Brasil.

Planta hospedeira: Pouteria torta (la. referência).

Material examinado: BRASIL. Rio de Janeiro: Alto da Boa Vis 
ta, Tijuca, 1 \&, III.1936, C.A.Seabra, exemplar no 2292, lâmi nas 2645 (abdome) e 2646 (asa) etiquetadas Anastrepha vires cens ? barnesi, 1 \%, sem data e coletor no 3034, lâmina 3352 (asa) etiquetada Anastrepha (?) barnesi (FOC). São Paulo: São Carlos, I 우 2.XII.1977, Malavasi (ESALQ). PANAMÄ. EI Cermeno Pan, I $9,13 . V I .1939$, Zetek (FOC).

Anastrepha barrettoi, sp. n.

$$
\text { (Figs, } 29 \text { e 90) }
$$

Espëcie média. Törax com 3,0mm de comprimento; mesonoto sem faixas mediana e laterais. Metanoto inteiramente amarelado. Macroquetas marrom claras; pilosidade amarelo cla ra (dourada). Asas com $7,5 \mathrm{~mm}$ de comprimento; faixas $C$ e $S$ es treitamente unidas; faixa $\mathrm{V}$ incompleta $\mathrm{e}$ isolada. Bainha do ovipositor com 4,0mm de comprimento; rasper com dentes delgados e espaçados entre si. Ovipositor com $3,75 \mathrm{~mm}$ de comprimen to e base pouco alargada; ápice de aspecto triangular con den tes sub-agudos, que se estendem atê o nivel do fim do oviduto.

Holötipo . Brasil, São Paulo, Araçatuba, Córrego Azul, II.1946, Barretto (MZUSP).

Esta espécie difere de todas as espécies de Anastrepha pelo aspecto do äpice do ovipositor.

Anastrepha belenensis, sp. $\mathrm{n}$.

(Figs. 30 e 91 )

Espēcie pequena. Törax com 3,0 mm de comprimento; mesonoto apenas com as faixas laterais nitidas. Metanoto e pós-escutelo não escurecidos lateralmente. Macroquetas pretas; esternopleural muito fina; pilosidade amarelada. Asas com 6,0mm de comprimento; faixas $C$ e $S$ unidas; fajxa $V$ incom pleta e separada da $S$. Bainha do ovipositor com 2,5m de comprimento; rasper com numerosos dentes. Ovipositor com 2,5m 
de comprimento; ápice liso e com leve constrição lateral apro ximadamente na metade apical.

Holötipo ł. Brasil, Parä, Belëm, sem data, A.B. da Silva (MZUSP).

A. belenensis difere de qualquer outra espécie de Anastrepha pelo aspecto do äpice do ovipositor.

Anastrepha benjamini Lima, 1938

(Fig. 31)

Anastrepha benjamini Lima, 1938b:16, figs. 2, 6-9 (holötipo + , Ägua Preta, Bahia, Brasil, FOC); Stone, 1942a:34, fig. 4B; pr. $4 \mathrm{C}$.

Anastrepha connexa; Lima, 1938a:61, fig. 18, pn. 5, fig. 1, pr. 6, fig. 4 (FOC).

Anastrepha (?) connexa; Lima, 1938b:16, figs. 3, 5 e 8 . Anastrepha discessa Stone, 1942a:34, fig. 4C (holötipo 9 , Campo Grande, Rio de Janeiro, Brasil, FOC). Syn. n.

Espëcie grande. Placa facial convexa. Törax com 3,8-4,0mm de comprimento; mesonoto apenas com as faixas laterais presentes. Metanoto totalmente amarelado. Macroquetas marrom escuras; pilosidade amarelada. Asas com 8,50-9,25mm de comprimento; faixas $\mathrm{C}$ e $\mathrm{S}$ estreitamente unidas; faixa $\mathrm{V}$ completa e unida à $\mathrm{S}$. Ovipositor com $8,75 \mathrm{~mm}$ de comprimento, com uma constrição antes da serra, esta com dentes sub-agudos e pequenos.

LIMA (1938) descreveu uma fêmea como sendo $A$. connexa Lima, 1934, que era conhecida de um ünico exemplar ma cho. Posteriormente, estudou nove exemplares cujas fêmeas eram idênticas à fêmea considerada como $A$. connexa, mas os machos possuiam genitália diferente de $A$. connexa. Descreveu com base nos nove exemplares a espêcie $A$. benjamini, e não esclare ceu o problema da fêmea de connexa. STONE (1942a), sem examinar a fêmea considerada como de $A$. connexa, consideroura nova espēcie, A. discessa. Assim, distinguiu discessa de benjamini 
pelo padrão alar e "bordadura" do ovipositor mais larga em discessa. Considerou, ainda, que de acordo com o comprimento do aedeagus de connexa $(4,4 \mathrm{~mm})$, a fêmea dessa espëcie deveria apresentar um ovipositor bem mais curto do que o de discessa.

Examinou-se o material tipo de benjamini ( 7 exs.) e o exemplar ünico de connexa. Concorda-se com STONE (cit. Loc,) que a fêmea descrita por lima não pode ser de connexa. Todavia, considerou-se as diferenças apontadas para separação de benjamini e discessa como variação intra-especifica" e assim, colocou-se discessa sinônimo de benjamini.

\section{Distribuição: Brasil (Bahia).}

Planta hospedeira: "guapeba branca".

Material examinado: BRASIL. Bahia: Aggua Preta, holötipo 9 , XII.1937, G.Bondar, exemplar no 3535-2, lâmina 3854 (abdome) (FOC); idem 6 parätipos $(2$ f, 4 \%) (FOC). Rio de Janeiro (Cam po Grande), I $9,9, V I .1936$, J.Gomes, exemplar n: 3033, lâmina 3355 (erroneamente considerado por lima como fémea de $A$. connexa lima) (FOC).

Anastrepha bezzii Lima, 1934

Anastrepha bezzii Lima, 1934a:498, fig. 5, pr. 64, fig. 8 (holötipo f, Rio de Janeiro, Brasil, FOC); Lima, 1937:63; Stone, $1942 \mathrm{a}: 20$.

Espécie grande. Tórax com 5, omm de comprimento; mesonoto sem faixas. Metanoto e pös-escutelo amarelos claros. Macroquetas marrom claras; pilosidade amarelada. Asas com 10,0mm de comprimento; faixa C cobrindo totalmente a cëlula $R_{I}$; faixa $S$ incompleta e indistinta anteriormente; faixa $V$ apenas com o ramo proximal. $R_{2+3}$ e $R_{4+5}$ sinuosas e célula $R_{3}$ constricta.

LIMA (1937) descreveu uma fémea, proveniente de Goiās, como bezzii. Todavia, descreveu o ovipositor sem ilus... 
tră-lo e não indicou onde depositou esse exemplar. $\bar{E}$ provävel que esta fêmea encontre-se no Centro de Pesquisas Centro-SuI, EMBRAPA, Rio de Janeiro. Trata-se de espécie próxima de $A$. grandis (Macquart) da qual difere pelas nervuras $R_{2+3}$ e $\mathrm{R}_{4+5}$ sinuosas.

Distribuição: Brasil (Rio de Janeiro e Goiās).

Material examinado: BRASIL. Rio de Janeiro: holötipo fo, Rio de Janeiro (Manguinhos), 24.III.1917, sem coletor, exemplar n: 1796, frasco 940, lâminas 1876 (asa) e 1877 (abdome) (FOC).

Anastrepha binodosa Stone, 1942

(Fig. 32)

Anastrepha binodosa Stone, 1942a:57, fig. 10A, pr. 10D (holöti po + , Pará, Brasil, BMNH).

Espécie grande. Törax com 4,0mm de comprimento; mesonoto com faixa mediana larga na metade posterior e faixas laterais distintas. Metanoto inteiramente amarelado. Macroquetas marrom escuras; pilosidade amarelada. Asas com 11,0mm de comprimento, todas as faixas unidas. Ovipositor com 4,0mm de comprimento, delgado, com um intumescimento ao nível do fim do oviduto e outro próximo ao início da serra, esta som dentes diminutos.

Esta espêcie caracteriza-se pelos intumescimentos laterais no âpice do ovipositor. Foi descrita com base em 3 exemplares provenientes do Parä.

Distribuição: Brasil (Parä).

Material examinado: BRASIL. Pará: Belèm, Utinga, I \&, 10.X.1962, J.Bechyne (MZUSP). 
Anastrepha bistrigata Bezzi, 1919

(Fig. 33)

Anastrepha bistrigata Bezzi, 1919a:4, 7-10, fig. 1 (sintipos $2 \nmid$ e 1 f, São Paulo, Brasil, MCSN); Bezzi, 1919b:373,fig. 1; Lima, 1934a:505, figs. 9-10, pr. 65, fig. 12; pr. 75; fig. 63; Stone, 1942a:3I, fig. 3B, pr. 3C; Korytkowski e Ojeda, 1968:52, figs. 18, 50, 148, 177.

Espëcie mëdia. Törax com $3,5 \mathrm{~mm}$; mesonoto com faixas medianas e laterais bem distintas. Hä, tambëm, 2 faixas escuras longitudinais, que vão da porção anterior do mesonoto atẻ a base do escutelo, onde se unem transversalmente. Macroquetas pretas; pilosidade nas regiões claras é esbranqui çadas e nas regiões escuras è amarelo escura. Asas com 8,5mm de comprimento; faixas $C$ e $S$ unidas; faixa $V$ separada da $S$ e incompleta. Ovipositor com $3,5 \mathrm{~mm}$ de comprimento; äpice sem dentes e com ponta arredondada.

Trata-se de espēcie pröxima de A. striata Schiner da qual difere pelo padrão torácico e aspecto do ovipo sitor.

Distribuição: Peru e Brasil.

Plantas hospedeiras: Psidium guineense, $P$. guajava e $P$. araga.

Material examinado: BRASIL, São Paulo: Taiüva, 1 \%, sem data, J.C.Durigan (ESALQ); Ribeirão Preto, 1 \&, 11.III.1976, A.Mala vasi e J.Morgante (ESALQ); Rio Claro, 1 \%, 3.V.1969, R.A. Zucchi (ESALQ); Piracicaba, I + , 2.IX.1967, E.Berti Filho. (ESALQ); idem, I ㅇ, IV.1977, K.Nakayama (ESALQ). Minas Gerais: Lavras, 1 \&, III.1977, L.O.Salgado.

Anastrepha bondari Lima, 1934

(Fig. 34)

Anastrepha bondari Lima, 1934a:537, figs. 37-38; pr.70, fig.36; pr. 75, fig. 60; (lectötipo \%, Bahia, Brasil, FOC); Lima, 1937a:34; Stone, 1942a:98, fig. 19D; pr.20D. 
Espëcie mëdia. Törax com 3,00-3,75m de comprimento; mesonoto com as faixas laterais mais nitidas do que a mediana. Metanoto totalmente amarelado. Macroquetas marrom escuras; pilosidade amarelada. Asas com 6,5 9,0mm de compri mento; faixas $C$ e $S$ unidas; faixa $V$ completa (pouco nitida no vërtice) e isolada da $S$. Ovipositor com 4,2-4,7mm de com.primento; ápice sem dentes e acentuadamente estreitado após o fim do oviduto.

Designação de lectótipo. O material tipo de A. bondari Lima examinado apresentava 6 sintipos ( $3 \hat{\delta} 3 q$ ) todos com o nümero 1837, provenientes da Bahia e coletados por G.Bondar (FOC). Dessa sërie sintípica, selecionou-se e rotulou-se una fêmea como lectötipo $e$ os demais exemplares como paralectötipos.

Material examinado: BRASIL. Bahia: lectötipo $q$, sem data, Bondar (FOC); idem 5 paralectótipos $(3 \delta, 2$ \&)(FOC).

\section{Anastrepha borgmeieri Lima, 1934}

Anastrepha borgmeieri Lima, 1934a:518, fig. 19; pr.67, fig. 21 (holötipo $\hat{o}, ?$ Rio de Janeiro, Brasil, FOC); Stone, 1942a: 55 .

Espécie pequena. Tórax com 2,50mm de comprimen to: mesonoto sem faixas mediana e laterais. Macroquetas marrom claras, pilosidade amarelada. Metanoto uniformemente amarelado. Asas com 6,0mm de comprimento; todas as faixas separadas; $R_{2+3}$ sinuosa na metade basal; célula $R_{3}$ constricta.

LIMA (1934a) comparou os caracteres de borgmeieri com as descrições de Wiedemann e Loew para $A$. paralleza, pois essa espëcie tambëm possui $R_{2+3}$ sinuosa. Porëm, devido ao porte reduzido de borgmeieri considerou-a espëcie nova. STONE (1942a) verificou que a genitälia do macho de parazlela difere da de borgmeieri, e assim considerou esta espécie válida.

Distribuição: Brasil (? Rio de Janeiro). 

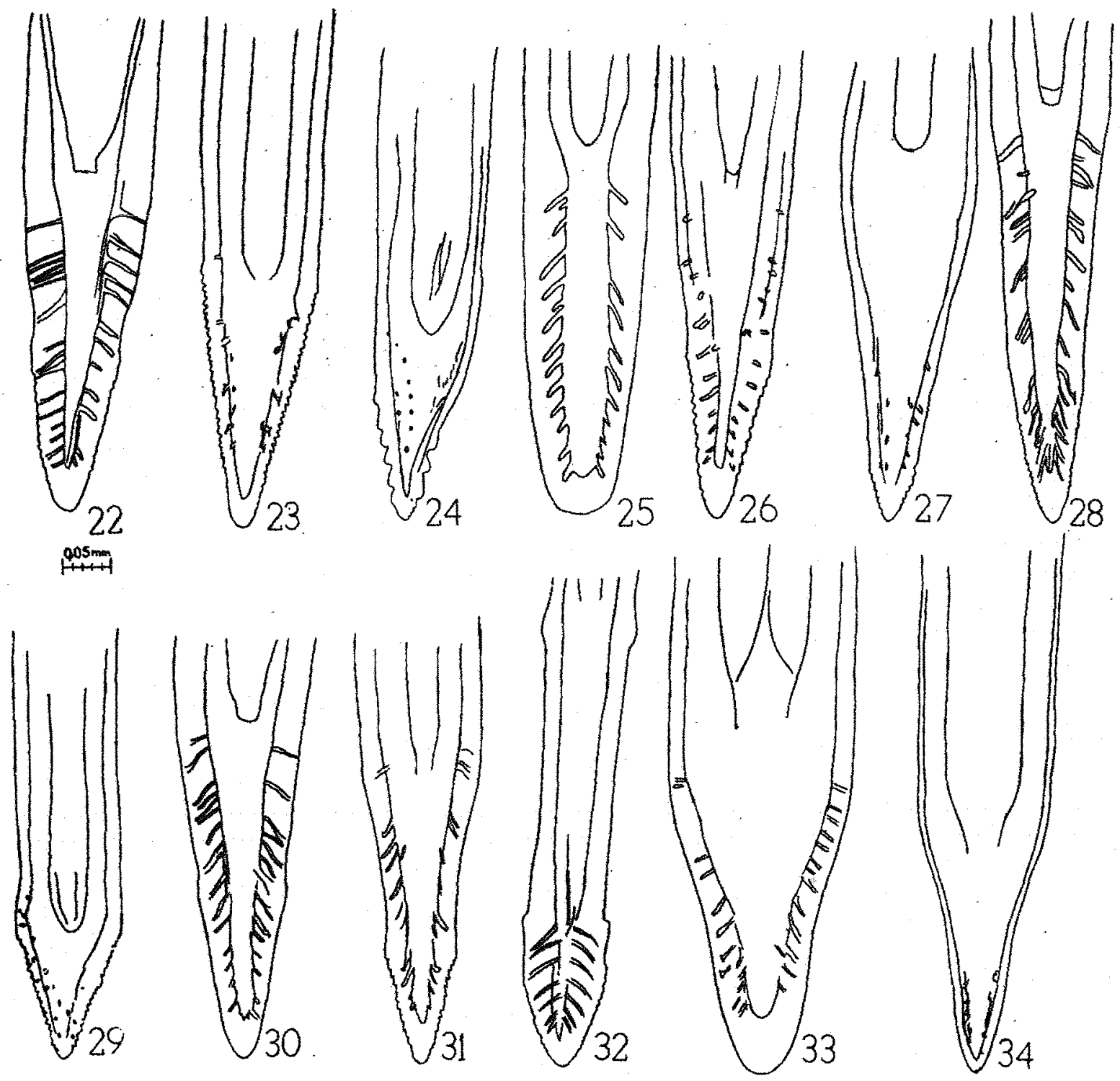

Apice do ovipositor. Fig. 22: amita. Fig. 23: amnis. Fig. 24: antunesi. Fig. 25: atrigona. Fig. 26: bahiensis. Fig. 27: barbiellinii. Fig. 28: barnesi. Fig. 29: barrettoi. Fig. 30: belenensia. Fig. 31: benjamini. Fig. 32: binodosa. Fig. 33: bistrigata. Fig. 34: bondari. 
Material examinado: BRASIL. Rio de Janeiro: holötipo $f$, sem data e coletor, exemplar no 1819, lâminas 1910 (asa) e 1911 (abdome) (FOC).

Anastrepha caudata stone, 1942

(Fig. 35)

Anastrepha caudata Stone, 1942a:85, fig. 17A (holótipo + , São Paulo, Brasil, BMNH).

Espëcie grande. Törax com 4,25mm de comprimento; mesonoto com faixas distintas. Metanoto inteiramente ama relo escuro. Macroquetas pretas; pilosidade amarelada. Asas com 9,25m de comprimento, todas as faixas unidas. ovipositor com $3,5 \mathrm{~mm}$ de comprimento; ápice com dentes sub-agudos em quase toda sua extensão.

E conhecido apenas o holótipo desta espécie. A descrição acima baseou-se em STONE, 1942a, que discutiu a possibilidade de $A$. caudata ser a fêmea de A. hendeliana Lima, descrita de 2 machos. Porém, até que se confirmasse conclusivamente esse fato, considerou mais viävel descrever a espécie caudata.

\section{Anastrepha concava Greene, 1934}

(Fig. 36)

Anastrepha concava Greene, 1934:169, pr. 23, fig. (holötipo, se xo desconhecido, Close's, Caño Saddle, Zona do Canal, Pana mä, NMNH); Stone, 1942a:93, fig. 18E, pr.19C.

Espécie grande. Törax com 4,2-4,6mm de compri mento, inteiramente marrom amarelado. Metanoto sem manchas es curas. Macroquetas pretas; pilosidade amarelada; esternopleu ral desenvolvida. Asas com 10,0-10,5mm de comprimento; faixas escuras e unidas entre si. Ovipositor com $6,3 \mathrm{~mm}$ de compri mento, delgado, äpice longo sem dentes (apud STONE, 1942a).

GREENE (1934) descreveu $A$. concava com base num 
único exemplar (? sexo) proveniente da Zona do Canal, Panamá. STONE (1942a) baseoumse em 2 fêmeas (BMNH e AMNH), provenientes de Santarëm, Brasil, que apresentavam caracteres externos semelhantes aos de concava, com exceção da concavidade sub-apí cal da margem costal das asas, que considerou uma anormalidade. Assim caracterizou o ovipositor desta espëcie e considerou-a vâlida.

\section{Anastrepha connexa Lima, 1934}

Anastrepha connexa Lima, 1934:530, fig. 28; pr.19, fig.29 (holótipo ô," São Paulo, Brasil, FOC); Stone, 1942a:94.

Espécie mëdia. Tórax com $3,5 \mathrm{~mm}$ de comprimento; mesonoto com faixas mediana e laterais nitidas. Metanoto totalmente amarelado. Macroquetas marrom escuras; pilosidade amarelada. Asas com 10,0mm de comprimento; faixas $C$ e $S$ un das; faixa $V$ incompleta e unida à $S$.

A. connexa ê conhecida apenas pelo holótipo macho. Assim, desde que a fêmea é desconhecida, torna"se difícil o reconhecimento desta espécie. A fêmea descrita por LIMA (1938) como connexa, certamente pertence a $A$. benjamini (vide pägina 32 ).

\section{Distribuição: Brasil (São Paulo).}

Material examinado: BRASIL. São Paulo: holötipo $\delta$, sem data e coletor, exemplar no 1826, lâminas 1925 e 1926 (asas) (FOC). A lâmina da genitália não foi examinada.

Anastrepha costalimai Autuori, 1936

(Figs. 21 e 37 )

Anastrepha costalimai Autuori, 1936:194, figs. 1-3 (sintipos f , Campo Belo, Santo Amaro, São Paulo, Brasil, IB); Lima, 1938a:62, pr. 7, fig. 2; Stone, 1942a:51.

Espëcie grande. Tórax com 4,0mm de comprimento; 
mesonoto sem faixas. Metanoto totalmente amarelado. Macroque tas marrom escuras; pilosidade amarelada. Asas com 9,0 mm de comprimento; todas as faixas separadas. $\mathrm{M}_{1+2}$ acentuadamente curvada no äpice. Ovipositor com $3,0-3,5 \mathrm{~mm}$ de comprimento; ápice sem dentes.

Trata-se de espëcie próxima de A. leptozona Hen del da qual difere pelo ápice do ovipositor liso, faixa $V$ completa e célula anal amarelada.

Distribuição: Brasil (São Paulo).

Material examinado: BRASIL. São Paulo: São Paulo (Butantã), I 9, V.1975, L.P.Travassos Filho (ESALQ).

\section{Anastrepha curitis Stone, 1942}

(Fig。38)

Anastrepha ouritis Stone, 1942a:32, fig. 3D, pr. 4A (holótipo + , Parä, Brasil, BMNH).

Espécie grande. Placa facial convexa. Törax com 4,5m de comprimento; mesonoto sem faixas distintas. Metanoto não escurecido lateralmente. Macroquetas pretas; pilo sidade marrom clara. Asas com $10,9 \mathrm{~mm}$ de comprimento; faixas C e $S$ amplamente unidas; faixa $\mathrm{V}$ completa isolada. Bainha do ovipositor com $8,75 \mathrm{~mm}$ de comprimento; ovipositor com cerca de $8,0 \mathrm{~mm}$ de comprimento edelgado, ápice longo com diminutos dentes sobre $2 / 3$ apical e com leve constrição antes da serra (ap ud STONE, 1942a).

Trata-se de espëcie afim de A. pallidipennis Greene da qual se separa pela maior distância dos espiräculos da bainha do ovipositor em relação à base.

Distribuição: Brasil (Parâ). 
Anastrepha cruzi Lima, 1934

Anastrepha cruzi Lima, 1934a:513, pr. 66, fig. 19 (holötipo, se xo desconhecido, Rio Amazonas, Brasil, FOC); Stone, 1942a: $: 40$.

Espëcie mëdia. Tórax com 4,0 mm de comprimento; mesonoto com faixas mediana e laterais distintas; duas man.chas amarelo claras adiante do escutelo. Ümero amarelo claro. Porção superior da pleura com uma faixa amarela clara. Metano to sem faixas escuras laterais. Macroquetas marrom claras; 1 losidade amarelada. As as com 8,5m de comprimento; faixas $C$ e $S$ unidas estreitamente: faixa $V$ com o ramo proximal estreitamente ligado $\mathrm{a} \mathrm{S}$; ramo distal curto.

Apesar de descrita com base num exemplar danifi cado, esta espécie possui um padrão toräcico característico, que possibilita a sua identificação.

Distribuição: Brasil (Rio Amazonas).

Material examinado: BRASIL. Rio Amazonas, holötipo (sem abdo me) no 1815, lâmina 1904 (asa), sem data e coletor (FOC). LIMA (1934a) afirmou que esta espêcie foi trazida da Amazônia, em 1909, pelo Dr. Oswaldo Cruz.

Anastrepha daciformis Bezzi, 1909

(Figs. 12 e 39 )

Anastrepha daciformis Bezzi, 1909:282, fig. 2 (sintipos $\delta$, São Paulo, Brasil, MNTHM); Bezzi, 1919a:6; Bezzi, 1919b: 374, fig. 2(1); Greene, 1934:143, pr. 19, fig. 3; Lima, 1938a:64, pr. 5, fig. 6; pr.6, fig. 1; pr. 7, fig. 3;

Blanchard, $1937: 41$.

Anastrepha (Pseudodacus) daciformis; Hendel, 1914:13; Bezzi, $1919 \mathrm{a}: 6$; Lima, 1934a:493, pr. 62, fig. 1.

Pseudodacus daciformis; Stone, 1939b:286, figs.I(3) e3;

Blanchard, 1961:293, fig. 4. 
Espécie pequena. Törax com 2,5m de comprimento. Coloração geral pardacenta escura. Faixas do mesonoto amarelo claras e bem evidentes. Metanoto totalmente marrom claro; pilosidade esbranquiçada. Asas com $6,0-6,5 \mathrm{~mm}$ de comprimento; faixa $C$ unida ao ramo superior da $S$, que cobrem a cêlula $R_{1}$ e o äpice da $R_{3}$; hä uma faixa basal obliqua em dire ção à margem interna da asa; faixa $V$ representada apenas pelo ramo proximal. Ovipositor com cerca de $2,0 \mathrm{~mm}$ de comprimento e delgado; äpice com dentes reduzidissimos; rasper com 5-6 pares de grossos dentes.

Distribuição: Bolívia, Brasil, Paraguai e Argentina.

Material examinado: BRASIL。 6 \& 2 , sem localidade, data $e$ coletor, exemplares n: 1997, identificados por Costa Lima (FOC): São Paulo: São Paulo (Ipiranga), I q, X.1937, Camargo Andrade; Barueri, I $\uparrow, 8 . X I .1954, K . L e n k o$ (MZUSP). Rio Grande do Sul: Porto Alegre, 1 \%, sem data, E.Salazar C. (ESALQ).

Anastrepha dissimizis stone, 1942

(Fig. 4I)

Anastrepha dissimilis stone, 1942a:40, fig. 5C, pr. 6B (holóti po $\&$, Near Plaisance, Haiti, NMNH); Blanchard, 1961:340, fig. II; Korytkowski e Ojeda, 1968:54, figs. 22, 58, 91, 117,150 e 179 .

Anastrepha similis; Greene, 1934:153 (partim.).

Anastrepha correntina Blanchard, 1961:339, fig. 10 (holötipo ?, Bella Vista, Corrientes, Argentina, (?) INTA); Korytkowski e Ojeda, 1968:54, figs. 24, 57, 92, 118, 151 e 180; Steyskal, $1977: 33$.

Espécie pequena a mëdia. Törax com $2,5-3,5 \mathrm{~mm}$ de comprimento; mesonoto com a faixa mediana, às vezes, indis tintas; faixas laterais evidentes. Metanoto uniformemente amarelado. Macroquetas marrom escuras; pilosidade amarelada. Asas com 7,0-9,0mm de comprimento; faixas $C$ e $S$ separadas ou 
estreitamente Iigadas; faixa $V$ separada e completa. Ovipositor com 2,75-3,00mm; äpice com dentes diminutos; serra apro ximadamente 2 vezes mais longa do que larga.

$\vec{E}$ espëcie muito pröxima de $A$. chiclayae Greene, da qual difere apenas pelo ovipositor mais longo. $\vec{E}$ provävel que dissimilis e chiclayae sejam co-especificas. STONE (1942a), que estudou o material típico de chiclayae, não discutiu na descrição de dissimilis a semelhança dessas duas espëcies. STEYSKAL (1977) que examinou o tipo dessas espēcies, apenas afirmou que provavelmente chiclayae, dissimilis e pastranai BIanchard deveriam ser co-especificas.

como não se examinou o tipo das espécies discutidas acima, considerou-se os exemplares brasileiros como dissimilis com base no comprimento do ovipositor.

Distribuição: Haiti, Guiana, Peru, Brasil e Argentina.

Planta hospedeira: "maracujá" (Passiflora sp.) (la. referência).

Material examinado: BRASIL. Parä: Belëm, 1 q, sem data, A.B. da Silva (ESALQ). Bahia: Cruz das Almas, 7 , sem data, A.S.Nascimento (ESALQ); Muritiba, 1 \&, 24.VIII.1977, A.S.Nas-cimento; Governador Mangabeira, 2 \%, 7.IX.1977 e 1 f. 10.VIII.1977, A.S.Nascimento (ESALQ). Mato Grosso: Utiariti, Rio Papagaio, 2 \&, X.1966, Lenko e Pereira (MZUSP). São Pau10: Barueri, 2 †, X.1954, K.Lenko (MZUSP); Piracicaba, I 9 , sem data e coletor (ESALQ). Rio Grande do Sul: Porto Alegre, 4 9, sem data, E.Salazar C. (ESALQ).

Anastrepha distincta Greene, 1934

(Fig. 40)

Anastrepha distincta Greene, $1934: 149$ (partim; holötipo + Chiclayo, Peru, NMNH); Stone 1942a:106, figs. 22B, pr.22D; Baker et alii, 1944:132, fig. 77, pr. 7, fig. C; Fernandez, 1953:38, fig. 12; Korytkowski e ojeda, 1968:67, figs. 
$8,65,66,99,127,158$ e 184.

Anastrepha fraterculus; Greene, 1934:164 (partim.).

Anastrepha silvai Lima, 1934a:545, figs, 49-50, pr. 72, figs.

44-45; pr. 75, fig. 65 (lectötipo f, exemplar 1848, sem data, coletor e localidade, FOC); Lima, 1937a:34; Capoor, $1955 \mathrm{~b}: 35$.

Espécie pequena. Törax com 2,5-3,0mm de comprimento; mesonoto com faixas mediana e laterais nitidas. Me tanoto escurecido lateralmente. Macroquetas marrom escuras; pilosidade amarelada. Asas com $6,0-6,5 \mathrm{~mm}$; faixas $C$ e $S$ unidas; faixa V separada e pouco nitida no vértice. ovipositor ao redor de $2,0 \mathrm{~mm}$ de comprimento; äpice com dentes sobre menos da metade apical.

Designação de lectötipo. A sërie sintípica de A. silvai Lima, que se encontra na Fundação Oswaldo Cruz, è constituida por 9 e 4 t, sendo uma fêmea no 1949 e os demais exemplares, sem data, localidade e coletor, soi n: 1848. Dessa série sintípica selecionou-se e rotulou-se uma fêmea como lectötipo e os demais exemplares como paralectötipo. A. silvai Lima foi descrita com base em $10 q$ e $13 \delta$, sendo que os demais paralectötipos encontram-se no National Museum Natural History. LIMA (1934a:546) citou Rio de Janeiro, Minas Gerais (Viçosa) e São Paulo como localidades da sêrie sintípica.

GREENE (1934) descreveu A. distineta em junho e A. sizvai foi descrita por LIMA (1934a) em setembro do mesmo ano. STONE (1942a) examinou o tipo de distincta e síntipos de silvai e considerou-os co-especificos, apesar dos exemplares peruanos possuirem ovipositor mais longo, assim considerou vālida a denominação distincta. CAPOOR (1955b) tentou revali dar silvai, porëm a diferença entre as espëcies baseadas somen te no comprimento do ovipositor não é consistente. Alëm disso, segundo o artigo $24 \mathrm{~A}$ do Código Internacional de Nomenclatura Zoolögico o primeiro revisor (no caso Stone) ë que atribui validade ao nome. 
Distribuição: EUA (Texas), México, Guatemala, Costa Rica, Panamä, Colômbia, Equador, Peru, Guiana, Trinidad e Brasil.

Plantas hospedeiras: Inga spp, Chrysophyllum cainito, Mangife ra indica e Eugenia capsium.

Material examinado: BRASIL. Pernambuco: S. Felix, 3 , V.1976, Morgante, Malavasi e Silva (ESALQ). Bahia: Cruz das Almas, 221 \%, sem data, A.S.Nascimento (ESALQ); idem, 18 \%, VII-X.1977, A.S.Nascimento (ESALQ); Muritiba, 7 \%, VII-X 1977, A.S.Nascimento (ESALQ); Governador Mangabeira, 23 9, VII-X.1977, A.S.Nascimento (ESALQ). Rio de Janeiro: Itatiaia, Faz. Serra, 1 ; : lectötipo $\$$ e 12 paralectótipos ( $\$, 4$ f) de silvai, sem data, coletor e localidade (FOC).

\section{Anastrepha duckei Lima, 1934}

(Fig. 42)

Anastrepha duakei Lima, 1934a:534, figs. 32-33; pr. 69, fig.32, pr. 75; fig. 59 (lectötipo 9 , Manaus, Amazonas, Brasil,FOC); Stone, 1942a:86, fig. 17B, pr.18A).

Espécie grande. Tórax com 4,0mm de comprimento; mesonoto com faixas mediana e laterais distintas. Metanoto sem faixas pretas laterais. Macroquetas pretas; pilosidade amare lada. Asas com 9,0mm de comprimento; faixas $C$ e $S$ unidas; faixa $\mathrm{V}$ completa e separada. Ovipositor com 3,75 a 4,00mm de comprimento, com nitida constrição antes da serra, esta com dentes sub-agudos sobre a metade do ápice.

Designação de lectötipo. A descrição original baseou-se em 31 sintipos (15 f e 16 \%, FOC, CPACS e NMNH). Na coleção Costa Lima (FOC) havia $7 \%, 7$ fom 0 ne 1828 e uma etiqueta vermelha escrito TYPo. Dessa sērie sintipica uma fê mea foi selecionada e rotulada como lectótipo e os demais exem plares como paralectótipos.

Distribuição: Brasil (Amazonas, Manaus). 
Planta hospedeira: Ancistrothyrsus tessmani.

Material examinado: BRASIL. Amazonas: Manaus, lectōtipo + 13 paralectótipos ( 7 , $6 \%$ ), V.1933, A.Ducke (FOC); idem, 8 9 , 4 , 28.XI.1935, A. Ducke (FOC).

\section{Anastrepha elegans BIanchard; 1937}

(Fig。 43)

Anastrepha elegans Blanchard, 1937:37, fig. 2 (sintipos †, Jaguarete; Corrientes, Argentina, (?) INTA); Stone, 1942a: 42, fig, 6A, pr. 6D: Blanchard, 1961:335, fig. 37. Anastrepha parallela; Greene, 1934:168, pr. 23, fig. 8.

Espëcie grande. Tórax com 3,5m de comprimento; mesonoto sem faixas. Metanoto amarelado. Macroquetas pretas; pilosidade amarelada. Asas com 10,0mm de comprimento, todas as faixas separadas: Ovipositor com $3,5 \mathrm{~mm}$ de comprimento, com distinta constrição antes da serra, esta com dentes sub-agudos. Distribuição: Brasil, Paraguai e Argentina.

Material examinado: BRASIL. São Paulo: Andes, 1 \%, II.1955 (MZUSP); Araçatuba, Córrego Azul, 1 q, III.1947, M.P. Barretto (MZUSP); Porto Cabral; Rio Paranä, 1 f, III.1944. Travassos Filho e E. Dente (MZUSP).

\section{Anastrepha ethalea (Walker, 1849)}

(Fig, 44)

Trypeta ethalea Walker, 1849:1015 (holötipo f, Parä, Brasil, $\mathrm{BMNH}$ ).

Anastrepha ethalea; Bezzi, 1909:283, 285; Lima, 1934a:532;

Stone, 1942a:66, fig. 13A, pr. 13D.

Espēcie mëdia. Tórax com 3,4-3,9mm de comprimento; mesonoto sem faixas. Metanoto sem manchas pretas. Ma- 
croquetas marrom escuras; pilosidade amarelada. Asas com $7,9-8,5 \mathrm{~mm}$ de comprimento; faixas $C$ e $S$ unidas; faixa $V$ sepa rada ou estreitamente Iigada à $S$. Ovipositor com 2,37-2,39mm de comprimento; äpice com pequenos dentes em toda sua extensão (apud STONE, 1942a).

Distribuição: Trinidad e Brasil.

Plantas hospedeiras: Passiflora quadrangularis e $P$. Zaurifolia.

Anastrepha fenestrata Lutz \& Lima, 1918

$$
\text { (Fig. 16) }
$$

Anastrepha fenestrata Lutz \& Lima, 1918:8, pr. 2, fig. 19 (holötipo t, Amazōnia, Brasil, FOC); Greene, 1934:169; Lima, 1934a:527, fig. 24, pr. 68, fig. 26; Lima, 1937a:38; Stone: $1942 a: 100$.

Espëcie grande. Coloração geral marrom amarela da. Metanoto sem faixas negras laterais. Faixa escura sobre a sutura escuto-escutelar. Asas com $9,5 \mathrm{~mm}$ de comprimento; fai xas escuras e todas unidas; faixa $S$ com um prolongamento basal que alcança a margem posterior (apud LUTZ \& LIMA, 1918).

Apesar de descrita com base num exemplar macho, A. fenestrata pode ser prontamente reconhecida pelo padrão alar caracteristico.

Distribuição: Brasil (Amazônia).

Material examinado: lâminas 1711 e 1919 (asas) do holótipo ( $F O C)$.

Anastrepha fischeri Lima, 1934

(Fig. 45)

Anastrepha fischeri Lima, 1934a:540, fig. 4I; pr. 71, fig. 39 (holötipo f, Fonseca, Rio de Janeiro, Brasil, FoC); Stone, $1942 \mathrm{a}: 77$. 
Espëcie mëdia. Törax com $3,5 \mathrm{~mm}$ de comprimento; mesonoto com faixa lateral amarelo clara, outra mais interna alaranjada e a mediana amarelo pardacenta. Metanoto sem faixas escuras laterais. Macroquetas marrom claras; pilosidade esbranquiçada. Asas com $3,0 \mathrm{~mm}$ de comprimento; faixas $C$ e $S$ unidas; faixa $\mathrm{V}$ isolada e completa. Ovipositor com 2,4mm de comprimento e $0,065 \mathrm{~mm}$ de largura; äpice com dentes sub-agudos sobre mais da metade apical.

A. fischeri é conhecida apenas pelo holötipo. Trata-se de espëcie caracteristica pelo ovipositor fino com dentes sobre mais da metade do äpice.

Distribuição: Brasil (Rio de Janeiro, Fonseca).

Material examinado: BRASIL. Rio de Janeiro: Fonseca, holóti po 9 , sem data, P.A. de Araujo, exemplar no 1840, lâminas 1947 (asa) e 1948 (abdome) (FOC).

Anastrepha flavipennis Greene, 1934

(Fig. 46)

Anastrepha flavipennis Greene, 1934:160; pr. 22, fig. 6 (holotipo ?, Boa Vista, Rio Tapajös, Brasil, NMNH); Stone, 1942a: $: 89$, figs. $18 \mathrm{~A}$, pr. $18 \mathrm{C}$.

Espëcie pequena a média. Tórax com 3,0-3,5mm de comprimento; faixas do mesonoto indistintas. Metanoto ama relado. Macroquetas marrom claras; pilosidade amarelada.Asas com $7,5 \mathrm{~mm}$ de comprimento; todas as faixas unidas. Ovipositor com 1,8-1,9mm de comprimento; âpice sem dentes.

Esta espēcie caracteriza-se pela célula M amare lada e ápice do ovipositor liso.

Distribuição: Panamá e Brasil.

Material examinado: PANAMĀ. Capira: I $\tilde{\delta}$, IV-V.1938, Zetek, exemplar 5307; idem, I 9, VIII.1938, Zetek, exemplar 5308, am bos determinados por stone (FOC). 
Anastrepha fraterculus (Wiedemann, 1830)

(Fig. 47)

Dacus fraterculus Wiedemann, 1830:524 (holötipo f, "Brasil", NM).

Tephritis mellea Walker, 1837:358 (holötipo + , São Paulo, Bra-" sil, BMNH); Foote, 1964:322.

Trypeta unicolor Loew, 1862:70, pr. 2, fig. 6 (holötipo f, New Grenada, Colombia, MCZ).

Anastrepha frateraulus; Wulp, 1899:404, pr. Il, fig. 21

(partim); Bezzi, 1909:283, 286 (partim); Brëthes, 1914:

59: Hendel, 1914:14, 18, pr. I, fig. 6; Lutze Lima, 1918:

4-7, pr. 1, figs. 4-6, 8-9; Bezzi, 1919a:11; Bezzi, 1919b:

374, fig. 2(II); Greene, 1934:164, pr. 22, fig.5 (partim);

Lima, 1934a:546, fig. 51; pr. 72, fig. 46; pr. 73, figs.

47-49; pr. 76, fig. 74; Stone, 1942a:78, fig. 15D;

pr. 16B-D; Baker et alii, 1944:138, fig. 80; pr. 8, figs.

A-F; pr. 9, figs. A-E; Fernandez, 1953:35, fig. 10;

Blanchard, 1961:317, fig. 24; Korytkowski e Ojeda, 1968:

60 ; figs. 26, 40, 76, 104, 132 e 166.

Anthomyia frutalis Weyenbergh, 1874:165, figs.7-13 (sintipos

machos e fèmeas, coleção desconhecida); Brëthes, 1914:58. Anthomyia frutuum, erro.

Anastrepha soluta Bezzi, 1909:284, 285 (como variedade de fraterculus; ? sintipos machos e fêmeas, São Paulo, Brasil, MCSN); Hendel, 1914:13 (como espēcie); Lutz e Lima, 1918: :6-8; pr. I, fig. 7 (como variedade); Bezzi; 1919a:10; Bezzi, 1919b:374, fig. 2(7) (como espëcie); Lima, 1937a: 34; Stone, 1942a:78; Blanchard, 1961:320; Korytkowski e Ojeda, 1968:62.

Anastrepha peruviana Townsend, 1913:345 (holötipo 9 , Chosica, Peru, NMNH); Greene, 1934:148; pr. 20, fig. I; Lima,

1934a:553; Stone, 1942a:78; Blanchard, 1968:320;

Korytkowski e 0jeda, 1968:62.

Anastrepha peruana, erro.

Anastrepha distans; Greene, 1934:149, pr. 20, fig. 7 (partim). Anastrepha distincta Greene, 1934:149, pr. 20, fig. 2 (partim):

Stone, 1942a:79. 
Anastrepha brasiliensis Greene, $1934: 154$, pr. 20, fig. 6 (holó tipo f, Viçosa, Minas Gerais, Brasil, NMNH): Stone, 1942a: :79; Korytkowski e Ojeda, 1968:62.

Anastrepha trinidadensis Greene, 1934:161 (partim);

Stone, $1942 a: 79$.

Anastrepha suspensa; Lima, 1934a:501; Stone, 1942a:79. Anastrepha costarukmani $i$ Capoor, 1954:28 (holötipo + , Itajubä, Minas Gerais, Brasil, FOC). Syn. n. Anastrepha scholae Capoor, 1955a:27 (lectötipo + , Ägua Preta, Bahia, Brasil, FOC). Syn. $n$. Anastrepha pseudofraterculus capoor, 1955a:28 (lectótipo ${ }_{9}$ Itatiaia, Rio de Janeiro, Brasil, FOC). Syn. n.

Espécie pequena. Törax com 2,75-3,25mm de comprimento; mesonoto com faixas mediana e laterais distintas. Metanoto com faixas escuras laterais. Macroquetas marrom escu ras; pilosidade amarelada. Asas com 5,25-7,25m de comprimento; faixas $C$ e $S$ unidas, às vezes separadas: faixa $V$ sepa rada ou estreitamente unida a $S$, completa ou incompleta. Ovipositor com 1,5 a 2,0mm de comprimento; äpice com distinta constrição antes da serra, esta com dentes arredondados sobre a metade apical.

Designação de lectôtipos. 1. Anastrepha scho zae Capoor. Foi descrita com base em 9 sintipos fêmeas (FOC) com os nümeros $2273,3017,3184,3185,3186,3189,3190,3484$ e 3592 com as respectivas lâminas (abdome) nümeros 2603, 3267 , $3460,3464,3762$ (e não 3764, CAPOOR, 1955a), 3468, 3478, 3480, 3762 e 3931 . A fêmea n: 3185 lâmina 3464 foi selecionada e ro tulada como lectótipo e os demais comoparalectötipos. 2. Anastrepha pseudofraterculus Capoor. A descrição original baseouse em 2 sintipos ( 0 \& FOC), que estão aparentemente perdidos, pois a numeração apresentada por CAPOOR (1955) corresponde a exemplares de A. zikani Lima (nümeros 5772 e 5773). Todavia, as preparações da asa e abdome encontram-se na coleção costa Lima (FOC) e apresentam os dados: A. pseudofraterculus Capoor, Itatiaia, 16.III.1934, Capoor 1954 det. Existem 4 Iâminas que 
apresentam cada uma abdomes (q f) e asas ( $q$ ). As numerações dessas lâminas foram riscadas e correspondem àquelas indicadas por CAPOOR ( 1955 ). Portanto, essas lâminas pertencem realmen te ao material tipico de pseudofraterculus. Assim as lâminas (asa e abdome) da fêmea foi selecionada e rotulada como lectōtipo e as lâminas (asa e abdome) do macho como paralectötipo.

Novas sinonimias: A. costarukmanii Capoor foi considerada sinonimia de $A$. fraterculus (Wiedemann) porque o äpice do ovipositor apresenta dentes mal formados (anormais), e não pouco visiveis como afirmou CAPOOR (1954), e desde que o formato geral do âpice desse ovipositor è semelhante ao de fraterculus, não hã razão para se considerar costarukmanii espécie válida. Por outro lado, A. scholae e A. pseudofraterculus Capoor são sinônimos de $A$. fraterculus (Wiedemann), visto que a ausência ou presença de mancha no rasper e coloração (clara e escura) da bainha do ovipositor não são caracteres consistentes para a caracterização dessas espécies.

A. fraterculus caracteriza-se pela nitida e lon ga constrição no äpice do ovipositor antes da serra e dentes do äpice arredondados. 0 holötipo foi estudado por STONE (1942a).

Distribuição: do Vale do Rio Grande (Texas, EUA) ao Chile e Argentina.

Plantas hospedeiras: as larvas de A. fraterculus desenvolvemse em aproximadamente 54 hospedeiros (WASBAUER; 1972).

Material examinado: BRASIL. Bahia: Ägua Preta, lectótipo $q$ de scholae, sem data, G.Bondar (FOC); 8 paralectótipos $q$ de scholae ( 5 de Ägua Preta, G.Bondar, 2 sem data e coletor e 1 de ? Umbupoca, 18.II.1937, sem coletor, FOC); Cruz das Almas, 99 \%, sem data, A.S.Nascimento (ESALQ); idem, 7 ; VII-VIII. 1977, A.S.Nascimento (ESALQ); Muritiba; 51 9, VII-X.1977. A.S. Nascimento (ESALQ); Governador Mangabeira, 27 \%, VII - VIII. 
1977; A.S.Nascimento (ESALQ); Santo Amaro da Purificação, 25 q, V.1976, Morgante, Malavasi e Silva (ESALQ). Itabuna, 4 q, idem (ESALQ); Conceição de Almeida, 6 \%, idem (ESALQ); Porto Seguro, 4 \%, idem (ESALQ). Rio de Janeiro: Itatiaia, Iectóti po $\$$, I paralectötipo $f$, de pseudofraterculus, 16.III.1934, sem coletor (FOC); Itatiaia, Campo Belo, II.1945, Barretto (MZUSP); Rio de Janeiro, 1 9, sem data, H.S.Lopes (MZUSP); Rio de Janeiro, estrada Rio-São Paulo, km 47, I †, 19.II.1949, W.Zikän (MZUSP); Angra dos Reis, I $9, X .1945$, L. Travassos Filho (MZUSP). Pernambuco: Recife (IPEANE), 11 \%, 03.V.1976, Mor gante, Malavasi e Silva (ESALQ); S.Felix, 1 q, idem (ESALQ). Alagoas: Arapira, 3 q, V.1976, Morgante, Malavasi e Silva (ESALQ). Sergipe: São Cristovão, 6 f, V.1976, Morgante, Mala vasi e Silva (ESALQ). Paranä: Curitiba, Fazenda Canaguiri, 19 \%, 24.X.1977, Pedrosa (ESALQ); Ponta Grossa, 2 \%, sem data, P.Machado (MZUSP). São Paulo: São Paulo, (Ipiranga), I 9 , sem data e coletor (MZUSP); idem, 1 \%, IV.1953, R.Correa (MZUSP); idem, 1 + , 26.I.1944, L.Travassos Filho (MZUSP); idem, (Horto Florestal); 2 \%, III.I926, sem coletor (MZUSP); idem, (Sumaré), 4 \%, II e IV.1954, M.Carrera (MZUSP); São Paulo, I + , I.1929, Gonçalves (MZUSP); Monte Alegre, Faz. Bom Jesus, 4 , 25.II.1944, J.L.lima (MZUSP); Porto Cabral, Rio Paranä, I q, III.1944, Travassos Filho, Carrera e Dente (MZUSP); SalesöpoIis, Est. Biol. Boracéia, 3 \&, Il.XI.1960, K.Lenko (MZUSP); idem, 1 9, X.1948, L.Travassos Filho (MZUSP); Araçatuba, Faz. Jacarecatinga, XI.1962, Lane e Rabello (MZUSP); idem, 4 , VI.1963, Rabello (MZUSP); Barueri, 2 + , 18.XII.1954 e 24.IX.1960, Lenko (MZUSP); Andes, I + , II.1955, Camera (MZUSP); Eldorado Paulista, I 9, 17.XI.1963, Rabello (MZUSP); Serra Negra, 4 \% 20.III.1976, Morgante (ESALQ); Campinas 4 \%, 05.IV.1976, Morgante e Malavasi (ESALQ); Josẻ Bonifäcio, 2 , 27.XI.1976, Malavasi e 0.Pavan (ESALQ); São Carlos; 7 , 28.XI.1976, Malavasi e 0.Pavan (ESALQ); Itaquera, 19 , 23.III.1977, Malavasi (ESALQ); Ibiuna, 2 P, 03.IV.1977, M.L. Barcioti (ESALQ); Monte Alegre do Sul, 8 P, 06.V.1977, H.J. Souza (ESALQ); São Paulo (Butantã), Il $f$, II.1977, C. Pavan 
(ESALQ); idem, Sumaré, $5 q$, sem data, A.Kogatto (ESALQ); Taiü va, 26 \%. III-IV.1975, J.C.Durigan (ESALQ). Santa Catarina: Florianōpolis, 3 , VII.1960, Casemiro (MZUSP); S. Joaquim da Barra, I q, III.1956, sem coletor (MZUSP); Videira, 33 q, 10 f, $2 \%$ sem. 1975, J.Bleicher (ESALQ). Rio Grande do Sul: Porto Alegre, 53 \%, sem data, E.Salazar C. (ESALQ); Nova Teutônia, 15 P, IV.1956, VI e X.1970, XI.197I, F.Plaumann (MZUSP); S. Leopoldo, I 9 , 15.III.1965, C.Valle (MZUSP); Marcelino Ramos, 1 †, sem data; A.Bieseck (MZUSP). Minas Gerais: Itajubá, holötipo $q$ de costarukmanii (FOC).

Anastrepha fumipennis Lima, 1934

(Figs. 18 e 48 )

Anastrepha fumipennis Lima, $1934 \mathrm{a}: 499$, fig. 6; pr. 65, fig.10; pr. 75, fig. 62 (2 sintipos $\delta$, Rio de Janeiro, Brasil, FOC); Stone, 1942a:90.

Coloração genal castanho ou alaranjada. Mesono to com faixas longitudinais amarelo claras. Metanoto internamente marrom escuro e lateralmente amarelo claro. Asas com C e $S$ amplamente ligadas, separadas apenas por uma mancha hialina na margem costal; faixa $V$ estreitamente separada em toda sua extensão da $S$; ramo distal ausente. Ovipositor com 4,25m de comprimento; ápice sem dente com a ponta rombuda rapud LIMA, $1934 a$ e STONE, 1942a).

o padrão alar e o ápice do ovipositor permitem facilmente a identificação desta espēcie, que todavia é pröxima de $A$. atrigona Hendel.

Distribuição: Brasil (Rio de Janeiro).

Material examinado: lâmina 1887 (abdome) de um dos sintipos. 


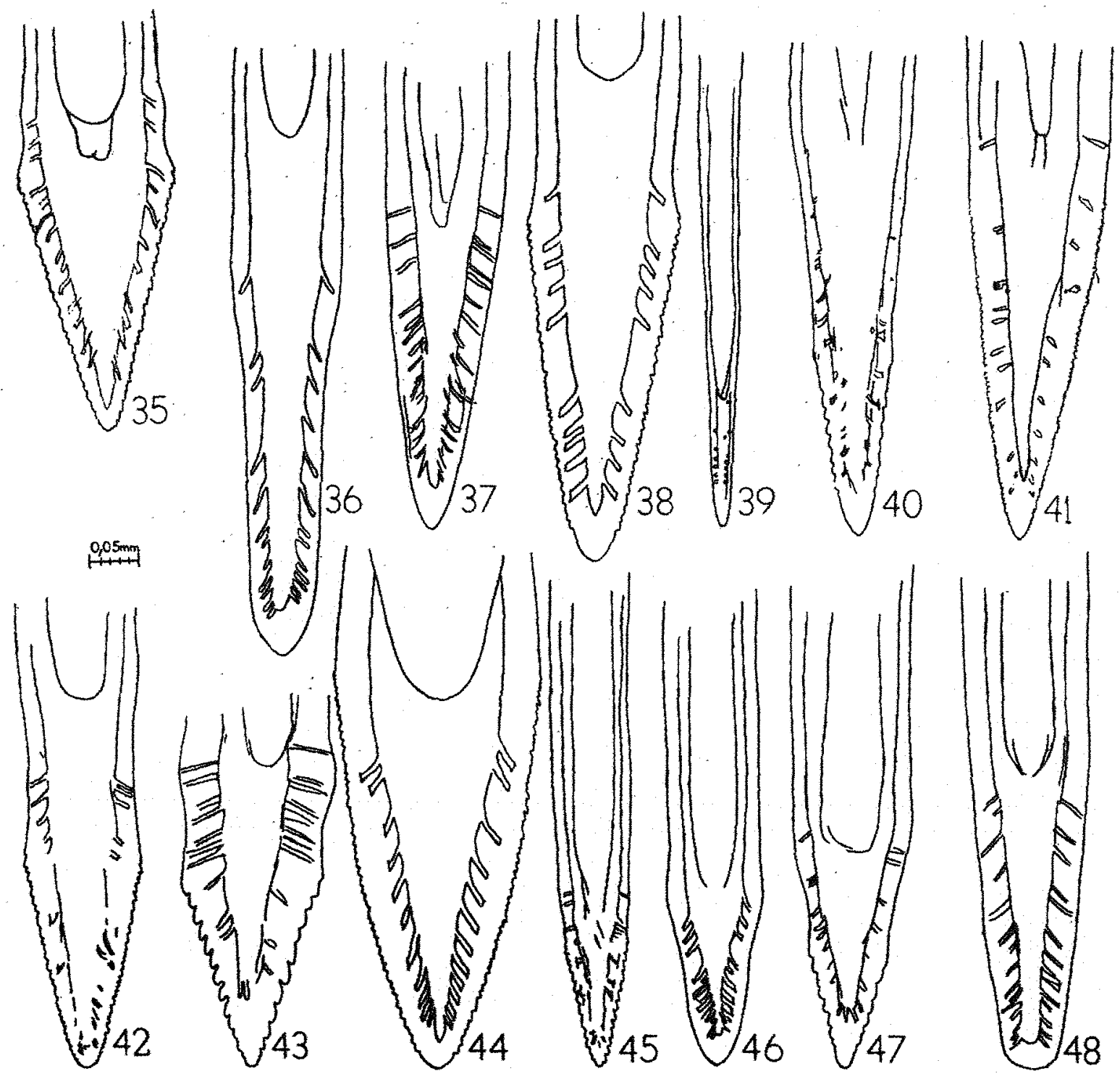

Āpice do ovipositor. Fig. 35: caudata. Fig: 36: concava. Fig. 37: costalimai. Fig. 38: curitis. Fig. 39: daciformis. Fig. 40: distincta. Fig. 41: dissimizis. Fig. 42: duckei. Fig. 43: elegans. Fig. 44: ethalea. Fig. 45: fischeri. Fig. 46: flavipennis. Fig. 47: fraterculus. Fig. 48 : fumipennis. 
Anastrepha furcata Lima, 1934

(Figs. 17 e 49)

Anastrepha furcata Lima, 1934a:529, fig. 27; pr. 68; fig. 28 (holötipo o, Amazonas, Brasil, FOC); Lima, 1937b:38, Lima, $1938: 65$; Stone, 1942a:91.

Anastrepha robusta; Stone, 1942a:30.

Espëcie média. Törax com 4,0 mm de comprimento: mesonoto com apenas as faixas laterais distintas; faixa escu to-escutelar pouco nitida (holötipo). Metanoto amarelado. Asas com 9,0mm de envergadura; faixas alares escuras e unidas: por ção basal da faixa $S$ com reenträncia aguda. Ovipositor $1,5 \mathrm{~mm}$ de comprimento, acentuadamente arqueado; äpice sem dentes.

LIMA (1934a) descreveu furcata com base num exemplar macho e posteriormente descreveu a fémea (LIMA, I937b). STONE (1942a) considerou a fêmea de furcata sinônimo de $A$. robusta Greene. Distinguiu furcata (holótipo $\hat{b})$ de robusta pela terminação da nervura $M_{1+2}$, ou seja, próxima da faixa $S$ em robusta e afastada em furcata. Chegou a essa conclusão pelo exame da fotografia do trabalho de ILIMA (1934a), pois não examinou o tipo de furcata.

Examinou-se o holótipo e o exemplan fêmea de furcata, e verificou-se que a nervura $M_{1+2}$ termina junto à fai xa $S$. Por outro lado, comparou-se a genitalia do holötipo com a genitália de exemplares machos coletados na Bahia e póde-se constatar que eram idênticas. Da mesma forma observou-se que as fêmeas dos exemplares provenientes da Bahia possuiam o äpice do ovipositor semelhante ao da fêmea de furcata descrita por LIMA, 1937. Portanto, a fêmea descrita por LIMA (cit. Zoc.) era realmente de furcata e não de robusta como foi considerado por STONE (1942a). Examinou-se, tambëm, um parátipo $q$ de $A$. robusta Greene (FOC) e verificou-se que o äpice do ovipositor $\hat{e}$ bem diferente do de furcata. Assim, $\hat{A}$. robusta ainda não foi constatada no Brasil.

Distribuição: Brasil (Amazonas, Pará e Bahia). 
Material examinado: BRASIL. Amazonas: Manaus, Rio Negro, ho lötipo f, 16.VII.1927, J.F.Zikân, exemplar no 1825, lâminas 1923 (asa) e 1924 (abdome) (FOC). Parâ: Cachoeira Paciência, Rio Cuminä, I f, 18.X.1936, F.d'Almeida, exemplan n: 3020, lầminas 3277 (asa) e 3279 (ovipositor) (FOC). Bahia: Cruz das Almas, 1 \%, sem data, A.S.Nascimento (ESALQ); idem, 1 +, 3 , VIII.1977, A.S.Nascimento (ESALQ); Muritiba, I \&, 14.IX.1977, A.S.Nascimento (ESALQ); Governador Mangabeira, 19 , 10.VIII.1977, A.S.Nascimento (ESALQ).

\section{Anastrepha grandis (Macquart, 1846)}

$$
\text { (Figs. } 10 \text { e } 50 \text { ) }
$$

Tephritis grandis Macquart, 1846:340(1846:212), pr. 18, fig.14 (holótipo \&, New Grenada, Colômbia, BMNH). Acrotoxa grandis; Loew, 1873:231, pr. 11, fig. 26. Anastrepha grandis; Bezzi, 1909:284; Bezzi, 1919a:6; Bezzi, 1919b:374, fig. 2(2); Fischer, 1932:302, figs. 1-10;

Fischer, 1934:17, figs. 1-8; Greene, 1934:145, pr. 19, fig. 7 (partim); Lima, 1934a:496, figs. $3-4 ;$ pr. 64, fig。 6-7; pr. 74, fig. 56; Lima, 1937b:63; Blanchard, 1937:41; Stone, 1942a:22, fig. ID, pr. 1C; Fernandez, 1953:19 Blanchard, 1961:297, fig. 7; Korytkowski e Ojeda, 1968:43; figs. $15,53,85,116,143$ e 172 .

Anastrepha schineri Hendel, 1914:19 (holótipo of Carioca, Boli via, MNTHM); Fischer, 1932:302.

Anastrepha latifasciata Hering, $1935: 227$, fig. 2 (holötipo + , Santa Catarina, Brasil, IZW); Lima, 1934a:496.

Espécie grande. Tórax com 3,5-4,0 mm de compri mento; mesonoto com faixas mediana e laterais distintas. Metanoto escurecido lateralmente. Pteropleura com mancha preta. Macroquetas marrom; pilosidade amarelada. Metanoto escurecido lateralmente. Asas com 10,0m de comprimento: faixas $\mathrm{C}$ e $S$ amplamente unidas, sem faixa hialina costal; faixa $V$ apenas com o ramo proximal. Ovipositor com cerca de $6,0 \mathrm{~mm}$ de compri- 
mento; apice afilado e sem dentes.

Distribuição: Panamá, Colômbia, Bolívia, Peru, Brasil, Para guai e Argentina.

Plantas hospedeiras: Cucurbita pepo: Cucumis sativus e Citruzzus vuzgaris.

Material examinado: BRASIL. Rio de Janeiro: estrada Rio-SP,

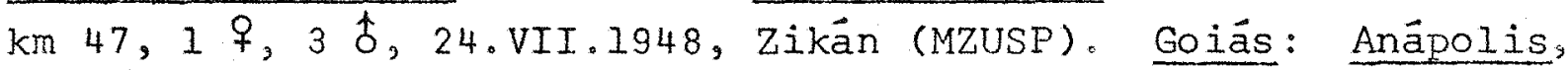
19 , VII.1935, M.E.S. (MZUSP). São Paulo: 1 9 , X.1939, Rama Iho (MZUSP); Barueri, I,+ 2 f, $\mathrm{V}$ eX.1961, Lenko (MZUSP); Itaporanga, I $\delta$, I.1946, Barretto (MZUSP). Paranä: Curitiba, 1 o, IV.1940, Claretiano (MZUSP). Santa Catarina: Videira, 1 f, sem data, J.Bleicher (ESALQ); Nova Teutónia, I f, V.1945, Plaumann (MZUSP); idem, If, I $9, \mathrm{~V}$ e X.1948, Plaumann (MZUSP); idem, 3 f, 3 f, V-VI-VII-1970, Plaumann (MZUSP); 6 f, 10 1971, Plaumann (ESALQ).

Anastrepha greenei Lima, 1937

(Fig. 5I)

Anastrepha greenei Lima, 1937a:37, figs. 3-4; pr. 1, fig. 7; pr. 2, fig. 2 (holötipo + , Bahia, Brasil, FOC); Stone, $1942 a: 52$.

Espécie pequena. Törax com 2,5m de comprimento; mesonoto sem faixas. Macroquetas marrom escuras; pilos dade esbranquiçada. Metanoto amarelado. Asas com $6,5 \mathrm{~mm}$ de comprimento e todas as faixas separadas; esternopleural desen volvida. Ovipositor com 3,5 - 4,0mm de comprimento e äpice sem dentes.

Distribuição: Brasil (Bahia).

Plantas hospedeiras: Quararibea turbinata e Q. penduliflora Material examinado: BRASIL. Bahia: holötipo $q$, sem data e 
coletor, exemplar n: 2323-2, lâmina 2712 (abdome); 3 parätipos: 1 f, 19 , sem data e coletor, exemplares 2323 e $2323-1$, lâmina 2711 (abdome) e 1 q, Água Preta, Bahia, 17.II.1937, G. Bondar, exemplar 3022 (FOC).

\section{Anastrepha hambletoni Lima, 1934}

\section{(Fig. 52)}

Anas trepha hambletoni Lima, 1934a:519, pr. 67, fig. 23; pr. 74, fig.58 (holötipo 9 , Viçosa, Minas Gerais, Brasil, FOC). Luoumaphila hambletoni: Stone, 1939a:343.

Espẹcie grande. Tórax com 3,5m de comprimento; mesonoto sem faixas. Macroquetas marrom claras; pilosidade amarelada. Metanoto totalmente amarelado. Asas com 7,5m de comprimento e todas as faixas separadas; $R_{2+3}$ levemente sinuo sa. Ovipositor com 4,5m de comprimento levemente arqueado; ápice com intumescimento após o fim do oviduto, seguido de leve constrição e outro intumescimento menor antes da ponta, que apresenta alguns dentes diminutos.

Distribuição: Brasil (Minas Gerais).

Material examinado: BRASIL. Minas Gerais: Viçosa, holötipo †, 25.IX.1933, E.J.Hambleton, exemplar no 1820 , lâminas 1912 (asa) e 1913 (abdome) (FOC).

\section{Anastrepha hastata Stone, 1942}

(Fig. 53)

Anastrepha hastata Stone, 1942a:55, fig. 9B. (holötipo + , Amazo nas, Brasil, BMNH).

Espécie grande. Placa facial levemente convexa : Törax com $3,7 \mathrm{~mm}$ de comprimento, uniformemente marrom amarelado. Metanoto totalmente amarelado. Macroquetas quase negras; pilosidade amarela. Asas com 9,9mm de comprimento. Ovipositor 
com 5,2mm de comprimento; äpice sem dentes com 2 intumescimen tos (apud STONE, 1942a).

Anastrepha hendeliana Lima, 1934 Anastrepha hendeliana Lima, 1934a:528, figs. 25-26; pr. 68, fig. 27 (lectötipo f, S.Gabriel, Amazonas, Brasil, FOC); Stone, $1942 a: 85$.

Espécie grande. Tórax com 4,5m de comprimento: mesonoto com faixas laterais e mediana distintas. Macroquetas pretas; pilosidade amarelada. Metanoto e pös-escutelo enegre cidos lateralmente. Asas com 10,0m de comprimento; faixas escuras e amplamente unidas.

Designação de lectötipo. A. hendeliana foi des crita com base em 2 machos provenientes de S.Gabriel, Amazonas (FOC). O exemplar no 1824, lâmina 1920 (abdome) foi seleciona do e rotulado como lectótipo e o exemplar n: 1823 como paralectötipo.

Apesar de descrita com base em exemplares machos, $A$. hendeliana pode ser identificada pelo padrão alar caw racterístico (ver discussão em $A$. Zongicauda Lima, pägina 62). Distribuição: Brasil (Amazonas).

Material examinado: BRASIL. Amazonas: S.Gabriel, Rio Negro, lectötipo f̂, 26.XI.1927, J.F.Zikän (FOC); idem, paralectóti po f, 6.X.1927, J.F.Zikän (FOC).

Anastrepha Kuhlmanni Lima, 1934

(Fig. 54)

Anastrepha kuhlmanni Lima, 1934a:520, figs. 20-21; pr. 67, fig. 24 ; pr. 74, fj.g. 57 (lectötipo \&, Rio Trapicheiro, Rio de Janeiro, Brasil, FOC); Blanchard, 1937:41; Stone, 1942a:56, fig. 9D, pr, 10B; Blanchard, 1961:313, fig. 21. 
Espëcie mëdia a grande. Tórax com 3,00-3,75mm de comprimento; mesonoto com faixas mediana e laterais eviden tes. Metanoto amarelado. Macroquetas marrom escuras; pilosi dade amarelada. Asas com 9,25-10,00 mm de comprimento; todas as faixas separadas; $R_{2+3}$ levemente sinuosa. Ovipositor com 4,5m de comprimento; ápice curto (cerca de $0,16 \mathrm{~mm}$ ), sem dentes.

Designação de lectötipo. A descrição original de A. kuhzmanni Lima baseou-se em 26 sintipos (11 $₫, 15$ FOC, CPACS e NMNH). Na coleção costa Lima (FOC) encontram-se 16 sin tipos ( 8 f, 7 o e 1 exemplar ? sexo), todos sob $\circ \mathrm{n}: 1821$ e com etiqueta TYPo. A fêmea no 1821, lâmina 1915 (abdome) foi sele cionada e rotulada como lectótipo e os demais exemplares como paralectótipos.

Distribuição: Brasil e Argentina.

Planta hospedeira: Tetrastylis ovalis.

Material examinado: BRASIL. Rio de Janeiro: Rio Trapicheiro, lectótipo $q$ e 15 paralectötipos sob o nümero 1821 (sem data, localidade e coletor, FOC). Segundo LIMA (1934a:521) os exemplares foram coletados por J.G.Kuhlmann, em Trapicheiro (RJ). Esses exemplares encontram-se na coleção da Fundação oswaldo Cruz sob a numeração 1821 e não 1822 como está na descrição ori ginal. Hâ, também, uma lâmina (1914) com uma asa (provavelmen te de um macho) e outra (1916) com o abdome de outro macho (FOC).

Anastrepha leptozon a Hendel, 1914

(Fig. 55)

Anastrepha Zeptozona Hendel, 1914:19 (holötipo fo, San Antonio, Mapiri, Bolivia, SMT); Greene, 1934:153, pr. 20, fig. 10; Lima, 1934a:515, figs. 17-18; pr. 67, fig. 20; pr.75, fig. 66; Lima, 1937a:34; Stone, 1942a:39, fig. 5B, pr. 6A;

Fernandez, 1953:23。 
Espëcie pequena a grande. Törax com 2,5-4,0mm de comprimento; mesonoto com faixas mediana e laterais distin tas. Metanoto amarelado, sem faixas escuras laterais. Macro-quetas pretas; pilosidade amarelada. Asas com 5,5-9,0 mm de comprimento; todas as faixas separadas; faixa $\mathrm{V}$ incompleta com o ramo distal reduzido ou ausente. $M_{1+2}$ com acentuada cur vatura apical. Ovipositor com 2,0-3,0mm de comprimento; äpi ce com diminutos dentes sobre mais da metade apical.

A. Leptozona Hendel caracteriza-se pela acentuada curvatura apical da nervura $M_{I+2}$, ramo distal da faixa $V$ atrofiado ou ausente e dentes reduzidos sobre mais da metade do àpice do ovipositor.

Distribuição: da Guatemala à Guiana, Bolívia e Brasil.

Plantas hospedeiras: Lucuma caimito, Lucuma sp, Chrysophyllum cainito, "bucumucha", "pau macaco" e "mapeba branca".

Material examinado: BRASIL. Bahia: Cruz das Almas, 2 , sem data, A.S.Nascimento (ESALQ). Rio de Janeiro: $\mathrm{km} \mathrm{47,} \mathrm{estrada}$ Rio-São Paulo, 1 \%, 14.II.1944, H.Mont Neto (MZUSP). Mato Grosso: Utiariti, Rio Papagaio, 5 \%, X.1966, Lenko e Pereira (MZUSP).

Anastrepha Longicauda Lima, 1934

(Fig. 58)

Anastrepha Zongicauda Lima, 1934a:525, pr.68, fig.25; pr. 74, fig. 53 (holótipo + , S.Gabriel, Rio Negro, Amazonas, Brasil, FOC).

Lucumaphila longicauda; Stone, 1939a:347.

Espécie grande. Tórax com 5, 0mm de comprimento; mesonoto com faixas laterais pouco distintas (faixa mediana transpassada pelo alfinete); manchas escuras na porção anterion do mesonoto. Macroquetas marrom escuras; pilosidade ama relada. Metanoto e pós-escutelo com faixas escuras lateralmen te. Asas com $10,5 \mathrm{~mm}$ de comprimento. Faixas alares indistintas 
(provavelmente porque o exemplar foi morto pouco após emergir do pupärio); faixas $C$ e $S$ unidas; faixa $V$ incompleta e unida à S. Ovipositor longo e fino, $8 \mathrm{~mm}$ de comprimento; äpice sem dentes; rasper com dentes reduzidos.

$\vec{E}$ provăvel que $A$. longicauda seja a fêmea de $A$. hendeliana Lima, pois as diferenças morfológicas entre os exemplares empregados na descrição dessas espécies devem-se, talvez, ao fato de longicauda ter sido morta logo após sua emergência, pois as faixas alares não estão nitidas. Além dis so, o comprimento do aedeagus de hendeliana è compativel com o comprimento do ovipositor de Zongicauda, assim como esses exem plares foram coletados na mesma época do ano e na mesma locali dade. Todavia, somente com mais exemplares será possível esclarecer essa questão.

\section{Distribuição: Brasil (Amazonas).}

Material examinado: BRASIL. Amazonas: S.Gabriel, Rio Negro, holötipo $9,6 . I X .1927$, J.F.Zikān, exemplar no 1822, lâminas 1917 (asa) e 1918 (abdome) (FOC).

Anastrepha Zuederwaldti Lima, 1934

(Fig. 56)

Anastrepha luederwaldti Lima, $1934 a: 510, \mathrm{pr} .66$, fig. 18; pr. 76, fig. 67 (2 sintipos f \&, são Paulo, Brasil, MZUSP). Lucumaphila iuederwaldti; Stone, 1939a:342.

Espëcie mediana. Tórax com 3,0 mm de comprimento; mesonoto com faixas mediana e laterais pouco distintas. Metanoto totalmente amarelado. Macroquetas marrom claras: pi losidade esbranquiçada. Asas com $7,75 \mathrm{~mm}$ de comprimento; todas as faixas alares separadas; faixa $\mathrm{V}$ incompleta. Ovipositor com cerca de $3,0 \mathrm{~mm}$ de comprimento, fino $(0,025 \mathrm{~mm}$ de largura); apice sem dentes.

As lâminas com os abdomes dos sintipos estão de saparecidas. Não se observou nos síntipos manchas claras adian 
te do escutelo, como descreveu LIMA (1934a:510). Identificouse como luederwaldti duas fêmeas que concordam com a descrição de LIMA (cit. toc.), que todavia não apresentam manchas claras antes do escutelo.

Distribuição: Brasil (são Paulo).

Material examinado: BRASIL. São Paulo: São Paulo, sintipos $1 \hat{f}, 1+$ (incompletos), XII.1925, Ipiranga e I.1926, Alto da Ser ra, respectivamente, Spits (MZUSP); Salesöpolis, Estação Biolögica de Boracëia, 2 †, VI.1949 e I.1952 (MZUSP).

\section{Anastrepha lutzi Lima, 1934}

(Fig. 57)

Anastrepha lutai Lima, 1934a:540, fig. 42; pr. 71, fig.40; pr. 76, fig. 71 (holötipo + , Rio de Janeiro, Brasil); Blanchard, 1937:41; Lima, 1938a:61, fig. 19; pr. 7, fig. 1; Stone, 1942a:65; Blanchard, 1961:331, fig. 34 .

Espëcie mediana. Törax com $3,5 \mathrm{~mm}$ de comprimento; mesonoto sem faixas mediana e laterais. Metanoto amarela do. Macroquetas marrom escuras; pilosidade amarelada. Asas com 9,0mm de comprimento; faixas $C$ e $S$ unidas; faixa $V$ completa e separada da $S$. Ovipositor com 1,75m de comprimento e alarga-se antes da serra, esta com dentes estendendo se alëm do nivel do fim do oviduto; ápice de aspecto triangular.

A. Zutzi caracteriza-se pelo äpice do oviposi tor de aspecto triangular com dentes estendendo-se alëm do nivel do fim do oviduto.

Distribuição: Brasil e Argentina.

Planta hospedeira: Passiflora sp.

Material examinado: BRASIL, Rio de Janeiro: Rio de Janeiro (Manguinhos), holötipo $\uparrow, 29 . V I I I .1912$, sem coletor, exemplar no 1841, Iâminas 1949 (asa) e 1950 (abdome) (FOC). 
Anastrepha macrura Hendel, 1914

(Figs. 13 e 59)

Anastrepha (Pseudodacus) macrura Hendel, 1914:16 (holótipo ${ }_{\text {, }}$ "Paraguai", MNTHM); Lima, 1934a:493.

Anastrepha macrura; Greene, $1934: 143, \mathrm{pr} .19$, fig. 4; Lima, 1937a:34; Lima, 1938a:64; pr. 5, fig. 4; pr. 6, fig. 3; pr. 7, fig. 4 .

Pseudodacus macrurus; Stone, 1939b:285; figs. I(2) e 2. Blanchard, 1961:294, fig. 5 .

Espëcie de tamanho médio Coloração geral escu ra. Faixas do mesonoto amarelas; faixa mediana com formato de $Y$ invertido. Escutelo com a base escura e äpice amarelo claro. Macroquetas marrom claras; pilosidade esbranquiçada. Asas com 7,5m de comprimento; faixas $C$ cobrindo as células $R_{1}$ e $R_{3}$; faixa basal distinta; faixa $V$ apenas com o ramo pro ximal, pouco distinto. Ovipositor com $5,5 \mathrm{~mm}$ de comprimento, delgado; rasper com 4-5 pares de dentes grossos; äpice sem dentes.

Distribuição: Paraguai, Brasil e Argentina.

Planta hospedeira: Pradosia Lactescens.

Material examinado: BRASIJ. Bahia: Água Preta, 24.I.1937, G.Bondar, 3 \& (lâmina 3434 , abdome) e 2 \& (lâmina 3435 - abdome e 3433 - asa) (FOC).

Anastrepha manihoti Lima, 1934

(Fig. 60)

Anastrepha manhioti Lima, 1934a:543, figs. 47-48; pr. 72, fig. 43; pr. 76, fig. 72 (lectôtipo q, Viçosa, Minas Gerais, Bra sil, FOC).

Anastrepha manihoti; Stone, 1942:64, fig. 12B, pr. 13A;

Fernandez, 1953:29; Korytkowski e Ojeda, 1968:55, figs.ll, $61,95,123$ e 154 . 
Espëcie pequena. Törax com 2,5m de comprimento; faixas mediana e laterais do mesonoto pouco distintas. Me tanoto totalmente amarelado. Macroquetas marrom claras; pilo sidade esbranquiçada. Asas com $7,0 \mathrm{~mm}$ de comprimento; faixas C e $S$ unidas; faixa $V$ completa e isolada. Ovipositor com 1,55$-1,65 \mathrm{~mm}$ de comprimento, grosso, com leve constrição antes do fim do oviduto; äpice triangular com dentes sub-magudos.

Designação de lectötipo. o material tipo de A. manihoti Lima consiste de 2 sintipos (f e $q$ ) sob número 1847 , provenientes de Viçosa, Minas Gerais. A fêmea (lâminas 1960 asa e 1961 - abdome) foi selecionada e rotulada como lectötipo e o macho como paralectótipo (FOC).

Distribuição: Venezuela, Peru e Brasil.

Planta hospedeira: Manihot dulcis.

Material examinado: BRASIL. Minas Gerais: Viçosa, lectötipo 7, 8.III.1933, E.J.Hambleton (FOC); idem, I paralectótipo fo (FOC). Bahia: Cruz das Almas, 22 \%, 1976-1977, Alba R.N. Farias e A.S.Nascimento (ESALQ).

Anastrepha materteza, sp. n.

(Figs. 6I e 92)

Espëcie média. Tórax com 3,5m de comprimento; mesonoto com faixas mediana e laterais distintas; ümero amare lo claro. Metanoto e pös-escutelo escurecidos lateralmente. Macroquetas pretas; esternopleural presente; pilosidade amarelada. Asas com $8,0 \mathrm{~mm}$ de comprimento; faixas $C$ e $S$ unidas; faixa $\mathrm{V}$ completa e estreitamente unida à $\mathrm{S}$. Bainha com $2,75 \mathrm{~mm}$ de comprimento; rasper com numerosos dentes delgados. Ovipositor com 2,0mm de comprimento e distinta constrição antes da serra. Ápice com dentes conspícuos e sub-agudos sobre mais da metade apical.

Holötipo + . Brasil, Bahia, Cruz das Almas (Cha 
padinha), 10.VII.1977, A.S.Nascimento (ESALQ).

Tratä-se de espëcie pertencente ao complexo fraterculus, porêm difere das demais espëcies desse complexo pela constrição antes da serra e äpice com mais de 15 dentes.

\section{Anastrepha minensis Lima, 1937}

(Fig. 62)

Anastrepha silvai minensis Lima, 1937b:60, fig. 12; pr. 3, fig. 2 ; pr. 4, fig. 2 (holötipo + , Viçosa, Minas Gerais, Brasil, FOC).

Anastrepha distincta var. minensis; Stone, 1942a:107.

Anastrepha extensa Stone, 1942a:104, fig. 21D (holótipo + , Rio de Janeiro, BRASIL, BMNH). Syn. $n$.

Espëcie pequena. Törax com 2,5m de comprimento; mesonoto com faixas mediana e laterais distintas. Metano to inteiramente amarelado. Asas com $6,0-8,0 \mathrm{~mm}$ de comprimento; faixas $C$ e $S$ estreitamente ligadas; faixa $V$ separada da $S$ e pouco distinta no verrtice. Ovipositor com 2,0-2,5m de comprimento; ápice longo com poucos dentes salientes sobre menos da metade apical.

LIMA (1937b), revendo exemplares de A. silvai (FOC), separou 6 exemplares, que possuiam numerosos dentes no rasper e descreveu a variedade minensis. STONE (1942a) reconheceu esta variedade e como silvai era sinônimo de distincta, considerou a variedade dessa espécie. Por outro lado, STONE (cit. 20c.), supondo que minensis apresentasse o metanoto escurecido lateralmente, descreveu $A$. extensa que possuia metanoto totalmente amarelado. Todavia, os 6 exemplares da série tipica de minensis apresentam o metanoto amarelado, e assim considera-se extensa sinônimo de minensis, que se elevou à categoria de espécie.

Distribuição: Brasil.

Planta hospedeira: "jabuticabeira da mata". 
Material examinado: BRASIL. Minas Gerais: Viçosa, holötipo †, 5.II.1934, O.Drummond, exemplar no 1850-3, lâmina 3298 (abdome) (FOC); idem 5 parátipos ( 3 ŝ 2 †) no 1850, lâminas 1967 (asa) e 1968 (abdome) (FOC).

$$
\begin{gathered}
\text { Anastrepha mixta, sp. } \mathrm{n} \text {. } \\
\text { (Figs. } 63 \text { e 93) }
\end{gathered}
$$

Espëcie grande. Törax com $3,5 \mathrm{~mm}$ de comprinento; mesonoto com faixa mediana larga e laterais presentes. Metano to inteiramente amarelado. Asas com 10,0mm de comprimento; faixas $C$ e $S$ unidas; faixa $V$ completa $e$ isolada. Bainha com 5,0 mm de comprimento; rasper com numerosos dentes delgados. ovipositor com 4,25m de comprimento; ápice com suave constri ção antes da serra, esta com dentes diminutos sobre mais da metade apical.

Holötipo 9. Brasil, Mato Grosso, Utiariti, Rio Papagaio, X.1966, Lenko e Pereira (MZUSP).

Trata-se de espëcie próxima de $A$. nigripalpis Hendel da qual difere pelos palpos totalmente amarelados e ovi positor mais curto. Separa de $A$. sodalis stone pelos dentes da serra mais nitidos e de A. curitis stone pela placa facial não convexa e bainha do ovipositor pouco alargada na base.

Anas trepha montei Lima, 1934

(Fig. 64)

Anastrepha montei Lima, 1934a:541, figs. 43-44; pr. 72, fig.41: pr. 76, fig. 68 (lectótipo 9, Belo Horizonte, Minas Gerais, Brasil, FOC); Lima, 1937a:34; Stone, 1942a:59, fig. 10C, pr. 11B; Fernandez, 1953:28. Anastrepha (Lucumaphila) montei; Blanchard, 1961:310, fig.18.

Espëcie pequena a média. Törax com $3,0-3,5 \mathrm{~mm}$ de comprimento; mesonoto com faixas mediana e laterais distin 

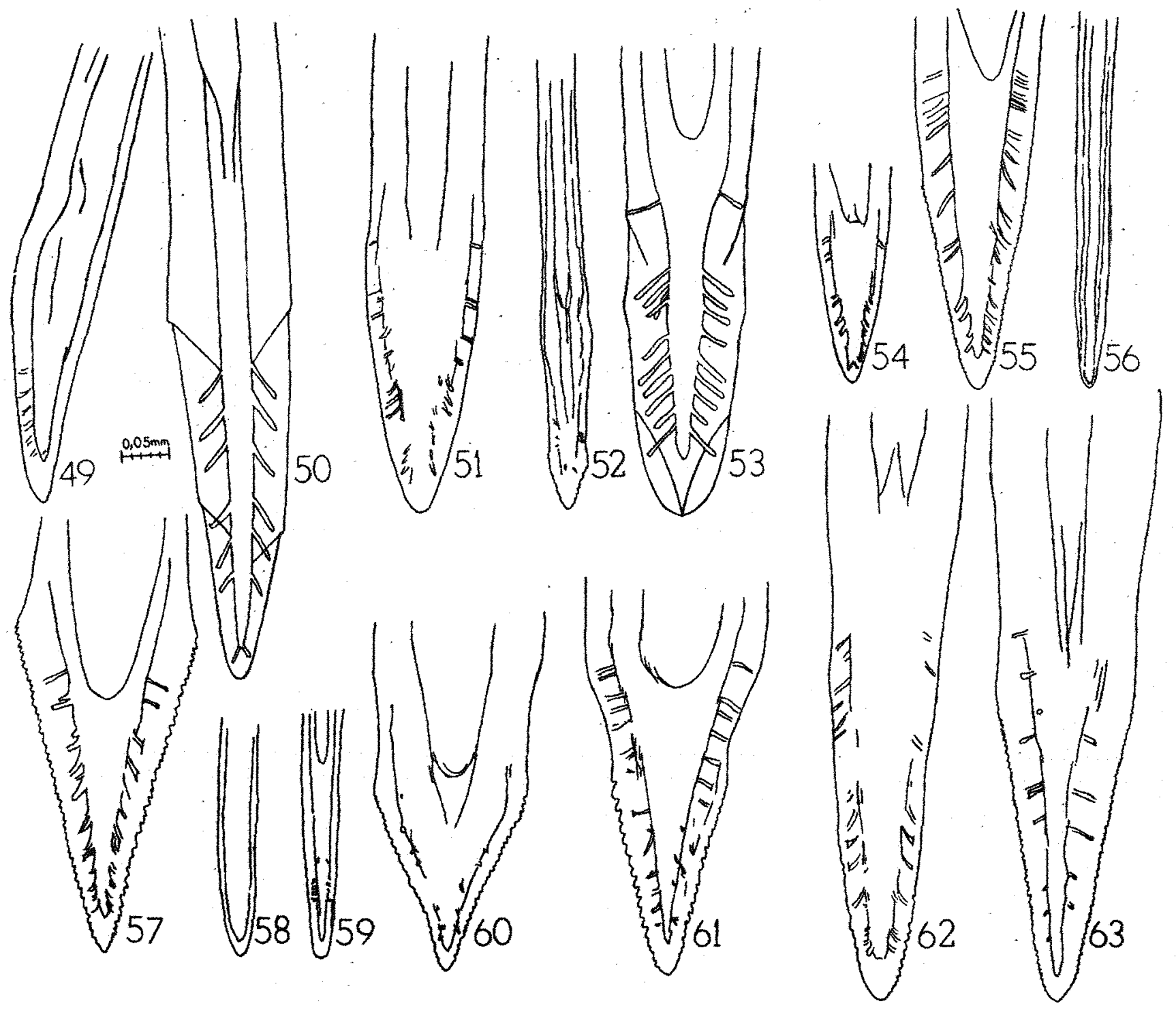

Âpice do ovipositor. Fig. 49: furcata. Fig. 50: grandis. Fig. 51: greenei. Fig. 52: hambletoni. Fig. 53: hastata. Fig. 54: kuhlmanni. Fig. 55: Zeptozona. Fig. 56: Zueder-. waldti. Fig. 57: Zutzi. Fig. 58: Zongiaauda. Fig. 59: macrura. Fig. 60: manihoti. Fig. 61: matertela.

Fig. 62: minensis. Fig. 63: mixta. 
tas. Metanoto totalmente amarelado. Macroquetes marrom escuras; pilosidade amarelada. Asas com 7,0-9,0mm de comprimento; faixas C e S estreitamente unidas; faixa V completa e separada da $S$. Ovipositor com 1,5-2,0mm de comprimento, afirando gradativamente da base à ponta; äpice sem dentes; rasper com numerosos dentes delgados.

Designação de lectötipo. A sërie sintípica de A. montei Lima consiste de $10 \$$ e 5 f provenientes de Minas Ge rais e Rio de Janeiro, sendo que 2 sintipos estão no National Museum of Natural History, 1 sintipo no centro de Pesquisas Agropecuärias Centro-Sul, EMBRAPA e apenas 9 estão na Fundação Oswaldo Cruz. A fêmea n: 1842, lâminas 1951 (asa) e 1952 (abdome) que se encontra na Fundação Oswaldo Cruz foi selecionada e rotulada como lectótipo, e os demais exemplares ( 1 f n: 1842 , Iâmina 1953 - abdome $\in 4$ \% 2 s sob o n: 1843) foram designados paralectötipos (FOC).

Distribuição: Costa Rica, Panamä, Venezuela, Brasil e Paraguai.

Plantas hospedeiras: Manihot aipi e Manihot sp.

Material examinado: BRASIL. Minas Gerais: Belo Horizonte, lectötipo +1 paralectótipo fo, VI.1932, 0.Monte, ambos sob o n: 1842, lâminas (f) 1951 (asa) e 1952 (abdome) e lâmina (f) 1953 (abdome) (FOC). Rio de Janeiro: Guaratiba, 6 paralectótipos ( 492 \$), sem data, A.Silva, sob a numeração 1843 (FoC). Bahia: Cruz das Almas, 1 f, 14.IV.1977, Alba R.N.Farias (ESALQ).

Anastrepha nascimentoi, sp. n.

(Figs. 65 e 94)

Espēcie pequena. Törax com $3,0 \mathrm{~mm}$ de comprimento; mesonoto com faixas mediana e laterais às vezes distintas; umero amarelo claro. Metanoto e pós-escutelo totalmente amare lados. Macroquetas pretas; pilosidade amarelada. Asas com 
8,0-9,0mm de comprimento; faixas $C$ e $S$ estreitamente unidas; faixa $V$ completa e isolada. Bainha do ovipositor com 2,0-2,5mm de comprimento; rasper com dentes delgados e espaçados entre si. Ovipositor com 1,75m de comprimento; äpice de aspecto triangular com dentes diminutos, que se estendem acima do nivel do fim do oviduto.

Holötipo $q$, Brasil, Bahia, Cruz das Almas, sem data, A.S.Nascimento (MZUSP); 1 parátipo + , idem (ESALQ).

A. nascimentoi difere de $A$. rheediae stone pelo padrão alar, aspecto do rasper e äpice do ovipositor; de $A$. umbrosa Blanchard pelo aspecto do äpice do ovipositor; das es pêcies do complexo spatulata pela ausência da faixa negra escu to-escutelar; de $A$. alveatoides Blanchard distingue-se princi palmente pela terminação arredondada do ápice.

Anastrepha obliqua (Macquart, 1835)

$$
\text { (Fig. 66) }
$$

Tephritis obliqua Macquart, 1835:464; Macquart, 1843:382

(1843:225) pr. 30, fig. Il (holótipo f, proveniente de "Cu ba", MNHN).

Trypeta obliqua; Loew, $1862: 59$ e 97 cobliqua Macquart nec obliqua Say).

Acrotoxa obliqua; Loew, 1873:337.

Anastrepha obliqua; Bezzi, 1919a:10; Bezzi, 1919b:374, fig.

2(6); Lima, 1934a:52, 522 e 604; Lima, 1937a:37; Steyskal, $1975: 357$.

Anastrepha fraterculus var. mombinpraeoptans Sein, 1933:187,

pr. 10, figs. $1,4,6-8 ; \mathrm{pr}$. 11 , figs. 9, 10, 14-17, 19-27

pr. 12, figs. 32-37, 40, 41; pr. 13, figs, 43-51; pr. 14,

figs. 52-56 (holótipo + , Rio Piedras, Porto Rico, NMNH);

Lima, 1934a:549 e 604, figs. 52-53; pr.73, fig. 51; pr.

76, fig. 76; Blanchard, 1961:319.

Anastrepha acidusa; Bates, 1933:161; Greene, 1934:162, pr.22,

fig. 3 .

Anastrepha ethalea; Greene, 1934:161; Stone, 1942a:68. 
Anastrepha trinidadensis Greene, 1934:161 (holötipo 9 , Tabaqui te, Trinidad, NMNH); Stone; $1942 \mathrm{a}: 68$.

Anastrepha fraterculus var. Zigata Lima, 1934a:552, fig. 54;pr. 73, fig. 52; pr. 76, fig. 75 (sintipos $f$ \%, Rio de Janeiro, Brasil, (PACS); Stone, 1942a:68.

Anastrepha mombinpraeoptans; Stone, 1942a:68, fig. 13C, pr.14B; Baker et alii, 1944:134, figs. 68A, 78 e 79; pr. 7 , figs. E, F, G; Fernandez, 1953:31, fig. 8; Korytkowski e Ojeda, $1968: 66$, figs.1, 2, 35, 46, 81, 108, 137 e 170 .

Espëcie pequena. Törax com 2,5-3,25mm de comprimento; mesonoto com faixas mediana e laterais distintas. Metanoto enegrecido lateralmente. Macroquetas marrom claras; pilosidade predominantemente amarelada. Asas com 5,75-7,50mm de comprimento; faixas $C$ e S unidas; faixa V completa ou não: unida ou não à S. Ovipositor com 1,30-1,60mm de comprimento; apice com dentes irregulares e agudos sobre mais da metade api cal; a constrição antes da serra é pouco acentuada.

Distribuição: Antilhas, Jamaica, EUA (Texas e Flörida); Mëxi co, Panamá, Venezuela, Equador, Peru, Brasil e Argentina.

Plantas hospedeiras: $A$. obliqua desenvolvemse em cerca de 64 plantas (NASBAUER, 1972).

Material examinado: BRASIL. Pernambuco: Recife,6 $9,03 . \mathrm{V} .1976$, Morgante, Malavasi e Silva (ESALQ). Rio de Janeiro: Rio de Janeiro, 1 q, sem data, H.Souza Lopes (MZUSP). Bahia: Cruz das Almas, 85 \&, VII.1976-V.1977, A.S.Nascimento (ESALQ); idem, 33 \%, VII-X.1977, A.S.Nascimento (ESALQ); idem, 4 , 14.IV.1977, Alba R.N. Farias (ESALC); Muritiba, 33 9,VII-X.1977, A.S.Nascimento (ESALQ); Governador Mangabeira, 18 9, VII-X.1977; A.S.Nascimento (ESALQ). São Paulo: Ribeirão Preto, $3 q$, 4.IV.1976, E.F.Silva (ESALQ); Piracicaba, 1297 o, 1977 ; R.A.Zucchi (ESALQ): Boa Esperança do Sul, Faz. Itaquerê, 3 , 25.XI.1963 e 20.XII. 1964, K.Lenko (MZUSP); Ibitinga, Faz. Itaquerê, $19,25 . I .1964, \mathrm{~K}$.Lenko (MZUSP); Nova Europa, Faz. Itaquerê, 7\%, XII.1963, I e V.1964, K. Lenko (MZUSP). 
Anastrepha obscura Aldrich, 1925

(Figs. 15 e 67)

Anastrepha obscura Aldrich, 1925:5 (holötipo f, Maraval, Trinidad, NMNH); Greene, 1934:157, pr. 21, fig. 2; Lima, $1934 a: 500$.

Lucumaphila obscura; Stone, 1939a:343, figs. 1 e 10.

Espëcie grande. Törax com 4,0-4,5m de compri mento; faixas do mesonoto indistintas. Macroquetas marrom claras; pilosidade amarelada. Metanoto totalmente amarelado. Asas com 10,0mm de comprimento; faixas alares indistintas; faixa hialina costal presente. Ovipositor com $5,5 \mathrm{~mm}$ de compri mento, muito fino $(0,035 \mathrm{~mm}$ de largura); ápice saliente e com as margens levemente denteadas.

A. obscura Aldrich é facilmente reconhecida pelo padrão alar e ovipositor muito fino.

Distribuição: Trinidad e Brasil.

Planta hospedeira: Lucuma multiflora.

Material examinado: 2 parätipos ( $f$ $f$ ), sem data e coletor, am bos sob o número 5320 (FOC).

Anastrepha paralzeza (Wiedemann, 1830)

(Figs. 19 e 68 )

Dacus parallelus Wiedemann, 1830:515 (lectótipo \%, "Brasil", NM). Acrotoxa paralzela; Loew, 1873:229, pr. 11, fig. 20 .

Anastrepha paralzeza; Bezzi, 1909:283; Hendel, 1914:13, pr.

1, fig. 9; Bezzi, 1919b:374, fig. 2(8); Lima, 1934a:517;

Lima, 1937a:34; Lima, 1937b:61, figs. 13-14; pr. 3, fig.3;

pr. 4, fig. 3; Stone, 1942a:53, figs. 9A, pr.9D.

Espëcie grande. Törax com 3,40-4,70mm de comprimento; mesonoto com faixas mediana e laterais distintas. Me tanoto inteiramente amarelado. Macroquetas pretas; pilosidade 
amarelada. Asas com $8,5-10,5 \mathrm{~mm}$ de comprimento; faixas $\mathrm{C}$ e $\mathrm{S}$ separadas; faixa $V$ completa, separada ou estreitamente unida à $S$; nervura $R_{2+3}$ sinuosa. Ovipositor com 4,00-5,25mm de comprimento; äpice sem dentes.

o âpice do ovipositor do Jectötipo è ilustrado pela primeira vez. o esquema do ovipositor de $A$. paraliela Wied. apresentado por STONE (1942a:54) concorda com o do material tipo.

Designação de lectötipo. A sêrie sintípica de parallela (NM) compreende 3 exemplares ( 192 t). A fêmea foi selecionada e rotulada como lectötipo e os machos como paralec. tötipos.

Distribuição: Mëxico, (?) Paraguai e Brasil.

Plantas hospedeiras: Lucuma sp. e Sterculia sp.

Material examinado: "BRASIL". lectötipo $q$, sem data, Winthem (NM); 2 paralectôtipos $f$, "BRASIL", sem data, coletados por Winthem e Wiedem (NM).

Anastrepha perdita stone, 1942

(Fig. 69)

Anastrepha perdita Stone, 1942a:76, fig. 15A (holötipo $q$, "Brasil", NMNH); Korytkowski e Ojeda, 1968:67, figs。32, $47,82,111$ e 138 .

Fspëcie pequena. Törax com 2,9mm de comprimento; mesonoto com faixas mediana e laterais. Metanoto escurem cido lateralmente. Macroquetas marrom a pretas; pilosidade amarelada. Asas com 6,5m de comprimento; todas as faixas uni das. Ovipositor com 1,60-1,75m de comprimento, grosso; äpi ce com dentes grossos sobre mais da metade apical (apud STONE, $1942 a$ ).

A descrição oniginal de $A$. perdita stone baseou se em duas fêmeas, que de acordo com STONE (1942a) encontravam 
se em pëssimas condições de conservação. Todavia o ovipositor desta espécie é característico e assegura a validade da espécie. Distribuição: Peru e Brasil.

Anastrepha phaeoptera Lima, 1937

Anastrepha phaeoptera Lima, 1937a:38, fig. 9; pr. I, fig. 3 (ho lötipo of, Bahia, Brasil, FOC); Stone, 1942a:92.

Espëcie grande. Tórax com 5,0 de comprimento; faixas mediana e laterais do mesonoto pouco distintas. Metano to inteiramente amarelado. Macroquetas pretas; pilosidade ama relada. Asas com $10,0 \mathrm{~mm}$ de comprimento; faixas alares marrom escuras; faixas $C$ e $S$ amplamente unidas, faixa $V$ incompleta, ramo proximal unida à $S$.

E conhecido apenas o holötipo desta espécie.

Planta hospedeira: Helicostylis poeppigiana.

Material examinado: BRASIL. Bahia: holötipo f̂, sem data, Bon dar, sob o nümero 2692, lâminas 2902 (abdome) e 3263 (asa) ( $F O C$ ).

Anastrepha pickeli Lima, 1934

(Fig. 70)

Anastrepha pickeli Lima, 1934a:542, figs. 45-46; pr. 72, fig. 42; pr. 76, fig. 73; (lectótipo 9 , Tapera, Pernambuco, Brasil, FOC); Lima, 1937a:34; Stone, 1942a:63, fig. 12A, pr. 12D; Fernandez, 1953:28; Blanchard, 1961:334, fig.36; Korytkowski e 0jeda, 1968:59, figs. 12,63, 98, 124 e 157.

Espëcie pequena. Törax com $3,0 \mathrm{~mm}$ de comprimen-m to; mesonoto com faixas mediana e laterais distintas. Metano to totalmente amarelado. Macroquetas marrom escuras; pilosidade amarelada. Asas com 6,25-7,00mn de comprimento; faixas $C$ e S separadas ou estreitamente ligadas; faixa $V$ completa e isolada (vértice pouco distinto). Ovipositor com 1,2-1,5mm de 
comprimento, grosso, afinando gradativamente ate o äpice; es te com dentes sub-agudos que se estendem até o nivel do fim do oviduto.

Designação de lectótipo. A sërie sintipica de A. pickeli lima consta de 9 q $1 \hat{f}$ (FOC, NMNH, CPACS). Na cole ção da Fundação Oswaldo Cruz encontram-se $2 \nmid 1$ sob número 1845; lâminas (P) 1955 (asa) e 1956 (abdome); lâmina 1957 (abdome f⿱⺊口) e 2 \& 1 f sob número 1846, lâminas ( 9 .. abdome) 1958 e 1959. Todos esses exemplares carregam uma etiqueta vermelha escrito TYPO. Os exemplares 1845 não estão relacionados na descrição original (LIMA, 1934a:543). Uma fêmea n: 1845, lâmi nas 1955 e 1956 (FOC) foi selecionada e rotulada como lectötipo e os demais exemplares como paralectötipos.

Distribuição: Panamá, Venezuela e Brasil.

Plantas hospedeiras: Manihot dulcis, M. esculenta e Quararibea turbinata.

Material examinado: BRASIL. Pernambuco: Tapera, lectötipo + , 2 paralectótipos ( $f$ \%), 9.III.1933, B.Pickel, exemplares no 1845, lâminas 1955, 1956 e 1957 (FOC); 3 paralectötipos (2 9 1 b), sem data e coletor, lâminas 1958 e 1957 (FOC). Bahia: Cruz das Almas, 89 , sem data, Alba R.N. Fanias e A.S.Nascimen to (ESALQ); idem, 6 \%, 30.v.1977, Morgante (ESALQ); idem, 4 ;, VII-VIII.1977, A.S.Nascimento (ESALQ); Governador Mangabeira, 4 \%, VII VIII.1977, A.S.Nascimento (ESALQ). Minas Gerais: Jai ba, I f, 3.II.1977, L.A.Gheiras (devolvida ao coletor).

Anastrepha pseudoparallela (Loew, 1873)

(Fig. 7I)

Acrotoxa pseudoparalleza Loew, 1873:230, pr. Il, fig. 24 (sintipos f $q$, "Brasil", ZMH).

Anastrepha pseudoparallela; Bezzi, 1909:283; Hendel, 1914:14; Bezzi, 1919a:11; Bezzi, 1919b:374, fig. 2(10); Greene, 1934:164, pr. 22, fig. 9 (partim); Lima, 1934a:536, figs. 
34-36; pr. 70, figs. 33-35; pr. 75, fig. 64; Stone, 1942a: 84, fig. 16C, pr. 17C; Blanchard, 1961:329, fig. 32 ; Korytkowski e 0jeda, 1968:55, figs. 21, 59, 93, 119, 152 e 181).

Espēcie grande. Törax com 3,0-4,0mm de compri mento; mesonoto com faixa mediana e laterais distintas. Meta noto totalmente amarelado. Macroquetas pretas; pilosidade amarelada. Asas com 8,00-9,25m de comprimento; faixas $\mathrm{C}$ e $S$ unidas; faixa $\mathrm{V}$ completa e isolada. Ovipositor com 2,5 - 3,0mm de comprimento; äpice com dentes sub-agudos e pequenos, sobre mais da metade apical.

Distribuição: Peru, Brasil e Argentina.

Plantas hospedeiras: Passiflora quadrangularis, (?) Psidium guajava e Mangifera sp (la. referência em manga).

Material examinado: BRASIL. Bahia: Cruz das Almas, 4 , 1976-1977, A.S.Nascimento (ESALQ). São Paulo: São Paulo, 5 \%, 18.XI.1976, E.M.Dessen (ESALQ); Barueri, 4. \%, VII, IX $巳$ XI.1954, K.Lenko (MZUSP); Oswaldo Cruz; I q, 14.XI.1977, E.F. Silva (ESALQ); Carapicuiba, 3 \%, 11.XI.1977, Cestari (ESALQ). Piracicaba, 8 9 , sem data, Milanes (ESALQ).

Anastrepha punctata Hendel, 1914

(Figs. 7 e 72 )

Anastrepha punctata Hendel, $1914: 14$ e 19 (sintipos fo + s. Ber nardino, Paraguai, MNTHM); Fischer, 1933:84-86; Greene, 1934:155, pr. 20, fig. 12; Lima, 1934a:508, pr.66, fig. 16; Blanchard, 1937:4I; Blanchard, 1961:303, fig. 11 . Anastrepha hendeli Greene, 1934:155, pr. 21, fig. I (holötipo + , São Paulo, Brasil, NMNH); Lima, 1934b:603; Stone, $1942 a: 36$.

Anastrepha minor Lima, 1934a:509, fig. 14, pr. 66, fig. 17 (ho10̈tipo f, Fazenda Murtinho, Mato Grosso, Brasil, CPACS); Lima, 1934b:603; Stone, 1942a:36. 
Espëcie pequena. Törax com 2,5-3,0mm de comprimento; mesonoto com faixas mediana e laterais. Metanoto totalmente amarelado. Macroquetas amarelo claras; pilosidade amarelada. Asas com 5,5-6,5m de comprimento; faixas alares separadas; faixa $V$ incompleta ou pouco distinta no ápice. Ovi positor com 1, $5 \mathrm{~mm}$ de comprimento, delgado; ápice curto sem den tes; rasper com poucos dentes delgados.

Hä confusões na identificação de A. punctata, pois os exemplares desta espécie podem apresentar ou não manchas negras no abdome. Assim, foram descritas hendeli e minor que não possuem tais manchas. STONE (1942a) observou variações nas manchas negras dos exemplares da sërie típica de henderi, e como não havia diferenças na genitälia (macho e fêmea) desta espécie e de punctata, considerou-as co-especificas.

Nas observações que fez ao trabalho de GREENE (1934), LIMA (1934b) havia considerado minor como provävel sinônimo de hendeli.

BLANCHARD ( 1961 ) considerou hendeli como espe-cie välida e descreveu quatro espëcies e uma variedade, todas muito próximas de punctata. Separou essas espécies de punctata em virtude da presença ou ausência de manchas no abdome, for mato dessas manchas (circular ou transversal) e presença ou ausência de microtriquias nas cëlulas. As espécies de Blanchard foram descritas com base num ünico exemplar. Muito pro vavelmente as diferenças apontadas por BLANCHARD (cit. loc.) são variações intra-especificas, e assim deveria ser considera da apenas a denominação punctata.

Distribuição: Brasil, Paraguai e Argentina.

Planta hospedeira: Psidium guajava.

Material examinado: 3 \%, 2 f (lâmina 2137 -abdome $q$ ), sem data e coletor, todos sob número 1988 e determinados como A. minor por LIMA (FOC). 
Anastrepha quararibeae Lima, 1937

(Fig. 73)

Anastrepha quararibeae Lima, 1937a:35, figs. 1-2: pr. I, figs.6 e 8; pr. 2, Fig. 4 (holôtipo +, Bahia, Brasil, FoC); Stone, 1942a:44, fig. 6E, pr. 7C).

Anastrepha quararibae, erro.

Espécie pequena. Törax com 2,0-3,0mm de com primento; mesonoto com faixas mediana e laterais distintas. Metanoto inteiramente amarelado. Macroquetas amareladas; $p i$. losidade amarelada. Asas com 4,0-6,0mm de comprimento; faixas C e S separadas ou Iigadas; faixa V estreitamente unida à S. Ovipositor com 1,50-1,80mm de comprimento; ápice sem dentes.

Distribuição: Brasil (Bahia).

Plantas hospedeiras: Quararibea turbinata e Q. "penduliflora". Material examinado: BRASIL. Bahia: Ägua Preta, holötipo $¥$, 17.II.1937; G.Bondar, exemplar n: 3021, lâminas 3247 (abdome): idem, 8 parätipos (5 9 3 f) sob no 3021; "Bahia" 9 parätipos ( 4 f 5 ) , sem data, Bondar (FOC).

Anastrepha quiinae Lima, 1937

(Fig. 74)

Anastrepha quiinae Lima, 1937a:37, figs.7-8: pr.1, fig. 2: pr. 2, fig. I (holōtipo + , Agua Preta, Bahia, Brasil, FoC); stone, 1942a:104, fig. 21C, pr. 22B.

Espécie mediana. Tórax com 3,25-3,50mm de com primento; mesonoto com faixas mediana e laterais. Metanoto totalmente amarelado. Macroquetas marrom escuras; pilosidade amarelada. Asas com 6,5-7,5m de comprimento; faixas alares estreitamente unidas. Ovipositor com $3,2 \mathrm{~mm}$ de comprimento; ápice sem dentes. 


\section{Distribuição: Brasil (Bahia).}

Planta hospedeira: Quiina glaziovii.

Material examinado: BRASIL. Bahia: Âgua Preta, holótipo of 17.II.1937, G.Bondar, exemplar n: 3027, lâminas 3259 (asa), 3260 (abdome) e 3261 (ovipositor) (FOC); idem, 3 parätipos (2f I $\delta$ ) sob no 3027 , lâmina 3262 (abdome $\hat{\delta}$ ) (FOC).

Anastrepha rheediae Stone, 1942

(Fig. 75)

Anastrepha rheediae Stone, 1942a:65, fig. 12C, E, pr. 13B (holotipo 9 , Bairro Colorado, Island, Zona do Canal, NMNH): Fernandez, 1953:29, fig. 7 .

Anastrepha rheedieaea, erro.

Espëcie mediana. Törax com 2,75-3,75m de com primento; mesonoto com faixas mediana e laterais distintas. Metanoto escurecido lateralmente. Macroquetas marrom escuras; pilosidade amarelada. Asas com 5,5-8,0 mm de comprimento; to das as faixas alares unidas. Ovipositor com 2,0-2,3mm de com primento; ápice de aspecto triangular, levemente mais largo do que o restante do ovipositor; dentes diminutos estendendose até o nivel do fim do oviduto; rasper com dentes grossos e de base larga.

A. rheediae Stone caracteriza-se pelo formato dos dentes do rasper e aspecto do äpice do ovipositor. É assi nalada aqui pela primeira vez no Brasil. Examinou-se uma fêmea identificada por KORYTKOWSKI e OJEDA (1968:55), como $A$. rheediae stone e verificou-se que provavelmente trata-se de nova espēcie.

Distribuição: EUA, Panamä, Trinidad e Brasil.

Plantas hospedeiras: Rheedia madruno e Ro braziliensis (Ia. referência nesse hospedeiro). 
Material examinado: BRASIL. Mato Grosso: Brasilândia, 2 , 3.XII.1977, Malavasi (ESALQ). São Paulo: Nova Europa, Fazenda Itaquerê, 3 9, 27.XI e 2.XI.1963, K.Lenko (MZUSP); Boa Es perança do Sul, Faz. Itaquerê, 2 ㅇ, XI.1963, K. Lenko (MZUSP). PANAMA. Bairro Colorado, Zona do Canal, 2 parätipos (f $q$ ), 17.I.1936, Zetek, ambos sob número 5324 (FOC).

Anastrepha sagittifera, sp. n.

$$
\text { (Figs. } 76 \text { e 95) }
$$

Espëcie grande. Tórax com 3,5mm de comprimento; faixas mediana e laterais do mesonoto, umero, porção superior da pleura e atrás da inserção das asas, junto ao metanoto, de coloração amarelo clara. Metanoto totalmente amarelado. Macro quetas marrom claras; pilosidade amarelo claras (douradas). Asas com 8,5mm de comprimento; faixas $C$ e $S$ unidas; faixa $V$ apenas com o ramo proximal, largo e amplamente unido à $S$. Bainha do ovipositor com 5,5m de comprimento; rasper com den tes curtos. Ovipositor delgado com 5,5m de comprimento; äpi ce com dentes diminutos e aspecto de ponta de seta.

Holötipo + . Brasil, Espírito Santo, Baixo Guan du, XI.1970, P.C.Elias (MZUSP).

A. sagittifera, sp. n. é próxima de A. sagitta ta Stone da qual se distingue pelo padrão alar e aspecto doápi ce do ovipositor.

Anas trepha serpentina. (Wiedemann, 1830)

$$
\text { (Figs. } 20 \text { e 77) }
$$

Dacus serpentinus Wiedemann, 1830:521 (holötipo $\$, " B r a s i l ", N M$ ). Lep toxys serpentina; Macquart, 1843:373.

Urophora vittithorax Macquart, 1851:259, pr. 26, fig. 11 (holó tipo + , "Indie", BMNH).

Anastrepha serpentina; Schiner, 1868:263; Hendel, 1914:14;

Tavares, 1915:52-54; Lima, 1915:99, fig. 9; Bezzi, 1919a: 
:7; Bezzi, 1919b:374, fig. 2(4); Greene, 1929:497, figs. 2E, 3J, 5E, 6J; Emmart, 1933:184-191, prs. 7-8, Dampf, 1933:262, figs. 1, 6, 12; Greene, 1934:142; pr.19, fig.1; Lima, 1934a:494, figs, 1-2; pr. 65, fig. 9; Lima, 1937a: :34; Stone, 1942a:27, figs. 2C, pr. 2D; Baker et alii, 1977:125, figs. 70B, 71 e 79; Fernandez, 1953:20, fig. 3; Blanchard, 1961:295, fig. 6; Korytkowski e 0jeda, 1968:49, figs. 16, 19, 51, 87, 120, 145 e 174.

Espëcie média a grande. Coloração genal escura. Törax com 3,3-4,0mm de comprimento; mesonoto com faixas mediana e laterais amarelas. Macroquetas pretas; pilosidade marrom escuras e amareladas. Asas com 7,25-8,50mm de comprimento; faixas $\mathrm{C}$ e $\mathrm{S}$ amplamente unidas; faixa $\mathrm{V}$ apenas com 0 ramo proximal e separada da $S$. Dorso abdominal com faixa mediana amarela. Ovipositor com 2,8-3,7mm de comprimento; apice com dentes pequenos sobre mais da metade apical.

Distribuição: EUA (Texas) ao Peru, Trinidad, Brasil e Argenti na.

Plantas hospedeiras: A. serpentina desenvolve-se em cerca de 40 hospedeiros (WASBAUER, 1972).

Material examinado: BRASIL, Parä: Boca do Cuminä-Miri, Ori ximinä, 1 q, I.1968, Exp. Perr. Amaz. (MZUSP). Pernambuco: Tapirema, 1 \& 2 f, sem data e coletor (ESALQ). Bahia: Cruz das Almas, 122 \&, 1976-1977, A.S.Nascimento (ESALQ); Governador Mangabeira, 49 , VII-IX.1977, A.S.Nascimento (ESALQ); Muritiba, 3 f, VII-IX.1977, A.S.Nascimento (ESALQ); Santo Antonio de Jesus, 10 \%, 31.V.1977, J.Morgante (ESALQ); Rio de Janeiro: Angra dos Reis, $10 \%$, sem data, 0.H.Pavan (ESALQ); Vassouras, 3 9, 2.XII.1976, Malavasi e Morgante (ESALQ). Minas Gerais: Matias Barbosa, 2 f, V.1960, Lẻa Monteiro (MZUSP). São Paulo: São Paulo, Ipiranga, 1 \&, VII.1951, E. Rabello (MZUSP); Piracicaba, 1 O , V.1971, M.A.Vulcano (MZUSP); Salesópolis, Est. Biol. Boracéia, 6 \$ 4 f̂, 2.XI.1960, K.Lenko (MZUSP). 
Anastrepha simulans, sp. $\mathrm{n}$.

(Figs. 78 e 96 )

Espëcie média. Törax com $3,0-3,5 \mathrm{~mm}$ de compri mento; mesonoto com faixas mediana e laterais distintas; fai xa escura na margem posterior do mesonoto. Metanoto totalmente amarelado. Macroquetas pretas; pilosidade amarelada. Asas com 8,0-9,0mm de comprimento; faixas alares unidas entre si; faixa $V$ completa ou não. Bainha do ovipositor com 2,0mm de comprimento. Ovipositor com 1,2-1,3mm de comprimento; äpice sem dentes com ponta arredondada.

Holötipo f. Brasil, São Paulo, Salesópolis, Bo racëia, 24-27.VI.1949, Travassos Filho e Rabello (MZUSP); parätipos: I q, São Paulo, Salesópolis, Boracëia, 24-30.I.1952 (ESALQ); 1 7, sem localidade, data e coletor, exemplar 5282, lâminas 4699 (asa), 4700 (abdome) e 4701 (ovipositor), erroneamente determinado como $A$. robusta por Capoon (FOC).

A. simulans, Sp. n. ë prôxima de A. nigrifascia Stone, da qual difere pelo porte mais robusto, coloração geral mais escura, ovipositor mais curto com apice mais largo e ponta arredondada. A. simulans ê afim, tambëm, de A. furcata Lima, A. flavipennis Greene e A. robusta Greene, das quais difere, respectivamente, pelo ovipositor reto, célula M hialina e ápice do ovipositor sem constrição. A. simulans foi considera da espécie nova após a comparação de 3 fêmeas com os parátipos ( 191 f) de A. nigrifascia Stone, que se encontram na Fundação Oswaldo Cruz.

Anastrepha sodalis Stone, 1942

(Fig. 79)

Anastrepha sodalis Stone, 1942a:102, fig. 21A (holötipo $q$, Santarëm, Brasil, BMNH).

Espêcie grande. Törax com 3,4mm de comprimento; mesonoto com faixas mediana e laterais. Metanoto totalmente 
amarelado. Macroquetas pretas; pilosidade amarelada.

Asas com 9,2mm de comprimento: todas as faixas alares estreitamen te unidas. Ovipositor com $3,4 \mathrm{~mm}$ de comprimento; ápice longo $(0,48 \mathrm{~mm}$ ) com dentes reduzidissimos sobre $2 / 3$ apicais (apud STONE, 1942a).

$\tilde{E}$ conhecido apenas o holötipo de A. sodalis. STONE (1942a) sugeriu a possibilidade de sodalis ser a fêmea de $A$. connexa Lima. Porèm, considerou mais viävel a descri. ção de sodalis como espëcie nova, uma vez que somente apōs a associação de machos e fêmeas poderia obter uma conclusão defi nitiva.

\section{Anastrepha sororcula, sp. n. (Figs. 80 e 97)}

Anastrepha sororcula - Nomen nudum (Steyskal, 1977b:34).

Espẻcie pequena. Tórax com 2,60-2,82mm de com primento; mesonoto com faixas mediana e laterais distintas. Metanoto escurecido lateralmente. Macroquetas marrom claras: pilosidade amarelada. Asas com 6,00-6,38mm de comprimento; faixas $C$ e $S$ unidas; faixa $V$ incompleta e separada da $S$. Ovi positor com 1,50-1,55mm de comprimento; äpice curto (cerca de $0,18 \mathrm{~mm}$ ), com distinta constrição antes da serra, esta com dentes sub-agudos.

Holótipo +. Brasil, São Paulo: Ribeirão Preto, 07.IV.1976, Maria M.T. da Silva, ex goiaba (MZUSP); idem, 13 parätipos (10 $\$ 3$ ) (ESALQ); idem, 2 parätipos $q$ (MZUSP); idem, 2 parătipos $q$ (NMNH); São Paulo, Taiủva, 12 parätipos + , 01.III.1975 e 13.IV.1975, J.C.Durigan (ESALQ); idem, 3 paräti

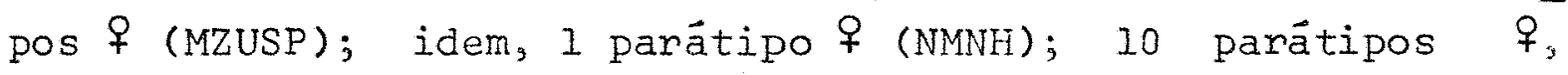
Bahia; Cruz das Almas, VII.1976 a V.1977, A.S.Nascimento (ESALQ); idem, 10 parätipos $\$$ (MZUSP).

Anastrepha sororcuza, Sp. n. è muito pröxima de A. fraterculus (Wied.) da qual difere $\cdots 10$ apice do ovipositor mais curto. Inicialmente, pensou-se que se tratasse de uma variação intra-especifica de fraterculus, todavia com o estudo 


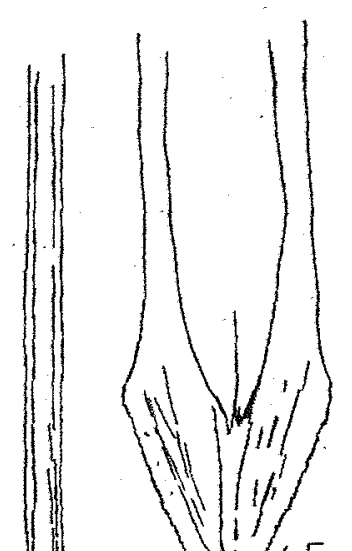

(64 64

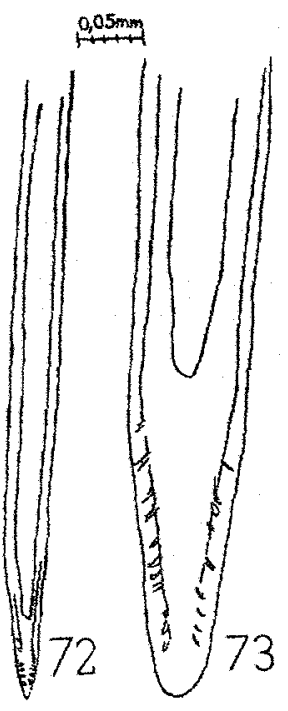

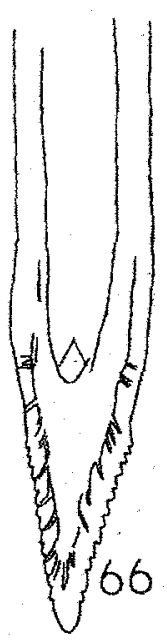
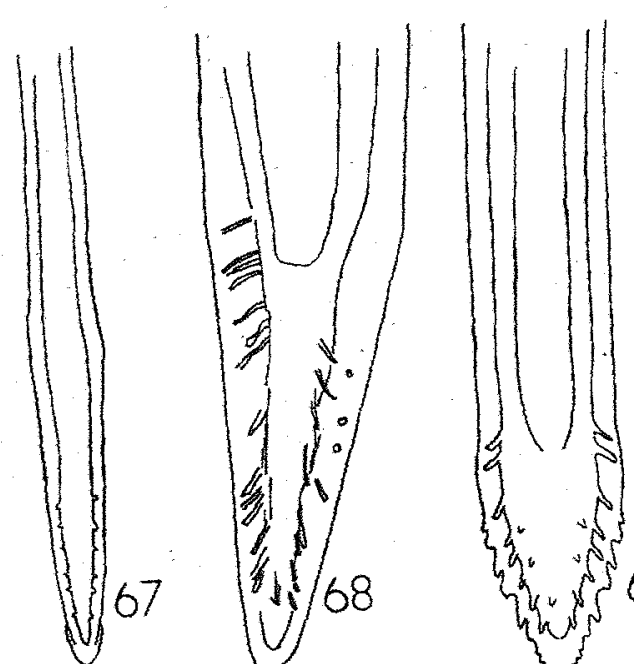

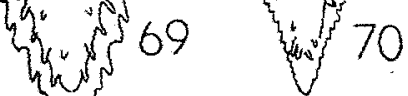
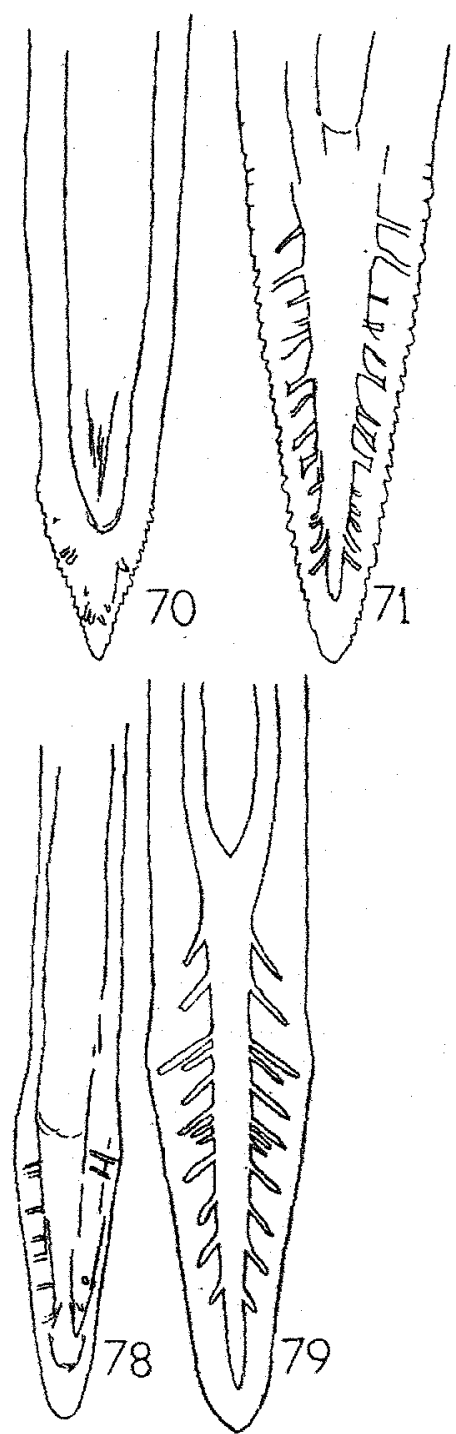

Apice do ovipositor. Fig. 64: montei. Fig. 65: nascimentoi. Fig. 66: obliqua. Fig. 67: obscura. Fig. 68: parallela. Fig. 69: perdita. Fig. 70: pickeli. Fig. 71: pseudoparallela.

Fig. 72: punctata. Fig. 73: quararibeae. Fig. 74: quinae. Fig. 75: rheediae. Fig. 76: sagittifera. Fig. 77: serpentina. Fig. 78: simulans. Fig. 79: sodalis. 
de amostras que continham apenas sororcula ou apenas fraterculus, essa hipótese foi descartada.

A. sororcula ainda não foi formalmente descrita, visto que figurou apenas num trabalho de dissertação (zUCCHI, 1977), e por esse motivo aqui é ainda citada como espécie nova. STEYSKAL (1977) relacionou sororcula em sua chave ilustrada, e como não havia sido descrita, conciderou-se aquela citação como nomen nudum.

\section{Anastrepha striata Schiner, 1868}

(Fig. 81)

Anastrepha striata Schiner, 1868:264 (holötipo 9 , venezuela, NM): Bezzi, 1909:283, 285; Hendel, 1914:19, pr.1, fig.7; Keilin e Picado, 1915:423, figs. 1-6; Greene, 1929:497, figs. 2D, 3I, 5D, 6I; Dampf, 1933:260, figs. I, 5, 12;

Emmart, 1933:184, pr. 7-8; McPhail e BIiss, 1933:2; Greene, 1934:145, pr. 19, fig. 8; Lima, 1934a:504, figs.7-8; pr. 65, fig. II; pr. 76, fig. 70; Stone, 1942a:29, fig.3A, pr. 3B; Baker et alii, 1944:130, figs.74, 75,76 e 79, pr. 7, fig. B; Fernandez, 1953:21, fig. 4; Korytkowski e ojeda, 1968:50, figs. 17, 49, 89, 109, 147 e 176 .

Espécie pequena a mëdia. Tórax com 2,45-3,50mm de comprimento; mesonoto com faixas medianas e laterais distintas. Mesonoto com faixas longitudinais escuras. Macroquetas pretas; pilosidade esbranquiçada. Metanoto totalmente es curecido ou apenas lateralmente. Asas com 6,0-7,7mm de comprimento; faixas $C$ e S unidas; faixa V com o ramo distal geralmente reduzido. Ovipositor com 2,0mm de comprimento; apice sem dentes.

o äpice do ovipositor do holötipo de A. striata Schiner $\vec{e}$ ilustrado pela primeira vez. As figuras do äpice do ovipositor de striata apresentadas por LIMA (1934a:504 e STONE (1942a:30) concordam com a do tipo.

0 holötipo apresenta 5 etiquetas: Lindig, 1864 . Venezuela; Striata, Alte Sammlung; Anastrepha striata Schiner; 
Type \%; Type 7 marked by D.E. Hardy - 1961.

Distribuição: México, Honduras, Costa Rica, Panamä, Colômbia, Equador, Bolivia, Venezuela, Trinidad, Suriname, Peru e Brasil.

Plantas hospedeiras: Psidium guajava, Calyptranthes tonduzii, Mangifera indica, Spondias sp, Manihot esculenta, Eugenia uni=flora e Achras zapota.

Material examinado: VENEZUELA. holötipo , marcado por D.E. Hardy, 1961 (NM); Rancho Grande, Aragua, I f, 16.XI.1968, H. Reichardt (MZUSP). TRINIDAD. Port of Spain, I官, I.1914; F.W.Urich (MZUSP). BRASIL. Parä: Belëm, 3 9, III-VII.1977, Malavasi; Mendes; Silva (ESALQ).

\section{Anastrepha submunda Lima, 1937}

(Fig。 82)

Anastrepha submunda Lima, 1937a:37, figs. 5-6: pr. 1, figs.4-5; pr. 2, fig. 3 (holótipo + , Bahia, Brasil, FOC); Stone, $1942 \mathrm{a}: 47$.

Espécie mediana. Törax com 3,5mm de comprimento; mesonoto com faixas mediana e laterais. Metanoto totalmente amarelado. Macroquetas marrom escuras; pilosidade amarelada. Asas com 6,25-8,00mm de comprimento; todas as fai xas alares separadas; faixa $V$ completa ou não. Ovipositor com 1,5m de comprimento; äpice sem dentes.

A descrição original baseou-se em 5 f e 89 pro venientes da Bahia, Brasil. Todavia na coleção da Fundação os waldo Cruz encontram-se 4 우 e 5 f.

Distribuição: Brasil (Bahia).

Plantas hospedeiras: "pinha vermelha de leite" (Annonaceae) e "mucuri branco" (Sapotaceae).

Material examinado: BRASIL. Bahia: holötipo $¥$, sem data e coletor, exemplar no 2289, lâmina 2713 (abdome) (FOC); 8 parâ 
tipos (5 53 q), idem, IX.1935, G.Bondar, exemplares n: 2289, lâminas 2640 (ô abdome), 2639 ( 9 abdome), 2631 e 2630 (asas) (FOC).

Anastrepha tenelza, sp. n.

(Figs. 83 e 98 )

Espëcie pequena. Coloração geral amarelo clara. Tórax com 2,5mm de comprimento; faixas do mesonoto pouco dis tintas; a faixa mediana é mais nitida na porção basal, onde se alarga e inclui as acrosticais; área umeral e porção supe rior da pleura amarelo pálido. Escutelo totalmente amarelo claro. Metanoto e pós-escutelo amarelados. Macroquetas marrom escuras; pilosidade amarelada. Asas com $6,5 \mathrm{~mm}$ de compri mento; faixas $C$ e $S$ estreitamente unidas; faixa $V$ incompleta e separada da $\mathrm{S}$. Bainha do ovipositor com 2,0mm de comprimento; rasper com numerosos dentes delgados. Ovipositor com $1,5 \mathrm{~mm}$ de comprimento; ápice longo (cerca de $0,44 \mathrm{~mm}$ ) e dentes grossos sobre $1 / 3$ apical.

Holötipo f. Brasil, Bahia, Cruz das Almas, sem data, A.S.Nascimento (MZUSP).

A. tenelza, sp. n. difere de A. minensis Lima pelo ovipositor mais curto e mais delgado e aspecto geral do ápice. O ovipositor de $A$. minensis apresenta um leve alargamen to ao nivel do fim do oviduto e os dentes são menos evidentes do que os de $A$. tenella, cujo ovipositor ê distintamente menor do que a bainha.

Anastrepha townsendi Greene, 1934

(Fig. 84)

Anastrepha townsendi Greene, $1934: 165, \mathrm{pr} .22$, fig. 10 (holöti po + , Boa Vista, Rio Tapajós, Brasil, NMNH); Stone, 1942a: 84, fig. 16D, pr. 17D.

Espëcie grande. Törax com 4,25m de comprimento; mesonoto com faixas mediana e laterais. Metanoto total- 
mente amarelado. Macroquetas pretas; pilosidade amarelada. Asas com 10,5mm de comprimento; faixas $C$ e $S$ unidas; faixa $V$ completa e isolada. ovipositor com 4,87m de comprimento; ápi ce longo com dentes sobre $3 / 5$ apical (apud STONE, 1942a).

E conhecido apenas o holötipo de $A$. townsendi

Greene.

Anastrepha xanthochaeta Hendel, 1914

(Fig. 85)

Anastrepha xanthochaeta Hendel, 1914:18 (holotipo 9 , Rio Grande do Sul, Brasil, NM); Greene, 1934: 163; Lima, 1934a: :516; pr. 63, fig. 4; Stone, 1942a:43, fig. $6 \mathrm{~B}$.

Espécie pequena a mëdia. Törax com 2,5-3,0mm de comprimento; faixas do mesonoto indistintas. Macroquetas amareladas; pilosidade amarelada. Metanoto totalmente amarelado. Asas com 7,5mm de comprimento; todas as faixas alares separadas. Ovipositor com 2,2mm de comprimento elargo $(0,122 \mathrm{~mm}$ de largura); serra de aspecto triangular com dentes pequenos.

Distribuição: Brasil.

Plantas hospedeiras: "Maracujä" (Passiflora sp., la. referên cia do hospedeiro).

Material examinado: BRASIL. São Paulo: Ibiuna, 8 9 V.1978. O.Pavan (ESALQ). Rio Grande do Sul: Nova Teutônia, 1 , IV.1970, F.Plaumann (MZUSP).

Anastrepha zenildae, sp. $\mathrm{n}$.

(Figs. 86 e 99)

Anastrepha zenildae - Nomen nudum (Steyskal 1977b:34).

Espécie pequena a média. Törax com 2,70-3,00mm de comprimento; mesonoto com faixas distintas. Metanoto escu recido lateralmente. Macroquetas pretas; pilosidade amarela- 
da. Asas com 6,30-6,80mm de comprimento; faixas C e $S$ unidas; faixa $V$ com vértice pouco distinto e isolada. Ovipositor com 1,80-1,90mm de comprimento; âpice com constrição sua ve antes da serra, esta com dentes sub-agudos sobre aproximada mente $2 / 3$ apical.

Holötipo +. Brasil, Cearä, Pacajus, 10.XII.1976, Zenilda B. de Castro, ex goiaba (MZUSP); idem, 2 parätipos (ơ (MZUSP); idem, 2 parätipos (今े q) (ESALQ); idem, 5 parátipos (NMNH); Ceará, Maranguape, 2 parátipos $\uparrow$, XII.1976, Zenilda B. de Castro (ESALQ); idem, 2 parátipos $q$ (MZUSP); Cearä, Ma racanau, 2 parátipos \%, 12.XII.1976, Zenilda B. de Castro (ESALQ); idem, 2 parätipos (MZUSP); Cearä, Fortaleza, 3 parä tipos 9, Zenilda B. de Castro, 12.XII.1976 (ESALQ); São Paulo, Taiúva, 1 parátipo $\$, 30 . I I I .1975$, J.C.Durigan (MZUSP); São Paulo, Ribeirão Preto, 1 parätipo, $\$$, 07.VI.1976, Maria M.T.da Silva (ESALQ); Bahia, Cruz das Almas, 5 parätipos $\$$, VII.1976 a V.1977, A.S.Nascimento (MZUSP); idem, 4 panätipos 9 (ESALQ). A. zenizdae, sp. n. difere de A. parishi stone e A. irretita stone pelo aspecto do äpice do ovipositor, faixas do mesonoto nitidas e metanoto enegrecido lateralmente; de $A$. guianae stone pelo ovipositor mais estreito $(0,10$ e

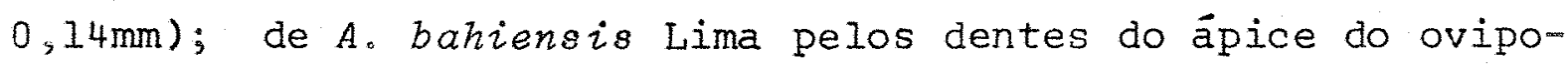
sitor mais conspícuos e mais próximos à abertura do oviduto.

Anastrepha zernyi Lima, 1934

(Fig. 87)

Dacus parallelus Wiedemann, 1830:515 (partim).

Anastrepha zernyi Lima, $1934 \mathrm{a}: 524$; pr. 62, figs. 2-3 (holótipo q, "Brasil", NM)。

Lucumaphiza zernyi; Stone, 1939a:348.

Anastrepha (Lucumaphila) zernyi; Blanchard, 1961:307, fig.16.

Espêcie grande. Törax com $3,9 \mathrm{~mm}$ de comprimento; mesonoto sem faixas. Metanoto totalmente amarelado. Macroque tas marrom escuras; pilosidade amarelada. Asas com 8,5mm de 
comprimento; todas as faixas alares unidas; faixa $V$ incomple ta. Bainha do ovipositor e ovipositor com $4 \mathrm{~mm}$ de comprimento.

A descrição original de $A$. zernyi Lima foi ba seada num sintipo 9 de $A$. paralzeza (Wied.). 0 ápice do ovipositor da fêmea é ilustrado pela primeira vez. 0 äpice do ovipositor ilustrado por BLANCHARD (1961:308) conconda com o tipo de $A$. zernyi.

$$
0 \text { holötipo apresenta } 5 \text { etiquetas: Brasilia, }
$$

Type, Anastrepha zernyi do C. Lima, paralzelus, Coll. Winthem, Lucumaphiza zernyi (Costa Lima).

Distribuição: Brasil e Argentina.

Material examinado: "BRASIL". Holötipo + , sem data, Winthem (NM). Bahia: Cruz das Almas, 1 q, sem data, A.S. Nascimento (ESALQ). São Paulo: São Paulo, Butantã, Horto Oswaldo Cruz, 1 t, V.1975, L.P.Trazassos Filho (MZUSP).

\section{Anastrepha zikani Lima, 1934}

(Fig. 88)

Anastrepha zikani Lima, 1934a:533, figs. 30-31; pr. 69, fig.31; pr. 74, fig. 55 (lectötipo 9 , Estrela, Rio de Janeiro, Bra sil, FOC).

Anastrepha consobrina; Lima, $1930: 160$, pr. 25, fig. 5-6: Stone, $1942 \mathrm{a}: 87$, fig. 17D, pr. $18 \mathrm{~B}$.

Espëcie grande. Törax com 4,0mm de comprimento; mesonoto com faixas mediana e laterais distintas. Metanoto to talmente amarelado. Macroquetas marrom escuras; pilosidade amarelada. Asas com 9,5 mm de comprimento; faixas $C$ e $S$ estreitamente unidas; faixa $V$ completa e isolada. $R_{2+3}$ levemen te ondulada. Ovipositor com 5,5-6,5m de comprimento; rasper com dentes numerosos e longos; dentes sub-agudos em todo äpice.

As considerações sobre $A$. zikani Lima foram dis cutidas junto com as de $A$. amnis stone (pág.25). 
Designação de lectötipo. A descrição original de $A$. zikani Lima baseou-se em 7 exemplares ( 4 t $3 \%$ ) provenientes de Estrela, Rio de Janeiro, frascos 454-459, lâminas 1015 e 1016 (asas), 1927 (abdome f) e 1928 (abdome + ) (FOC). Foi selecionada e rotulada a fêmea do frasco 457, lâmina 1015 como lectótipo e os exemplares dos demais frascos como para. lectótipos.

Distribuicão: Brasil (Rio de Janeiro).

Planta hospedeira: Passiflora quadrangularis.

Material examinado: BRASIL. Rio de Janeiro: Estrela, lectótipo \%, I.1930, Lima (FOC); idem, 6 paralectótipos ( 4 \& 2 \%) (FOC).

\subsection{Espëcies Incertae Sedis}

Os tipos de três espécies de Anastrepha estão desaparecidos. E desde que as descrições originais não permi tem reconhecê-las, considerou-as espëcies incertae sedis.

Anastrepha consobrina (Loew, 1873).

LIMA (1930, 1934a) e STONE (1942a) apresentaram opiniões diferentes sobre a identificação de $A$. consobrina (Loew). Assim, LIMA (1930) havia identificado alguns exempla res como A. consobrina (Loew). Posteriormente, LIMA (1934a) considerou aqueles exemplares pertencentes à nova espécie $A$. aikani, e identificou como $A$. consobrina um exemplar que concordava com as dimensões apresentadas por LOEW (1873). STONE (1942a) considerou A. zikani Lima sinônimo de $A$. consobrina (Loew), e o exemplar identificado por LIMA 


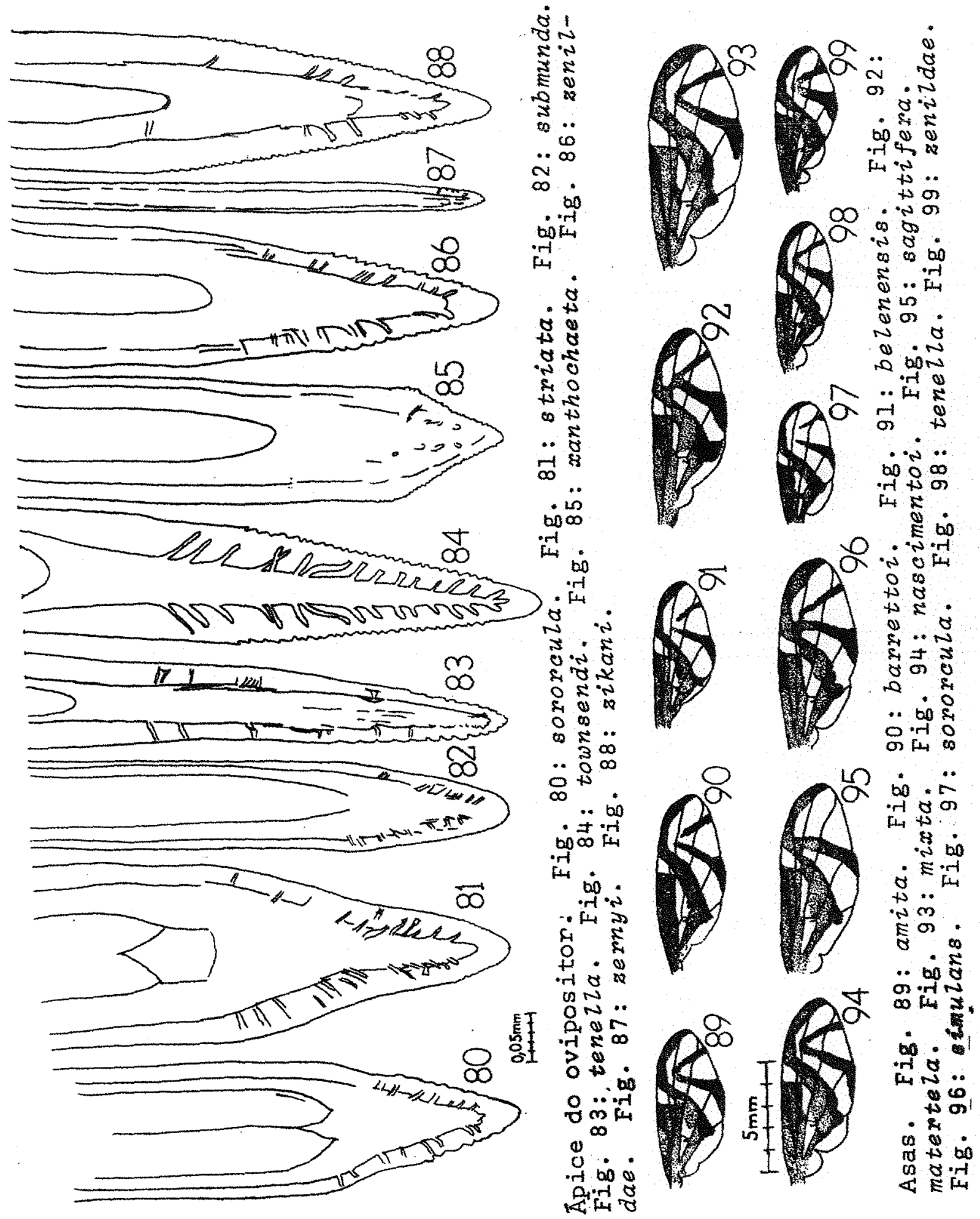


(1934a) como A. consobrina (Loew) considerou espécie nova, $A$. amnis, sem todavia ter examinado esse exemplar.

Como foi observado por CAPOOR (1955b) pode-se separar facilmente os exemplares de $A$. zikani Lima e de $A$. amnis stone pelo formato e nümero de dentes do rasper. Porëm, atë que se encontre o tipo de $A$. consobrina, é impossivel as.sociar ou não essas duas espécies com a espëcie descrita por Loew. Assim, é mais viável considerar A. zikani Lima e $A$. amnis Stone espëcies välidas e A. consobrina Loew espëcie incertae sedis.

\section{Anastrepha hamata (Loew, 1873)}

Não é possivvel a identificação dessa espëcie, cuja descrição original baseou-se em 2 sintipos ( $f+q$ ) provenientes do "Brasil". Os sintipos não se encontram no Museum fü Naturkunde der Humboldt-Universität zu Berlin de acordo com o Dr. H. Schumann (informação pessoal).

STONE (1942a) apresentou uma descrição dessa es pëcie com base em 6 espëcimens (NMNH), que julgou pertencer à A. hamata (Loew). Todavia, sem o estudo do ápice do ovipositor do síntipo, $\vec{e}$ impossivel o reconhecimento dessa espécie.

\section{Anastrepha integra (Loew, 1873)}

A. integra (Loew) foi descrita com base em 2 sintipos (f $q$ ) provenientes do "Brasil". STONE (1942a) nãoen controu os sintipos no Museum of Comparative Zoology, Harvard $e$ sugeriu que deveriam estar em Berlim. Porëm, segundo Dr. H. Schumann os sintipos não se encontram no Museum für Naturkunde der Humboldt - Universität zu Berlin (informação pessoal).

Os exemplares identificados por Hendel e Greene como $A$. integra (Loew) foram descritos como espëcies novas por STONE (1942a). Ainda, de acordo com esse autor, a espëcie mais próxima de $A$. integra (Loew) è A. barnesi Aldrich, cuja sinonimia não pode ser confirmada sem o exame do material típi co de A. integra (Loew). 
6. CONCLUSÕES

1) Ocorrem no Brasil, atê o momento, 74 espëcies de Anastrepha.

2) São descritas 11 espëcies novas: A. amita (localidadetipo Cruz das Almas, BA); A. barrettoi (localidade-tipo Araçatuba, Cörrego Azul, SP); A. belenensis (localidade -tipo Belèm, PA); A. matertela (localidade-tipo Cruzdas Almas, BA); A. mixta (localidade-tipo Utiariti, Rio Papagaio, MT); A. nascimentoi (localidade-tipo Cruz das Almas, BA); A. sagittifera (lcalidade-tipo Baixo Guandu, ES); $A$. simuzans (localidade-tipo Salesópolis, SP); $A$. sororcula (localidade-tipo Ribeirão Preto, SP); A. te-" ne rza (localidade-tipo Cruz das Almas, BA); A. zenizdae (localidade-tipo Pacajus, CE).

3) São consideradas as seguintes novas sinonimias: A. dis cessa Stone, 1942 e $A$. extensa Stone, 1942 são sinônimos 
de A. benjamini Lima, 1938 e. A. minensis Lima, 1937 res pectivamente, e A. costarukmanii Capoor, 1954, A. scholae Capoor, 1955 e A.pseudofraterculus Capoor, 1955 são sinônimos de $A$. fraterculus (Wied., 1830).

4) A. consobrina (Loew, 1873), A. hamata (Loew, 1873) e A. integra (Loew, 1873), cujos tipos estäo perdidos, são consideradas espécies incertae sedis.

5) A. zikani Lima, 1934 e A. amnis stone, 1942 são consideradas espécies välidas.

6) A variedade minensis Lima 1937 é elevada à categoria de espëcie.

7) A fêmea descrita por Lima como sendo de A. furcata Lima, 1934 e considerada como sinonimia de A. robusta Greene, 1934 por stone, em realidade é uma fêmea de $A$. furcata Lima.

8) A. robusta Greene, 1934 ainda não foi assinalada no Brasil.

9) Os exemplares identificados por Lima como Anastrepha vi-m rescens $\vec{e}$ realmente $A$ obarneei Aldrich, 1926.

10) A. rheediae Stone, 1942 é assinalada pela la. vez no Brasil.

11) As espēcies mais abundantes são: A. fraterculus (Wied., 1830), A. obliqua (Macquart, 1835), A. serpentina (Wied., 1830), A.distincta Greene, 1934 e A. sororcula, sp. n.

12) As novas referências de plantas hospedeiras com as respectivas espēcies são:
Mangifera sp.
Pouteria torta
- A. pseudoparallela (Loew, 1873)
Rheedia braziliensis - A. rheediae Stone, 1942
Passiflora sp.
- A. dissimilis stone, 1942
Passiflora sp.
- A. xanthochaeta Hendel, 1914 
7. SUMMARY

The Brazilian species of the genus Anastrepha Schiner, 1868 (Diptera, Tephritidae) are fully revised, keys to, and description of, all species are given. Morphological characters useful in distinguishing taxa are discussed and illustrated. Seventy four species are recognized in Brazil, eleven new species are described and five specific names are placed in synonymy. Twelve lectotypes are newly designated. Types of thirty eight species are studied. A. rheediae is recorded for the first time in Brazil. The ovipositor of paralzela, striata and zernyi are figured for the first time.

The revision is mainly based on the material belonging to the Fundação Oswaldo Cruz (Collection Costa Lima), Rio de Janeiro, and specimens collected in fifteen Brazilian states.

The types of new taxa are deposited in the Museu de Zoologia, Universidade de São Paulo. 
8. LITERATURA CITADA

ALDRICH, J.M., 1905. A catalogue of North American Diptera. Smithsonian Miscellaneous Collections. Washington, D.C., $\underline{46}(2): 601$.

ALDRICH, J.M., 1925. New Diptera or two-winged flies in the United States National Museum. Proceedings of the United States National Museum. Washington, D.C., 66 (18):1-36.

AUTUORI, M., 1936. Uma nova espécie do gênero Anastrepha Schin. (Dipt. Trypetidae). Revista de Entomologia. Petröpolis, $\underline{6}$ (2) : 194-196.

BAKER, A.C. : W.E.STONE; C.C.PLUMER E M.MCPHAIL, 1944. A review of studies on the Mexican fruit fly and related Mexican species. United States Department of Agriculture.

Miscellaneous Publications. Washington, D.C., 531:1-155. BATES, M., 1933. Notes on West Indian Trypetidae (Diptera). Bulletin of the Brooklyn Entomological Society, Lancaster; 
Pa., 28:160-172。

BEZZI, M., 1909. Le specie dei generi Ceratitis, Anastrepha e Dacus. Bollettino de Laboratorio di Zoologia Generale e Agraria della Facoltà Agraria in Fortici. Portici, 3:273$-313$.

BEZZI, M., 1919a. Una nova specie brasiliana del genere Anastrepha (Dipt.). Bollettino de Laboratorio di Zoologia Generale e Agraria della Facoltà Agraria in Portici. Porti ci, 13:3-14.

BEZZI, M., 1919b. Descoberta de uma nova mosca das fructas no Brasil. Chäcaras e Quintaes. São Paulo, 19:372-374.

BLANCHARD, E.E., 1937. Dipteros argentinos nuevos o poco co= nocidos. Revista de la Sociedad entomológica da Argentina. Buenos Aires, 9:35-58.

BLANCHARD, E.E., 1961. Especies argentinas del gēnero Anastrepha Schiner. Revista de Investigaciones Agricolas. Bue nos Aires, $15(2): 281-342$.

BRETHES, J., 1914. Notes synonymiques sur quelques insectes argentins. Bulletin de la Sociëtê entomologique de France. Paris, 58-59.

CAPOOR, V.N., 1954. Uma nova espêcie do gênero Anastrepha

(Diptera, Trypetidae). Agronomia. Rio de Janeiro, 12 $(3,4)$ : :213-215.

CAPOOR, V.N., 1955a. Duas espëcies novas do gênero Anastrepha (Dipt., Trypetidae). Arquivos do Instituto Biolögico. São Paulo, 22:23-30.

CAPOOR, V.N., 1955b. Discussão e confirmação de algumas espécies do gênero Anastrepha (Dipt. - Trypetidae). Arquivos do Instituto Biológico. São Paulo, 22:31-38. 
CRAMPTON, G. ., 1942. The External Morphology of the Diptera. In: Guide to the insects of Connecticut (Part VI). State

Geological and Natural History Survey of Connecticut: 10-165.

COQUILLET, D.W. 1899. Notes and descriptions of Trypetidae. Journal of the New York Entomological Society. New York, 7:259-268.

DAMPF, A., 1933. Estudio sobre el oviscapto de las moscas de la fruta (Anastrepha spp.) de México. Irrigación en Mëxico. México, $\underline{6}(3): 253-264$.

EMMART, E.W., 1933. The eggs of four species of fruit flies of the Jenus Anastrepha. Proceedings of Entomological Society of Washington. Washington, D.C., 35(8):184-191.

FERNANDEZ Y, F., 1953. Contribucion al estudio de las moscas de las frutas del genero Anastrepha Schiner (Diptera: Try-petidae) de Venezuela. II Congresso de Ciencias Naturales Y Afines. Caracas, $1: 1-42 \mathrm{p}$.

FISCHER, C.R., 1932. Nota taxonomica e biológica sobre Anas trepha grandis Macq. (Dipt., Trypetidae). Revista de Entomologia. Petrópolis, 2:302-310。

FISCHER, C.R., 1933. Nota sobre Anastrepha punctata Hendel (Dipt. Trypetidae) e uma espëcie nova de Cyrtonotum (Dipt. Drosophilidae). Revista de Entomologia. Petrópolis, 3: :83-92.

FISCHER, C.R., 1934. Variação das cerdas frontaes e outras no tas sobre duas espécies de Anastrepha (Dipt. Trypetidae). Revista de Entomologia. Petröpolis, 4:17-22.

FOOTE, R.H., 1964. Notes on the Walker types of new World Tephritidae. Journal of the Kansas Entomological Society. McPherson; Manhattan, 37:316-326. 
FOOTE, R.H., 1967. Family Tephritidae. In: A Catalogue of the Diptera of the Americas South of the United States. Departamento de Zoologia, Secretaria da Agricultura. São Paulo, 57:1-91.

GREENE, C.T., 1929. Characters of the larvae and pupae of certain fruit flies. Journal of Agriculture Research, Washington, D.C., 38(9):489-504.

GREENE, C.T., 1934. A revision of the genus Anastrepha based on a study of the wings and on the length of the ovipositor sheath (Diptera: Trypetidae). Proceedings of the Entomological Society of Washington. Washington, D.C., 36 (6) :127-179.

GURNEY, A.B.; J.P.KRAMER e G.C.STEYSKAL, 1964. Some techniques for preparation study, and storage in microvials of insect genitalia. Annals of the Entomological Society of America. Columbus, $0 ., 57(2): 240-242$.

HENDEL, F., 1914. Die Bohrfliegen Südamerikas. Übersicht und Katalog der bisher aus der neotropischen Region beschriebenen Tephritinen. Abhandlungen und Berichte des Kgl. Zoologischen u. Anthropologisch - ethnographischen Museums zu Dresden, Dresden, 14(3):1-85.

HERING, E.M., 1935. Neue südamerikanische Bohrfliegen aus dem Steftiner Museum. Stettiner Entomologische Zeitung. Stettin, $96: 225-229$.

HERING, E.M., 1940. Neue alt- und neuweltlische Bohrfliegen. Arbeiten Uber Morphologische und Taxonomische Entomologie aus Berlin-Dahlem. Berlin-Dahlen, $7: 50-57$.

HERING, E.M. Trypetidae. In: Beiträge zur Fauna Perus, I: $: 121-176$. 
HERRERA, A.L.; A.F.RANGEL e L. DE LA BARREDA, 1900. El gusano de la fruta. Boletin Comision Parasitologia Agricola, I(1): :1-30.

KEILEN, D. e C.PICADO, 1920. Biologie et morphologie larvaires d'Anastrepha striata Schiner, mouche des fruits de l'Amérique Centrale. Bulletin scientifique de la France et de la Belgique. Londres, Paris, Berlim, 48(4):423-44I.

KORYTKOWSKI G., C. e D.OJEDA P., 1968. Especies del genero Anastrepha Schiner, 1868 en el Nor-oeste peruano. Revista Peruana de Entomologia. Lima, II(1):32-70.

KORYTKOWSKI G., C., 1974. Una nueva especie del genero Anastrepha Schiner (Diptera: Tephritidae). Revista Peruana de Entomologia. Lima, I7(I):I-3.

LIMA, A. DA COSTA, 1915. Sobre a mosca de frutas Anastrepha serpentina (wied.). Boletim do Ministërio da Agricultura, Indústria e Comércio. Rio de Janeiro, 4:99-104.

LIMA, A. DA COSTA, 1930. Sobre as moscas de frutas que vivem em maracujäs (Passiflora sp.). Memörias do Instituto Oswal do Cruz. Rio de Janeiro, 23(3):159-162.

LIMA, A. DA COSTA, 1934a. Moscas de frutas do genero Anastrepha Schiner, 1868 (Diptera: Trypetidae). Memörias do Instituto Oswaldo Cruz. Rio de Janeiro, 28 (4):487-575.

LIMA, A. DA COSTA, 1934b. Nota adicional ao artigo sobre as especies do genero Anastrepha. Memórias do Instituto Oswaldo Cruz. Rio de Janeiro, 28(4):603-604.

LIMA, A. DA COSTA, 1937a. Novas moscas de frutas do genero Anastrepha (Diptera: Trypetidae). O Campo. Rio de Janeiro, $\underline{8}: 34-38$.

LIMA, A. DA COSTA, 1937b. Novas moscas de frutas do genero Anastrepha (Diptera: Trypetidae), O Campo. Rio de Janeiro, $8: 60-64$. 
LIMA, A. DA COSTA, 1938a. Novas moscas de frutas do genero Anastrepha (Diptera: Trypetidae). O Campo. Rio de Janeiro, $9: 61-64$.

LIMA, A. DA COSTA, 1938b. Sobre uma nova especie de Anastrepha da Bahia (Diptera: Trypetidae). O Campo. Rio de Janeiro, $\underline{9}: 16$.

LOEW, H., 1862. Monographs of the Diptera of North America. Part I. Smithsonian Miscellaneous Collections. Washington, D.C., 6 (1) (publ. 141):1-221.

LOEW, H., 1873. Monographs of the Diptera of North America. Part III. Smithsonian Miscellaneous Collections. Washington, D.C., 11(3) (publ. 256):1-351.

LUTZ, A. e A. DA COSTA LIMA, 1918. Contribuição para estudo das Tripaneidas (moscas de frutas) brasileiras. Memórias do Instituto Oswaldo Cruz. Rio de Janeiro, 10:5-15.

MACQUART, J., 1835. Histoire naturelle des Insectes. Diptères. In: Collection des suites à Buffon, N.E. Roret, Ed., 2: $703 \mathrm{p}$.

MACQUART, J.s 1843. Diptēres exotiques nouveaux ou peu connus. Mémoires de la Sociētë Royale des sciences, de I'Agniculture et des Ants. Lille (1842):162-460. (Publi cado separadamente como vol. 2, pt. 3, pp. 4-304).

MACQUART, J., 1846. Diptères exotiques nouveaux ou peu connus. ler. Supplëment. Mémoires de la Sociēté Royale des Sciences, de I'Agriculture et des Arts. Lille (1845)(1844): 133-364. (Publicado separadamente como supplëment I, PP. $5-238)$.

MACQUART, J., 1851. Diptères exotiques nouveaux ou peu connus. Suite du 4 me. Supplëment. Mëmoires de la Sociēté Royale des Sciences, de 1'Agriculture et des Arts. Lille (1850): 134-294. (Publicado separadamente como supplëment IV(part), 
PP. $161-336$

SCHINER, I.R., 1868. Diptera (Art. 1), 388 pp. In: Reise der osterreichische Fregatte Novara um die Erde. Wien, Zoo., 2 (Abt. I, Sect. B).

SEIN Jr. F., 1933. Anastrepha fruit flies in Puerto Rico. The Joumal of the Department of Agriculture of Puerto Rico. Rio Piedras, 17:183-196.

SHAW, J.C., 1962. Species of the spatulata group of Anastrepha. Journal of the Kansas Entomological Society. McPherson; Manhattan, 35:408-414.

STEYSKAL, G.C., 1975. Anastrepha obliqua (Macquart) the prior name for Anastrepha mombinpraeoptans Sein (Fruit Flies, Tephritidae, Diptera). Cooperative Economic Insect Report. Bureau of Entomology and Plant Quarantine, U.S. Department of Agriculture. Washington, 25(18):357-358.

STEYSKAL, G.C.; 1977a. Two new neotropical fruitflies of the genus Anastrepha, with notes on generic symonymy (Diptera, Tephritidae). Proceedings of the Entomological Society of Washington, Washington, D.C., 79(1):75-81.

STEYSKAL: G.C., 1977b. Pictorial key to species of the genus Anastrepha (Diptera: Tephritidae). The Entomological Society of Washington. Washington, D.C., 35pp. STONE, A., 1939a. A new genus of Trypetidae near Anastrepha (Diptera). Journal of the Washington Academy of Sciences. Washington, D.C., 29(8):340-350.

STONE, A., 1939b. A revision of the genus Pseudodacus Hendel (Dipt., Trypetidae). Revista de Entomologia. Petröpolis, $10: 282-289$.

STONE, A., 1942a. The fruitflies of the genus Anastrepha. U.S.D.A. Miscellaneous Publication. Washington, D.C, 439 : $: 112 \mathrm{pP}$. 
STONE, A., 1942b. New species of Anastrepha and notes on others (Diptera, Tephritidae). Journal of the Washington Academy of Sciences. Washington, D.C., 32(10):298-304.

TAVARES, J.S., 1915. A Anastrepha serpentina Wied. nova praga dos frutos no Brasil. Brotëria. Lisboa, 13(1):52-54.

TOWNSEND, C.H.T., 1913. The peruvian fruit- fly (Anastrepha peruviana n. sp.). Journal of Economic Entomology. Washington, D.C., 6:345-346.

VOCKEROTH, J.R., 1966. A method of mounting Insects from alcohol. The Canadian Entomologist. Guelp., Ont., 98: :69-70.

WALKER, F.M., 1837. Descriptions, etc.s of the insects collected by Captain P.P. King, R.N., F.R.S., in the survey of the Straits of Magellan. Diptera. The transactions of Linnean Society of London. London, 17:357-358.

WALKER, F.M., 1849. List of the specimens of diptereousinsects in the collection of the British Museum. 44:689-1172. British Museum (Nat. Hist.), London.

WASBAUER, M.S., 1972. An annotated host catalog of the fruit flies of America North of Mexico (Diptera: Tephritidae). Bureau of Entomology, Department of Agriculture, California. Occasional Papers. Sacramento, 19:172pp.

WEYENBERGH, H., 1874. LOs insectos daniños a la agricultura Argentina, no 6. An. agric. Argentina, 2:165.

WEYENBERGH, H., 1880. Bibliographie scientific principalement zoologique du Dr. H. Weyenbergh. Periödico zoolögico argen. tino, $3: 1-34$.

WHERVIN, L.W. VAN, 1974. Some fruitflies (Tephritidae) in Jamaica. PANS. London, 20(1):11:19. 
WIEDEMANN, C.R.W., 1830. Aussereuropäische zweiflügelige Insecten. Vol. 2, XII + 684pp. Hamm.

WULP, F.M. VAN DER, 1899. Fam. Muscidae. In: Biologia Centrali-Americana. Zoologia - Insecta-Diptena, F.D.GODMAN e 0.SAVIN, Ed., London, 2:385-408.

ZUCCHI, R.A., 1977. Taxonomia das espëcies brasileiras de Anastrepha Schiner, 1868 do complexo fraterculus (Diptera, Tephritidae), 63p. (Dissertação de Mestrado, ESALQ, USP). 